\title{
Progress and perspectives in dielectric energy storage ceramics
}

\author{
Dongxu LI ${ }^{a, b, \dagger}$, Xiaojun ZENG ${ }^{a, \dagger}$, Zhipeng $\mathrm{LI}^{a}$, Zong-Yang SHEN ${ }^{a, *}$, Hua HAO ${ }^{b}$, \\ Wenqin $\mathrm{LUO}^{a}$, Xingcai $\mathrm{WANG}^{c}$, Fusheng $\mathrm{SONG}^{a}$, Zhumei $\mathrm{WANG}^{a}$, Yueming $\mathrm{LI}^{a}$ \\ ${ }^{a}$ Energy Storage and Conversion Ceramic Materials Engineering Laboratory of Jiangxi Province, China National \\ Light Industry Key Laboratory of Functional Ceramic Materials, School of Materials Science and Engineering, \\ Jingdezhen Ceramic University, Jingdezhen 333403, China \\ ${ }^{b}$ State Key Laboratory of Advanced Technology for Materials Synthesis and Processing, School of Materials Science \\ and Engineering, Wuhan University of Technology, Wuhan 430070, China \\ ${ }^{c}$ Chengdu Hongke Electronic Technology Co., Ltd., Chengdu 610000, China
}

Received: February14, 2021; Revised: April 29, 2021; Accepted: May 17, 2021

(C) The Author(s) 2021.

\begin{abstract}
Dielectric ceramic capacitors, with the advantages of high power density, fast chargedischarge capability, excellent fatigue endurance, and good high temperature stability, have been acknowledged to be promising candidates for solid-state pulse power systems. This review investigates the energy storage performances of linear dielectric, relaxor ferroelectric, and antiferroelectric from the viewpoint of chemical modification, macro/microstructural design, and electrical property optimization. Research progress of ceramic bulks and films for Pb-based and/or $\mathrm{Pb}$-free systems is summarized. Finally, we propose the perspectives on the development of energy storage ceramics for pulse power capacitors in the future.
\end{abstract}

Keywords: energy storage ceramics; dielectric; relaxor ferroelectric; antiferroelectric; pulse power capacitor

\section{Introduction}

Electric energy, as secondary energy, plays a dominant role in human daily life, industrial manufacture, and scientific research owing to its cost-effectiveness, versatility, and convenient transportation. Compared with traditional fossil fuels, electrical energy generated from renewable resources can effectively cope with resource depletion and reduce environmental pollution. However, the characteristics of intermittence, fluctuation,

\footnotetext{
$\dagger$ Dongxu Li and Xiaojun Zeng contributed equally to this work.

* Corresponding author.

E-mail: shenzongyang@163.com
}

and randomness result in a time and space difference between practicality and expected demand, and thereby seriously hinder its large-scale development and application [1]. It is urgent to develop advanced technologies to address the issue of electric energy storage and conversion. Currently, the researches of energy storage technologies are mainly concentrated on dielectric capacitors [2,3], electrochemical capacitors [4], batteries [5], and solid oxide fuel cells [6], whose corresponding characteristics are given in Fig. 1.

Ceramic capacitor, as a passive component, possesses high power density $(\sim \mathrm{GW} / \mathrm{kg})$, fast charge-discharge speed ( $\mu \mathrm{s}$, or even ns), well fatigue endurance $\left(\geqslant 10^{6}\right.$ cycles), and high temperature stability, playing an 


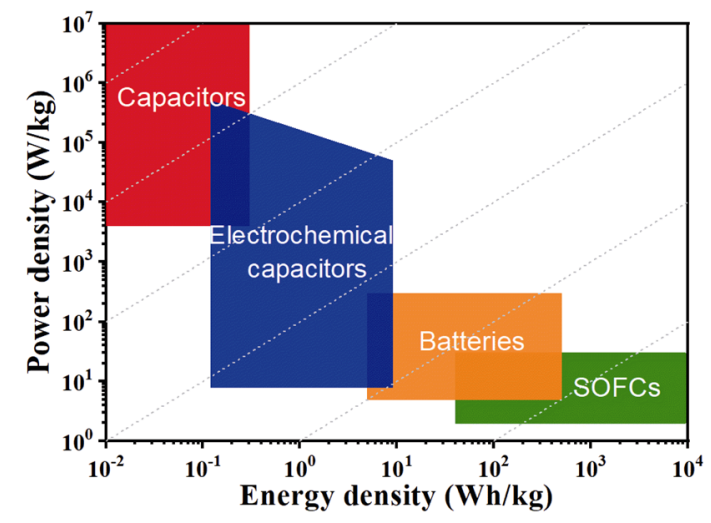

Fig. 1 Ragone pattern of different energy storage technologies.

indispensable role in solid-state power systems [1,7]. Generally, ceramic capacitors with a physical power supply based on dipole orientation, have relatively lower energy density than lithium-ion batteries and solid oxide fuel cells. Therefore, it is critical to improve the energy density of ceramic capacitors for expanding their practical applications.

Polarization behavior of dielectric materials under external electric field can be characterized by $P-E$ loops (hysteresis loops) [8,9], as exhibited in Fig. 2. According to different $P-E$ loop characteristics, dielectric materials can be classified into linear dielectric, ferroelectric, and antiferroelectric, of which ferroelectric includes normal ferroelectric and relaxor ferroelectric. Based on basic principle and reported literature, the polarization of linear dielectric is linearly proportional to the electric field, whereas its relatively low dielectric constant $\left(\varepsilon_{\mathrm{r}}\right)$ makes it difficult to achieve high energy density. Normal ferroelectric also possesses limited energy density because of its high remanent polarization $\left(P_{\mathrm{r}}\right)$. Relaxor ferroelectric and antiferroelectric could achieve both high energy density and efficiency, owing to their relatively high maximum polarization $\left(P_{\max }\right)$, low remanent polarization $\left(P_{\mathrm{r}}\right)$, and moderate breakdown strength $\left(E_{\mathrm{b}}\right)$, and thus have been considered to be the most potential candidates for pulse power systems.

Currently, the researches of energy storage ceramics are mainly concentrated on bulk ( $>100 \mu \mathrm{m})$, thick film $(1-100 \mu \mathrm{m})$, and thin film $(<1 \mu \mathrm{m})$. It should be noted that these three dielectric ceramics categories possess a big difference in actual energy storage capability, and thus one cannot treat them as one object in the same way. Meanwhile, the device application type also has different categories: ceramic bulk, multilayer structure capacitor, flexible electronic, integrated circuit, etc. This review combines the related work of authors, discusses the progress of energy storage performances of linear dielectric, relaxor ferroelectric, and antiferroelectric with emphasis on composition modification, macro/microstructural modulation, and electrical property optimization.

\section{Key parameters for evaluating energy storage properties}

\section{1 Energy storage density}

Generally, energy storage density is defined as energy in per unit volume $\left(\mathrm{J} / \mathrm{cm}^{3}\right)$, which is calculated by [2]:

$$
W=\int_{0}^{D_{\max }} E \mathrm{~d} D
$$

where $W, E, D_{\max }$, and $\mathrm{d} D$ are the total energy density, applied electric field, maximum electric displacement at $E$, and increment of electric displacement per unit of the electric field, respectively. For ceramic dielectric, $D$ is an unmeasurable microscopic physical quantity, and is usually expressed by polarization as following:

$$
D=\varepsilon_{0} E+P
$$

Meanwhile, $P$ is dependent on $E$ as follows:

$$
P=\varepsilon_{0} \chi E
$$

where $\varepsilon_{0}$ is the vacuum dielectric constant of $8.854 \times$ $10^{-12} \mathrm{~F} / \mathrm{m}, \chi$ is the dielectric polarization coefficient, so
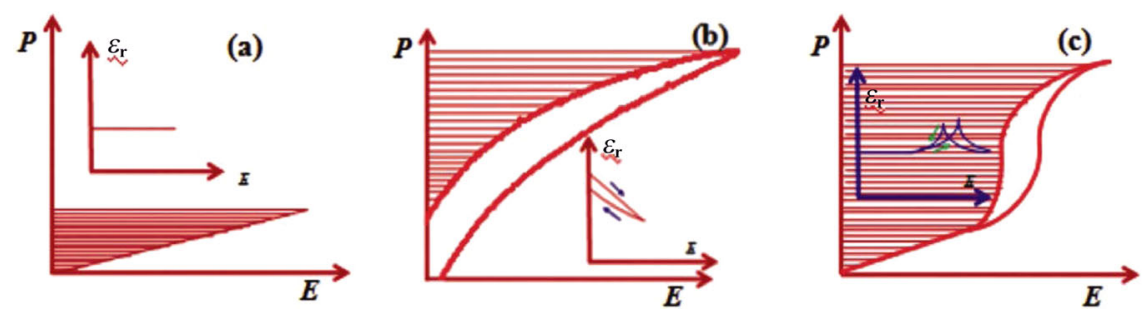

Fig. 2 Typical dependence of polarization and permittivity on electric field for (a) linear dielectric, (b) relaxor ferroelectric, and (c) antiferroelectric. Reproduced with permission from Ref. [2], (c) WILEY-VCH Verlag GmbH \& Co. KGaA, Weinheim 2017. 
that Eq. (2) can be expressed as

$$
D=\varepsilon_{0}(\chi+1) E=\varepsilon_{0} \varepsilon_{\mathrm{r}}(E) E
$$

where $\varepsilon_{\mathrm{r}}(E)$ is the relative dielectric constant at $E$. Therefore, Eq. (1) after the change is as follows:

$$
W=\int_{0}^{E_{\max }} \varepsilon_{0} \varepsilon_{\mathrm{r}}(E) E \mathrm{~d} E
$$

It is obvious that high $\varepsilon_{\mathrm{r}}$ and high $E_{\mathrm{b}}$ are important factors for achieving high $W[10]$. However, these two factors are hard to obtain simultaneously in a given material due to the trade-off relationship.

It should be noted that $W$ is a sum of effective energy density $\left(W_{\text {rec }}\right)$ and energy loss $\left(W_{\text {loss }}\right)[8,11]$. In practice, $W_{\text {rec }}$ is more important than $W$ in evaluating the energy storage performances of dielectric materials. As shown in Fig. 2, $W_{\text {rec }}$ is determined by the area enclosed by the discharge curve of its $P-E$ loops and the polarization axis. The equation is given as follows:

$$
W_{\text {rec }}=\int_{P_{\mathrm{r}}}^{P_{\max }} E \mathrm{~d} P
$$

Obviously, high $P_{\max }$, low $P_{\mathrm{r}}$ (i.e., large $\Delta P=P_{\max }-P_{\mathrm{r}}$ ), and high $E_{\mathrm{b}}$ are essential factors to achieve high $W_{\text {rec. }}$

\section{2 Energy storage efficiency}

Energy storage efficiency $(\eta)$ is another important parameter to evaluate energy storage performances of dielectric materials, which is expressed as

$$
\eta=\frac{W_{\text {rec }}}{W} \times 100 \%=\frac{W_{\text {rec }}}{W_{\text {rec }}+W_{\text {loss }}} \times 100 \%
$$

where $W_{\text {loss }}$ is the energy loss during the discharge process, which equals to the area enclosed by the $P-E$ loop in number. $W_{\text {loss }}$ is mainly dissipated as heat, and a higher value means a stronger negative effect on the service life of ceramic capacitors. Therefore, it is vital that $P-E$ loops gradually go slim to enhance $\eta$, and then improve its practical application.

According to Eqs. (6) and (7), $P-E$ loops go slim accompanied with high $P_{\max }$, low $P_{\mathrm{r}}$ (i.e., high $\Delta P=$ $P_{\max }-P_{\mathrm{r}}$ ), and high $E_{\mathrm{b}}$, which become the key issues in optimizing the energy storage characteristics of dielectric materials. There are two strategies: For one, to optimize the polarization behavior and strengthen their relaxor characteristics, which means that $P-E$ loops go slim; for the other, to improve the breakdown behavior of dielectric ceramics, i.e., enhancing its $E_{\mathrm{b}}$. This paper chooses linear dielectric, relaxor ferroelectric, and antiferroelectric as targets, and discusses the influences of chemical modification and macro/ microstructural design on polarization behavior and breakdown strength of dielectric materials.

\section{3 Rapid charging-discharging characteristics}

Generally, energy storage performances of ceramic materials can be reflected by $P-E$ loops measured by a modified Sawyer-Tower circuit. Meanwhile, the energy storage characteristics of ceramic capacitors, including effective discharging time $\left(t_{0.9}\right)$ and power density $(P)$, are more accurately reflected by the charging-discharging curve recorded at a specific RLC circuit [12]. The simple equivalent circuit model is exhibited in Fig. 3(a). In the charging process ("1" connected to " 3 "), the potential difference $(\Phi)$ between two surfaces of capacitor equals the applied voltage $(V)$, representing the charging process is finished. And then, the vacuum switches automatically and quickly rotate ("2" connected to " 3 ") to achieve the discharging process. Current flows to the oscilloscope via a load $\left(R_{0}\right)$, which is recorded as wave function as a function of time. The discharging density is given by

$$
J(t)=\frac{\int_{0}^{t} V(t) I(t) \mathrm{d} t}{\varphi}=\frac{\tau V_{0}^{2}}{2 \varphi R_{0}}\left(1-\mathrm{e}^{-\frac{2 t}{\tau}}\right)
$$

where $\varphi$ is the effective volume, $\tau$ is the relaxation time, and $V(t)$ and $I(t)$ are the voltage and current as function of time, respectively. Discharging current $(I)$ and energy density $(J)$ versus time $(t)$ are shown in Fig. 3(b).

It is reported that the value of $J$ calculated by Eq. (8) is generally smaller than that of $W_{\text {rec }}$. For the reasons, it may be closely related to two factors. Firstly, the domains cannot switch and orientate promptly due to fast discharge speed, and thus the energy is not completely released [13]. Secondly, the circuit has equivalent series resistance that generates Joule energy [14]. In order to acquire higher value of $J$ and $W_{\text {rec}}$, reducing domain size (e.g., polar nanoregions) only from material itself may be an effective method [15].

Power density $(P)$ is also an important parameter of dielectric ceramic capacitors, which is determined as follows:

$$
P=\frac{\pi f \varepsilon_{0} \varepsilon_{\mathrm{r}} E_{\mathrm{b}}^{2}}{2 \tan \delta}
$$

where $f$ is the testing frequency, and the others are the same as those discussed above. It can be seen that high $\varepsilon_{\mathrm{r}}$, high $E_{\mathrm{b}}$, and low $\tan \delta$ are the basic requirements of 

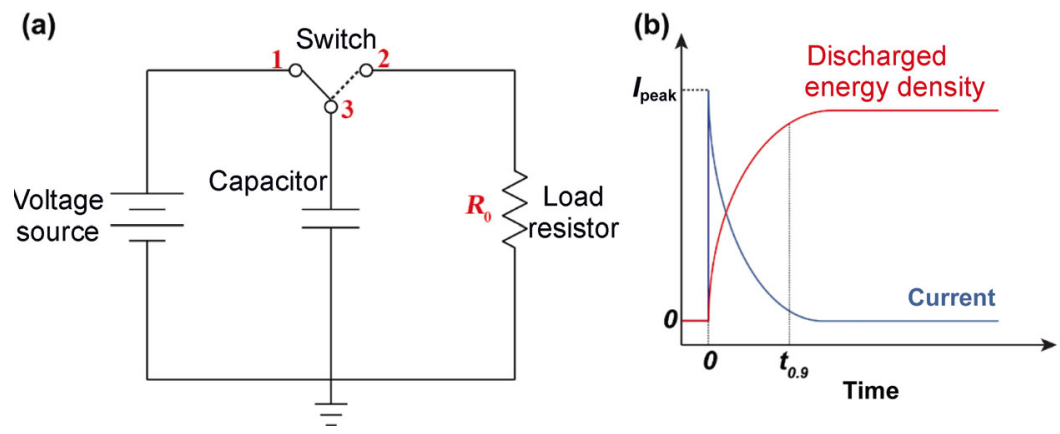

Fig. 3 (a) Circuit of charging-discharging. (b) Discharging current $(I)$ and energy density $(J)$ versus time. Reproduced with permission from Ref. [1], (C) Elsevier Ltd. 2018.

achieving high $P$. Meanwhile, $P$ has an obvious dependence on frequency $(f)$, which means high $f$ corresponds to high $P$. In addition, $t_{0.9}$ is an important factor for influencing the practical application of ceramic capacitors. The smaller the value of $t_{0.9}$, the stronger the pulse current can be generated in a short time. It is worth mentioning that the value of $t_{0.9}$ is dependent on not only the intrinsic properties of the dielectric materials, but also some external factors. For example, Li et al. [15] found that $t_{0.9}$ can be controlled by adjusting the load $\left(R_{0}\right)$ in the circuit.

\section{4 Reliability of work}

No matter with dielectric material or pulse capacitor, the reliability of work is a crucial factor to influence its application scenes. Generally, reliability of work requires keeping stability of electric properties of material and device under thermal, electric, mechanical, magnetic, etc., external field stimulus.

Temperature stability usually requires that dielectric properties and polarization of material have a gentle fluctuation as a function of temperature. For example, dielectric constant needs to maintain a $\pm 15 \%$ variation over a temperature range from -55 to $125{ }^{\circ} \mathrm{C}$ (X7R), to $150{ }^{\circ} \mathrm{C}$ (X8R), and even to $300{ }^{\circ} \mathrm{C}$, especially in high temperature working environments. Therefore, one should know the Joule heat categories: dielectric loss or leakage current, and to solve corresponding issues. Generally, different electric field conditions such as cycle number, frequency, voltage category, magnitude, etc., all require keeping good energy storage stability. Specially, fatigue endurance is a very important issue to influence capacitor working capability. In 2009, Lou [16] reviewed different fatigue mechanisms in ceramic bulks, films, and single crystalline, which help us better understand fatigue behavior of material. In addition, mechanic and magnetic fields both influnence its polarization behavior of material, and its importance may be playing a crucial role in the future multifunctional coupling requirement. Therefore, the evaluation criterion of reliability of working should be a complicated project.

\section{Dielectric ceramics for energy storage capacitors}

As given in Fig. 2, dielectric materials mainly include three categories, namely linear dielectric, relaxor ferroelectric, and antiferroelectric. Therefore, we here compare and analyze the energy storage properties of some representative dielectric ceramic bulks and films.

\section{1 Linear dielectric ceramics}

Linear dielectric ceramics usually possess characteristics of low $\varepsilon_{\mathrm{r}}$ and $\tan \delta$, as well as moderate $E_{\mathrm{b}}$. It is thereby hard to obtain high $W_{\text {rec }}$ despite under high electric field. In this regard, the researches of linear dielectric ceramics are mainly concentrated on increasing $\varepsilon_{\mathrm{r}}$ or improving polarization behavior based on maintaining high $E_{\mathrm{b}}$.

\subsection{1 $\mathrm{TiO}_{2}$ based ceramics}

$\mathrm{TiO}_{2}$ is a typical linear dielectric, with characteristics of moderate $E_{\mathrm{b}}(>350 \mathrm{kV} / \mathrm{cm})$, low $\tan \delta(<0.1 \%)$, dielectric constant $(\sim 110)$, and wide band gap $(\sim 3.2 \mathrm{eV})$, and thus receives wide use in contemporary electronic ceramic industries and photocatalysis field [17-20]. Generally, $\mathrm{TiO}_{2}$ has three crystal structures including orthorhombic brookite, tetragonal rutile, and anatase. The rutile phase is more stable and easier to be synthesized than others, and hence gains more attention in ceramic bulks and films [21,22].

In 2013, Hu et al. [23] firstly reported that (In, Nb) 
co-doped $\mathrm{TiO}_{2}$ ceramics displayed a giant dielectric constant $\left(>10^{4}\right)$ as well as low $\tan \delta(<5 \%)$, and possessed good temperature and frequency stabilities over a wide temperature range $(80-450 \mathrm{~K})$. The authors claim that this phenomenon should be closely related to defect clusters and localized electrons, and thus propose a "localized defect polarization" mechanism. However, the specified reason of giant dielectric constant appearing in donor/acceptor co-doped $\mathrm{TiO}_{2}$ ceramics still has some controversies. Li et al. $[24,25]$ attempted to explain the phenomenon by using an internal barrier layer capacitance (IBLC) model, similar to $\mathrm{CaCu}_{3} \mathrm{Ti}_{4} \mathrm{O}_{12}$ (CCTO) ceramics from extrinsic factors influencing dielectric constant. Actually, most of subsequent discussion on the physical origin of different-type donor/acceptor co-doped $\mathrm{TiO}_{2}$ ceramics is basically around above two mechanisms [26-28], even though no significant progress has been achieved in $W_{\text {rec }}$ for donor/acceptor co-doping $\mathrm{TiO}_{2}$ ceramics because of the expense of a rapid reduction in $E_{\mathrm{b}}$.

In another way, improving the sintering behavior of $\mathrm{TiO}_{2}$-based ceramics would be effectively enhancing $E_{\mathrm{b}}$, such as refining grain size [17,29], adding glass phase [30], applying special sintering technology (SPS), and so on. Liu et al. obtained a $W_{\text {rec }}$ of 1.15 $\mathrm{J} / \mathrm{cm}^{3}$ for alkali-free glass modified $\mathrm{TiO}_{2}$ ceramics at $501.7 \mathrm{kV} / \mathrm{cm}$. Unfortunately, $W_{\text {rec }}$ of those ceramic bulks after different modification ways is still only at a scale of $1 \mathrm{~J} / \mathrm{cm}^{3}$, which is less than other energy storage dielectric materials. It should be noticed that high quality $\mathrm{TiO}_{2}$ film is a good direction owing to their high $E_{\mathrm{b}}$. For instance, Chao and Dogan [31] fabricated $0.1-\mathrm{mm}$ thick $\mathrm{TiO}_{2}$ films using tape-casting method, which achieve $W_{\text {rec }}$ of $14 \mathrm{~J} / \mathrm{cm}^{3}$ at $1400 \mathrm{kV} / \mathrm{cm}$.

\subsection{2 $\mathrm{SrTiO}_{3}$ based ceramics}

$\mathrm{SrTiO}_{3}(\mathrm{ST})$ is a cubic paraelectric phase with $\mathrm{ABO}_{3}$ type perovskite structure, accompanying to space group of $P m \overline{3} m$ and lattice constant of $a=3.905 \AA$ $[32,33]$. ST ceramics possess moderate $\varepsilon_{\mathrm{r}}$ of $\sim 300, E_{\mathrm{b}}$ of $\sim 100 \mathrm{kV} / \mathrm{cm}$, and low $\tan \delta$ of $\sim 10^{-3}$, as well as good temperature-, frequency-independent dielectric properties, bias voltage stability, and thermoelectric energy conversion efficiency [34-36]. Therefore, it is considered to be a potential energy storage and conversion candidate. Compared with $\mathrm{TiO}_{2}$ ceramic $(\sim 110)$ and polymer linear dielectric $(<10)$, ST has an advantage of relatively high $\varepsilon_{\mathrm{r}}$, and thus is more suitable for pulse capacitor.
Utilizing $\mathrm{Ca}^{2+}, \mathrm{Ba}^{2+}$, and $\mathrm{Pb}^{2+}$ ions to replace $\mathrm{Sr}^{2+}$ on the A-site of ST could adjust the Curie temperature $\left(T_{\mathrm{C}}\right)$ to room temperature, and thus dielectric constant could be enhanced [37,38]. Especially, $\mathrm{Ba}_{x} \mathrm{Sr}_{1-x} \mathrm{TiO}_{3}$ (BST) solid solutions combine the characteristics of high $E_{\mathrm{b}}$ of $\mathrm{SrTiO}_{3}$ and high $\mathcal{E}_{\mathrm{r}}$ of $\mathrm{BaTiO}_{3}$, and receive much more attention in recent years [39]. The structure and performance of BST can be adjusted over a wide range to meet the requirements of different applications. As the molar fraction of $\mathrm{Ba}$ increases from 0 to 1 , phase composition of BST varies from cubic paraelectric (ST) to tetragonal ferroelectric (BT), accompanying by the $T_{\mathrm{C}}$ increase from near absolute 0 to $\sim 393 \mathrm{~K}$. According to theoretical calculation of BST solid solution by Fletcher et al. [40], it is easier to obtain an ideal energy storage property if the $T_{\mathrm{C}}$ of the ceramic composition is far away the working temperature. Thereby, BST compositions with $x \leqslant 0.4$ would be more suitable pulse power capacitor candidates because $P-E$ loops display linear or weak nonlinear characteristic at room temperature, as shown in Fig. 4. In 2015, Wang et al. [37] investigated energy storage performances of $\mathrm{Ba}_{x} \mathrm{Sr}_{1-x} \mathrm{TiO}_{3}(x \leqslant 0.4)$ ceramics, and found that $\mathrm{Ba}_{0.4} \mathrm{Sr}_{0.6} \mathrm{TiO}_{3}$ achieved the highest $W_{\text {rec }}$, while relatively low and rapidly decreased $\eta$ becomes a serious problem to hinder its application. By comparison, $\mathrm{Ba}_{0.3} \mathrm{Sr}_{0.7} \mathrm{TiO}_{3}$ possessed moderate $W_{\text {rec }}$, high $\eta(\geqslant 95 \%)$, and very low dielectric $\operatorname{loss}(\tan \delta=$ $7.6 \times 10^{-4} @ 1 \mathrm{kHz}$ ), making it more suitable for the fabrication of solid state compact portable pulse power electronics.

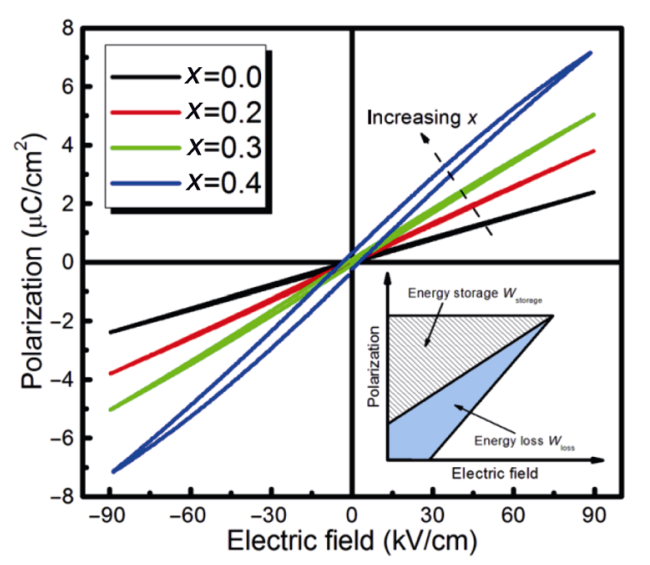

Fig. 4 Polarization-electric field $(P-E)$ hysteresis loops of $\mathrm{Ba}_{x} \mathrm{Sr}_{1-x} \mathrm{TiO}_{3}$ (BST, $x \leqslant 0.4$ ) ceramics. The inset shows the effective energy storage and energy loss during the charge-discharge process. Reproduced with permission from Ref. [37], (C) Elsevier Ltd and Techna Group S.r.l. 2015. 
For aliovalent doping in A-site of ST, a similar phenomenon with giant dielectric $\mathrm{TiO}_{2}$ can be observed, and corresponding mechanisms are widely studied. Chen et al. [41-43] reported $(\mathrm{Bi}, \mathrm{Sr}) \mathrm{TiO}_{3}$ ceramics with giant dielectric constant, discussed the related physical mechanisms, and proposed that the first and second ionization of oxygen vacancies as well as corresponding thermal movement were the main reasons. To avoid the problem of Bi-containing oxides volatilizing at high temperature, Shen et al. [34,44-46] used trivalent nonvolatile rare earth ions $\left(\mathrm{Re}^{3+}=\mathrm{La}\right.$, $\mathrm{Sm}, \mathrm{Gd}, \mathrm{Er}, \mathrm{Nd}$, etc.) to replace $\mathrm{Sr}^{2+}$, and designed three composition formulas based on three possible charge compensation mechanisms such as equimolar substitution, introducing $\mathrm{Sr}$ or Ti vacancy in advance, and successfully fabricated ceramics with perovskite structure. It is experimentally verified the feasibility of introducing ion vacancies in advance for charge compensation, and then the concept of "forced charge compensation mechanism" is summarized and proposed. For instance, Shen et al. [44] synthesized $\mathrm{Re}_{0.02} \mathrm{Sr}_{0.97} \mathrm{TiO}_{3}$ ceramics by introducing $\mathrm{Sr}$ vacancy in advance, displaying a high dielectric constant and good bias voltage stability, as shown in Figs. 5 and 6. Furthermore, multiple mechanisms such as MaxwellWagner interface polarization, variable charge of $\mathrm{Ti}$ element, defect clusters, etc., are all proposed to illustrate donor and/or acceptor doping ST ceramics.

Microstructure regulation plays an important role in enhancing $E_{\mathrm{b}}$ of ST ceramics. In 2014, Song et al. [47] prepared $\mathrm{Ba}_{0.4} \mathrm{Sr}_{0.6} \mathrm{TiO}_{3}$ ceramics with various grain

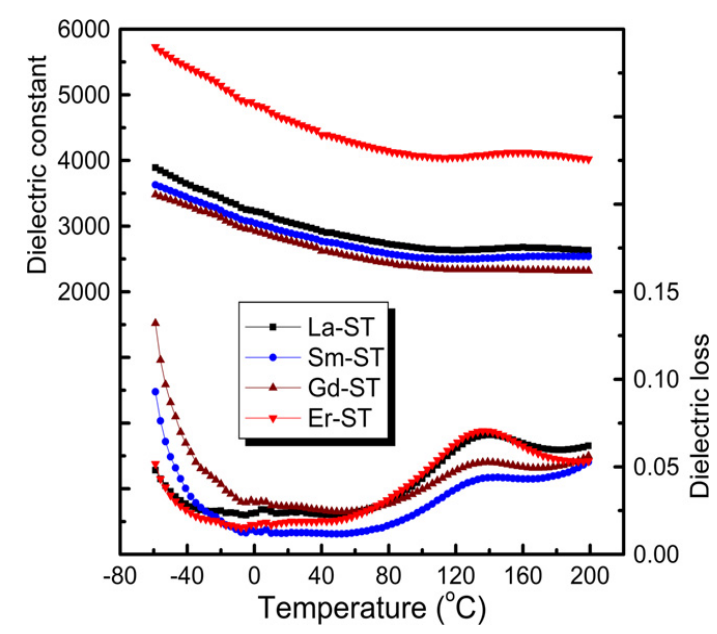

Fig. $5 \varepsilon_{\mathrm{r}}$ and $\tan \delta$ of the $\mathrm{Re}_{0.02} \mathrm{Sr}_{0.97} \mathrm{TiO}_{3}$ ceramics as a function of measuring temperature from -60 to $200{ }^{\circ} \mathrm{C}$. Reproduced with permission from Ref. [44], (C) The American Ceramic Society 2013.

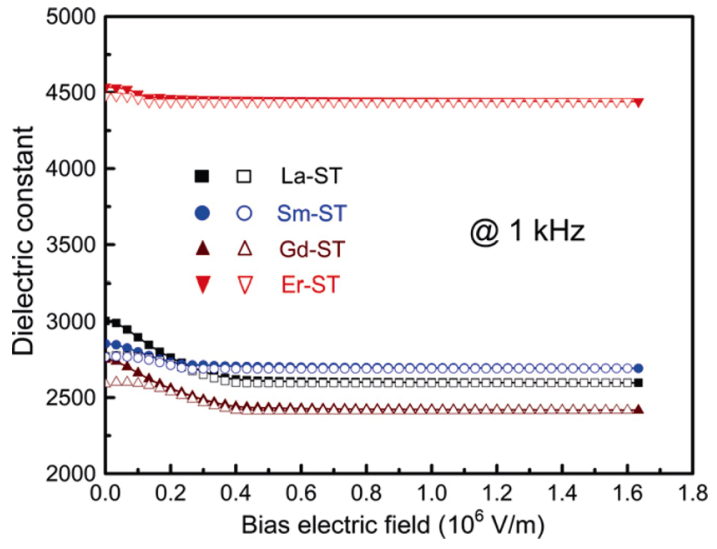

Fig. $6 \varepsilon_{\mathrm{r}}$ of the $\mathrm{Re}_{0.02} \mathrm{Sr}_{0.97} \mathrm{TiO}_{3}$ ceramics as a function of bias electric field. Filled pattern: increasing bias. Open pattern: decreasing bias. Reproduced with permission from Ref. [44], (C) The American Ceramic Society 2013.

sizes $(0.5-5.6 \mu \mathrm{m})$, and observed that dielectric peak gradually depressed and broadened and $E_{\mathrm{b}}$ gradually increased with decreasing grain size, which should be closely related to the ratio of grain/grain boundary and polar nanoregions (PNRs). $\mathrm{Ba}_{0.4} \mathrm{Sr}_{0.6} \mathrm{TiO}_{3}$ ceramic bulk with grain size of $0.5 \mu \mathrm{m}$ achieves a high $W_{\text {rec }}=$ $1.28 \mathrm{~J} / \mathrm{cm}^{3}$ measured at the highest $E_{\mathrm{b}}$ of $243 \mathrm{kV} / \mathrm{cm}$. $\mathrm{Wu}$ et al. [48] compared microstructure and energy storage properties of spark plasma sintered (SPS) and conventionally sintered (CS) $\mathrm{Ba}_{0.3} \mathrm{Sr}_{0.7} \mathrm{TiO}_{3}$ ceramics. The SPS sintered ceramics consists of tetragonal and cubic phases with an average grain size of $880 \mathrm{~nm}$, while CS ones are only of the tetragonal phase. The maximum $W_{\text {rec }}$ of SPS samples is $1.13 \mathrm{~J} / \mathrm{cm}^{3}$ at $E_{\mathrm{b}}=$ $230 \mathrm{kV} / \mathrm{cm}$, which is approximately twice as much as that of CS samples $\left(0.57 \mathrm{~J} / \mathrm{cm}^{3}\right)$. In addition, the addition of suitable glass compositions is also an effective method to enhance $E_{\mathrm{b}}$ and reduce the sintering temperature of ST based ceramics $[49,50]$. In 2019, Shen et al. [51] used a homemade glass frit to modify BST enhancing the $E_{\mathrm{b}}$ and reducing the high temperature resistivity, which expanded the working temperature range for energy storage ceramic capacitor applications.

"Defect engineering" is an effective tool to enhance $W_{\text {rec }}$ by strengthening relaxor characteristics for ST-based ceramic films. Yang et al. [52] fabricated $\left(\mathrm{Sr}_{1-1.5 x} \mathrm{Bi}_{x}\right) \mathrm{Ti}_{0.99} \mathrm{Mn}_{0.01} \mathrm{O}_{3}$ (SBTM, $x=0.01,0.05,0.1$ ) thin films with a thickness of $217 \mathrm{~nm}$ using sol-gel method. As $x$ value increases, relaxor behaviors are gradually strengthened due to a slight rotation of the $\left(\mathrm{TiO}_{6}\right)$ octahedra induced by the formation of $\mathrm{Bi}^{3+}-\mathrm{V}_{\mathrm{sr}}^{\prime \prime}$ defect complex. Under an electric field of $1982 \mathrm{kV} / \mathrm{cm}$, 
$\left(\mathrm{Sr}_{0.85} \mathrm{Bi}_{0.1}\right) \mathrm{Ti}_{0.99} \mathrm{Mn}_{0.01} \mathrm{O}_{3}$ possess a $W_{\text {rec }}$ of $24.4 \mathrm{~J} / \mathrm{cm}^{3}$ accompanied by the largest $\Delta P\left(P_{\max }-P_{\mathrm{r}}=34.3 \mu \mathrm{C} / \mathrm{cm}^{2}\right)$. Actually, the introduction of other Bi-contained compounds such as $\mathrm{Bi}_{0.5} \mathrm{Na}_{0.5} \mathrm{TiO}_{3}$ (BNT) [53], $\mathrm{BiFeO}_{3}$ (BF) [54] has a similar effect to strengthen relaxor characteristics. For example, Pan et al. [54] deposited $5 \mathrm{~mol} \% \mathrm{Mn}$-doped $0.6 \mathrm{SrTiO}_{3}-0.4 \mathrm{BiFeO}_{3}(0.6 \mathrm{ST}-0.4 \mathrm{BF})$ thin film on $\mathrm{Nb}$-doped $\mathrm{SrTiO}_{3}$ single crystal substrate using pulsed laser deposition (PLD), and acquired that $W_{\text {rec }}$ and $\eta$ were $51 \mathrm{~J} / \mathrm{cm}^{3}$ and $64 \%$, respectively. In addition, the energy storage performances exhibited good temperature stability over $(-40)-140{ }^{\circ} \mathrm{C}$ and well fatigue endurance after $2 \times 10^{7}$ cycles. In the related mechanism studies, Hou et al. [55] investigated the influence of interface difference and thickness on the energy storage performances for ST thin films, and observed the existence of ionic diffusion layers and oxygen vacancies using high resolution transmission electron microscope (HR-TEM). Moreover, they observed that $E_{\mathrm{b}}$ and $P_{\max }$ (up to $10^{2} \mu \mathrm{C} / \mathrm{cm}^{2}$ ) along the positive direction were higher than the negative direction. Therefore, a maximum $W_{\text {rec }}$ of $\mathrm{ST}$ thin films reach $307 \mathrm{~J} / \mathrm{cm}^{3}$ for positive direction, which may be related to local electric field and redistribution of oxygen vacancy.

Various meaningful and interesting works have been done in the optimization of macro/micro structures to improve energy storage properties of ST-based ceramic films. It is well known that the amorphous phase usually possesses higher $E_{\mathrm{b}}$ but lower $\varepsilon_{\mathrm{r}}$ than their crystalline counterparts. Gao et al. [56] studied energy storage behaviors of amorphous ST thin films with different top electrodes, proposed "self-healing" mechanism based on the anodic oxidation reaction in aluminum electrolytic capacitors. At a relative humidity of $60 \%$, amorphous ST films with Al top electrode achieve the $W_{\text {rec }}$ of $15.7 \mathrm{~J} / \mathrm{cm}^{3}$ at $3500 \mathrm{kV} / \mathrm{cm}$, which approaches to 8 times of the samples with $\mathrm{Au}$ electrode. Since then, Gao et al. [57] inserted insulating $\mathrm{Al}_{2} \mathrm{O}_{3}$ as a blocking layer to form heterostructure, and achieved a maximum $W_{\text {rec }}$ of $39.49 \mathrm{~J} / \mathrm{cm}^{3}$ at $E_{\mathrm{b}}=$ $7542.3 \mathrm{kV} / \mathrm{cm}$ when interface number equals 4. Recently, Chen et al. [58] used $\mathrm{Ca}_{0.2} \mathrm{Zr}_{0.8} \mathrm{O}_{1.8}$ (CSZ) as dead layer to enhance $E_{\mathrm{b}}$ of $\mathrm{Ba}_{0.3} \mathrm{Sr}_{0.7} \mathrm{Zr}_{0.18} \mathrm{Ti}_{0.82} \mathrm{O}_{3}$ (BSZT) thin films. Due to the formation of a high electron injection barrier, Schottky electron emission is suppressed, and thus $E_{\mathrm{b}}$ and $W_{\text {rec }}$ are enhanced from 5.4 to $6.3 \mathrm{MV} / \mathrm{cm}$ and 64.8 to $89.4 \mathrm{~J} / \mathrm{cm}^{3}$, respectively. Energy storage properties of partially $\mathrm{Pb}$-free linear dielectric ceramics are summarized and listed in Table 1.

In summary, for linear dielectric ceramic bulks, giant dielectric constant can be observed in $\mathrm{TiO}_{2}$-based with donor/acceptor co-doping at B-site, and ST-based with donor/acceptor co-doping at B-site or aliovalent doping of at A-site bulks by chemical modification. Related physical mechanisms, some controversies, however, are still existed. Energy storage properties of ceramic bulks are limited at expense of a rapid decrease in $E_{\mathrm{b}}$. Adding of suitable glass phase, special sintering technology and refining grain size are both able to enhance $E_{\mathrm{b}}$ of ceramic bulks. For ST-based ceramic films, adjusting suitable ratio of amorphous and crystalline or introducing a high insulating layer would be a good way to improve its breakdown behavior.

Table 1 Energy storage properties of Pb-free linear dielectric ceramic bulks and films

\begin{tabular}{|c|c|c|c|c|c|c|c|}
\hline Composition & Category & $t$ & $W_{\mathrm{rec}}\left(\mathrm{J} / \mathrm{cm}^{3}\right)$ & $\eta(\%)$ & $\varepsilon_{\mathrm{r}} @ \mathrm{RT}$ & $E_{\mathrm{b}}(\mathrm{kV} / \mathrm{cm})$ & Ref. \\
\hline $\mathrm{TiO}_{2}+15 \mathrm{wt} \% \mathrm{BBAS}$ & Bulk & - & 1.15 & - & 103 & 501.7 & {$[30]$} \\
\hline $\mathrm{TiO}_{2}$ & Thick film & $0.1 \mathrm{~mm}$ & 14 & - & 108 & 1400 & {$[31]$} \\
\hline $\mathrm{Ba}_{0.3} \mathrm{Sr}_{0.7} \mathrm{TiO}_{3}$ & Bulk & $0.6 \mathrm{~mm}$ & 0.23 & 95.7 & 650 & $\sim 90$ & {$[37]$} \\
\hline $\mathrm{Ba}_{0.4} \mathrm{Sr}_{0.6} \mathrm{TiO}_{3}$ & Bulk & $0.3 \mathrm{~mm}$ & 1.28 & - & $\sim 1500$ & 243 & [47] \\
\hline $\mathrm{Ba}_{0.3} \mathrm{Sr}_{0.7} \mathrm{TiO}_{3}(\mathrm{SPS})$ & Bulk & - & 1.13 & 86.8 & - & 230 & [48] \\
\hline$\left(\mathrm{Sr}_{0.85} \mathrm{Bi}_{0.1}\right) \mathrm{Ti}_{0.99} \mathrm{Mn}_{0.01} \mathrm{O}_{3}$ & Thin film & $217 \mathrm{~nm}$ & 24.4 & 64.7 & 550 & 1380 & {$[52]$} \\
\hline $0.5 \mathrm{~mol} \% \mathrm{Mn}$-doped $0.6 \mathrm{ST}-0.4 \mathrm{BF}$ & Thin film & $500 \mathrm{~nm}$ & 51 & 64 & 240 & 3600 & [54] \\
\hline ST & Thin film & $610 \mathrm{~nm}$ & 307 & 89 & $\sim 350$ & 6600 & [55] \\
\hline Amorphous ST & Thin film & $300 \mathrm{~nm}$ & 15.7 & - & 29.1 & $\sim 3500$ & {$[56]$} \\
\hline $\mathrm{ST} / 4 \mathrm{AO}$ & Thin film & $370 \mathrm{~nm}$ & 39.49 & - & $\sim 15$ & 7542.3 & [57] \\
\hline BSZT & Thin film & $610 \mathrm{~nm}$ & 89.4 & 65 & $\sim 160$ & 6300 & {$[58]$} \\
\hline
\end{tabular}

BBAS: $\mathrm{BaO}-\mathrm{B}_{2} \mathrm{O}_{3}-\mathrm{Al}_{2} \mathrm{O}_{3}-\mathrm{SiO}_{2}$; ST: $\mathrm{SrTiO}_{3} ; \mathrm{BF}: \mathrm{BiFeO} ; \mathrm{AO}: \mathrm{Al}_{2} \mathrm{O}_{3}$; BSZT: $\mathrm{Ba}_{0.3} \mathrm{Sr}_{0.7} \mathrm{Zr}_{0.18} \mathrm{Ti}_{0.82} \mathrm{O}_{3}$. 


\section{2 Relaxor ferroelectric ceramics}

Ferroelectric is a special dielectric material that possesses spontaneous polarization $\left(P_{\mathrm{s}}\right)$ at a certain temperature range and the direction of $P_{\mathrm{s}}$ can be changed with an external electric field. Compared with linear dielectric, ferroelectric displays an obvious nonlinear characteristic since the domain cannot fast respond to electric field stimulation. Generally, polarization behavior of dielectric material can be characterized by $P-E$ loop, and thus ferroelectric can be classified into normal ferroelectric and relaxor ferroelectric [59], as illustrated in Fig. 7. Normal ferroelectric possesses high $P_{\max }$ while its high $P_{\mathrm{r}}$ leads to that most of energy is dissipated during the discharge process. By contrast, relaxor ferroelectric exhibits slim $P-E$ loop with high $P_{\max }$ and low $P_{\text {r }}$ (i.e., high $\Delta P=P_{\max }-P_{\mathrm{r}}$ ) meaning that electric energy can be effectively released, and thus obtains better energy storage performances [60]. Note that strengthening the relaxor characteristics and enhancing $E_{\mathrm{b}}$ have become important factors for enhancing $W_{\text {rec }}$. Furthermore, ferroelectric here discussed mainly refers to relaxor ferroelectric.

\subsubsection{Pb-based relaxor ferroelectric ceramics}

$\mathrm{PbZr}_{1-x} \mathrm{Ti}_{x} \mathrm{O}_{3}(\mathrm{PZT}, 0 \leqslant x \leqslant 1)$ ceramic located at morphotropic phase boundary (MPB) where $\mathrm{Zr}$ :Ti is of $52: 48$, possesses a high piezoelectric activity ( $d_{33}$ up to $300 \mathrm{pC} / \mathrm{N}$ ) and good temperature stability, and becomes an extremely popular dielectric material [61-63]. In addition, other ceramic compositions such as PZT 65/35, 70/30 also received more attention and no limitation by piezoelectric properties $[64,65]$. For example, the researches of actuator in PZT ceramics are increasing due to a large electrostrain under low electric field. In 2019, Kumar et al. [66] reported $\left(\mathrm{Pb}_{0.89} \mathrm{La}_{0.11}\right)\left(\mathrm{Zr}_{0.70} \mathrm{Ti}_{0.30}\right)_{0.9725} \mathrm{O}_{3}$ (PLZT 11/70/30) ceramics achieved a $W_{\text {rec }}$ only of $0.85 \mathrm{~J} / \mathrm{cm}^{3}$ due to low electric field. Generally speaking, current energy density of $\mathrm{Pb}$-based relaxor ferroelectric ceramic bulks is less than $3 \mathrm{~J} / \mathrm{cm}^{3}$. In 2017, Zhang et al. [67] investigated energy storage properties of $\mathrm{PbZr}_{0.52} \mathrm{Ti}_{0.48} \mathrm{O}_{3}$-based thin films, acquired a high $W_{\text {rec }}=28.2 \mathrm{~J} / \mathrm{cm}^{3}$ for $\mathrm{PbZrO}_{3} /$ $\mathrm{PbZr}_{0.52} \mathrm{Ti}_{0.48} \mathrm{O}_{3}$ bilayer thin films at $2410 \mathrm{kV} / \mathrm{cm}$. In addition, they continued to design a sandwich structure of $\mathrm{PbZr}_{0.52} \mathrm{Ti}_{0.48} \mathrm{O}_{3} / \mathrm{Al}_{2} \mathrm{O}_{3} / \mathrm{PbZr}_{0.52} \mathrm{Ti}_{0.48} \mathrm{O}_{3}$ (PZT/AO/PZT) to enhance $E_{\mathrm{b}}$ [68]. Due to the formation of so-called "built-in electric field" at the interface and the high insulating characteristic of $\mathrm{AO}, \mathrm{PZT} / \mathrm{AO} / \mathrm{PZT}$ annealed at $550{ }^{\circ} \mathrm{C}$ achieved a $W_{\text {rec }}$ of $63.7 \mathrm{~J} / \mathrm{cm}^{3}$ at $5.7 \mathrm{MV} / \mathrm{cm}$. It should be mentioned that PZT 52/48 system still possesses relatively high $P_{\mathrm{r}}$ restricting its energy storage properties.

Generally, a small amount of $\mathrm{La}^{3+}$ (about 7$10 \mathrm{~mol} \%$ ) replacing $\mathrm{Pb}^{2+}$ would effectively strengthen the relaxor characteristics of PZT-based ceramics owing to a disrupted long-range ferroelectric order and diffuse phase transition $[71,72]$. $(\mathrm{Pb}, \mathrm{La})(\mathrm{Zr}, \mathrm{Ti}) \mathrm{O}_{3}(\mathrm{PLZT})$ based relaxor ferroelectric is therefore considered to be a promising energy storage ceramic capacitor candidate. Adjusting suitable $\mathrm{La} / \mathrm{Zr} / \mathrm{Ti}$ ratio generates an important influence on electric properties because of the complicated phase structure. For example, $\mathrm{Hu}$ et al. [73] investigated the effect of different $\mathrm{Zr} / \mathrm{Ti}$ ratios on the energy storage properties of PLZT thin films at a fixed La content of $8 \mathrm{~mol} \%$. As $\mathrm{Ti} /(\mathrm{Zr}+\mathrm{Ti})$ ratio gradually increases, $\varepsilon_{\mathrm{r}}$ enhances while $\tan \delta$ shows an opposite trend indicating phase structure gradually transforms from relaxor ferroelectric into normal ferroelectric. At $E_{\mathrm{b}}=2180 \mathrm{kV} / \mathrm{cm}, W_{\text {rec }}, \eta$ of the PLZT $8 / 52 / 48$ relaxor ferroelectric thin films are $30 \mathrm{~J} / \mathrm{cm}^{3}$ and $78 \%$, respectively. In chemical doping, Liu et al. [74] used $\mathrm{Mn}$ as a dopant of $\left(\mathrm{Pb}_{0.91} \mathrm{La}_{0.09}\right)\left(\mathrm{Zr}_{0.65} \mathrm{Ti}_{0.35}\right) \mathrm{O}_{3}$ (PLZT 9/65/35) to enlarge the polarization difference of $P_{\max }-P_{\mathrm{r}}$, measured a $W_{\text {rec }}$ of $30.8 \mathrm{~J} / \mathrm{cm}^{3}$ for $1 \mathrm{~mol} \% \mathrm{Mn}$

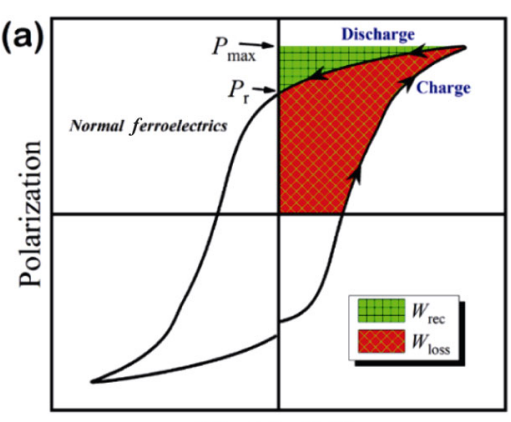

Electric field

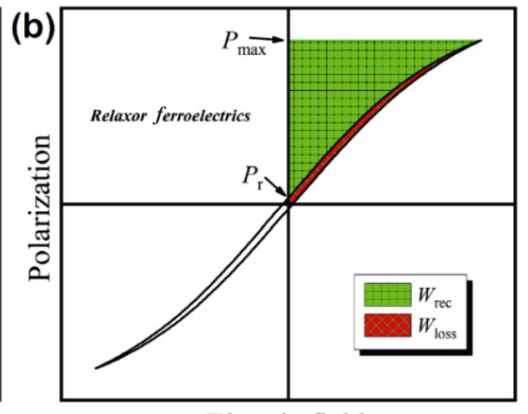

Electric field

Fig. 7 Schematic of hysteresis loop: (a) normal ferroelectric and (b) relaxor ferroelectric. 
thick films. In addition, the addition of excess $\mathrm{Pb}$ is a common chemical compensation method to solve the problems of $\mathrm{Pb}$ volatilization during the annealing process, and of suppressing the formation of pyrochlore phase [75].

Reasonable design and selection of heterostructure for $\mathrm{Pb}$-based thin films, is an important step in optimizing energy storage properties. In 2013, Zhang et al. [76] prepared a compositionally gradient $\left(\mathrm{Pb}_{1-x} \mathrm{La}_{x}\right)\left(\mathrm{Zr}_{0.65} \mathrm{Ti}_{0.35}\right) \mathrm{O}_{3}$ (PLZT, $\left.x=0.08,0.09,0.1\right)$ thick films using sol-gel method. Up-graded PLZT films possess a $W_{\text {rec }}$ of $12.4 \mathrm{~J} / \mathrm{cm}^{3}$ at $800 \mathrm{kV} / \mathrm{cm}$, down-graded one of $8.9 \mathrm{~J} / \mathrm{cm}^{3}$, and the lowest single composition one of $7.1 \mathrm{~J} / \mathrm{cm}^{3}$. It is accepted that high texture quality and dense structure are both severely influencing breakdown behaviors and energy storage performances [77,78]. Nguyen et al. [77] deposited $\left(\mathrm{Pb}_{0.9} \mathrm{La}_{0.1}\right)\left(\mathrm{Zr}_{0.52} \mathrm{Ti}_{0.48}\right) \mathrm{O}_{3}$ (PLZT 10/52/48) thin films using $\mathrm{PLD}$ on $\mathrm{Si}$ substrate choosing $\mathrm{Ca}_{2} \mathrm{Nb}_{3} \mathrm{O}_{10}$ (CNOns) and $\mathrm{Ti}_{0.87} \mathrm{O}_{2}$ (TiOns) nanosheets as the template layer. Highly textured (001)-oriented PLZT 10/52/48 films grown on CNOns possess a high $W_{\text {rec }}$ of
$58.4 \mathrm{~J} / \mathrm{cm}^{3}$, which exceeds $W_{\text {rec }}$ of $44 \mathrm{~J} / \mathrm{cm}^{3}$ for (110)oriented PLZT 10/52/48 films grown on TiOns. Generally speaking, there are differences in lattice constants and thermal expansion coefficients in hetero-interfaces, which provide good conditions for stress. Figure 8 (a) shows $P-E$ loops of PLZT 8/52/48 thick films at different substrates. Ma et al. [69] utilized XRD to analyze residual stress for PLZT 8/52/48 thick films, and considered compressive stress can in a certain extent improve tunability of the polarization, enhance $E_{\mathrm{b}}$ and domain switch ability. In addition, note that Peng et al. [70] recently prepared Mn-doped $\mathrm{Pb}_{0.97} \mathrm{La}_{0.02}\left(\mathrm{Zr}_{0.905} \mathrm{Sn}_{0.015} \mathrm{Ti}_{0.08}\right) \mathrm{O}_{3} \quad$ (PLZST) relaxor ferroelectric thin films, and innovatively proposed a "low-temperature poling" method to improve $E_{\mathrm{b}}$, and called it "wake-up" mechanism. Figure 8(b) shows $P-E$ loops of PLZST films before and after "awaken state". $E_{\mathrm{b}}$ and $W_{\text {rec }}$ at room temperature are greatly enhanced (nearly doubled) from 1286 to $2000 \mathrm{kV} / \mathrm{cm}$, and from 16.6 to $31.2 \mathrm{~J} / \mathrm{cm}^{3}$, respectively. Energy storage performances of $\mathrm{Pb}$-based relaxor ferroelectric materials are summarized and listed in Table 2.
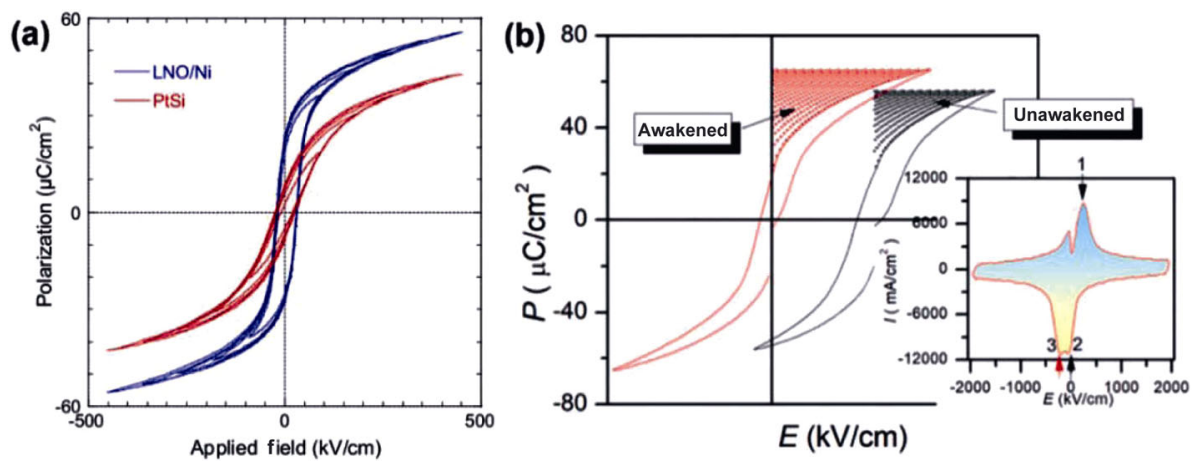

Fig. 8 (a) $P-E$ loops of the PLZT films on different substrates. Reproduced with permission from Ref. [69], (C) Springer Science Business Media New York 2015. (b) $P-E$ loops of the $\mathrm{Pb}_{0.97} \mathrm{La}_{0.02}\left(\mathrm{Zr}_{0.905} \mathrm{Sn}_{0.015} \mathrm{Ti}_{0.08}\right) \mathrm{O}_{3}$ films before and after "awaken state", with the inset showing the $I-E$ curve after "awaken state". Reproduced with permission from Ref. [70], (C) Elsevier Ltd. 2020.

Table 2 Energy storage properties of Pb-based relaxor ferroelectric ceramic bulks and films

\begin{tabular}{cccccccc}
\hline Composition & Category & $t$ & $W_{\mathrm{rec}}\left(\mathrm{J} / \mathrm{cm}^{3}\right)$ & $\eta(\%)$ & $\varepsilon_{\mathrm{r}} @$ RT & $E_{\mathrm{b}}(\mathrm{kV} / \mathrm{cm})$ & Ref. \\
\hline PLZT 11/70/30 & Bulk & $1 \mathrm{~mm}$ & 0.85 & 92.9 & $\sim 3500$ & 85 & {$[66]$} \\
PZ/PZT 52/48 & Thin film & $350 \mathrm{~nm}$ & 28.2 & $\sim 50$ & - & 2615 & {$[67]$} \\
PZT/AO/PZT & Thin film & $330 \mathrm{~nm}$ & 63.7 & 81.3 & $\sim 50$ & 5711 & {$[68]$} \\
PLZT 8/52/48 & Thin film & $690 \mathrm{~nm}$ & 30 & 78 & $\sim 1500$ & 2180 & {$[73]$} \\
Up-graded PLZT & Thick film & $1.5 \mu \mathrm{m}$ & 30.8 & $\sim 70$ & 1378 & 1679 & {$[74]$} \\
PLZT 10/52/48 & Thick film & $1.5 \mu \mathrm{m}$ & 12.4 & - & 2170 & 800 & {$[76]$} \\
PLZT & Thick film & $1000 \mathrm{~nm}$ & 58.4 & 81.2 & - & 3400 & {$[77]$} \\
Low-temperature-poling PLZST & Thick film & $\sim 2 \mu \mathrm{m}$ & 85 & 65 & $\sim 1300$ & $\sim 2600$ & {$[69]$} \\
\hline
\end{tabular}

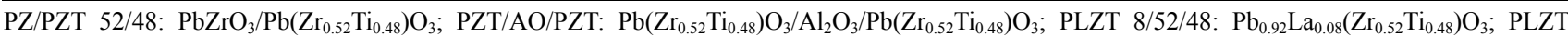
9/65/35: $\left(\mathrm{Pb}_{0.91} \mathrm{La}_{0.09}\right)\left(\mathrm{Zr}_{0.65} \mathrm{Ti}_{0.35}\right) \mathrm{O}_{3}$; up-graded PLZT: $\left(\mathrm{Pb}_{1-x} \mathrm{La}_{x}\right)\left(\mathrm{Zr}_{0.65} \mathrm{Ti}_{0.35}\right) \mathrm{O}_{3}\left(x=0.08\right.$, 0.09, and 0.10); PLZT 10/52/48: $\mathrm{Pb}_{0.9} \mathrm{La}_{0.1}\left(\mathrm{Zr}_{0.52} \mathrm{Ti}_{0.48}\right) \mathrm{O}_{3}$; PLZST: $\mathrm{Pb}_{0.97} \mathrm{La}_{0.02}\left(\mathrm{Zr}_{0.905} \mathrm{Sn}_{0.015} \mathrm{Ti}_{0.08}\right) \mathrm{O}_{3}$. 


\subsubsection{Lead-free relaxor ferroelectric ceramics}

Lead is a toxic metal, and its volatilization problem at high temperature results in serious environmental and human health concerns. Moreover, some legislation in countries and regions also promote researchers to explore a new lead-free ceramic substitute. Currently, lead-free relaxor ferroelectric ceramics mainly focused on $\mathrm{Bi}_{0.5} \mathrm{Na}_{0.5} \mathrm{TiO}_{3}$ (BNT), $\mathrm{BaTiO}_{3}(\mathrm{BT}), \mathrm{BiFeO}_{3}(\mathrm{BF})$, and $\mathrm{K}_{0.5} \mathrm{Na}_{0.5} \mathrm{NbO}_{3}(\mathrm{KNN})$ systems, which will be discussed in the following sections.

(1) $\mathrm{Bi}_{0.5} \mathrm{Na}_{0.5} \mathrm{TiO}_{3}$ based ceramics

$\mathrm{Bi}_{0.5} \mathrm{Na}_{0.5} \mathrm{TiO}_{3}$ (BNT) is a ferroelectric material firstly discovered by Smolenskii et al. [79], which possesses complicated phase structure and good dielectric, piezoelectric, and ferroelectric properties, especially high $P_{\max }\left(\sim 40 \mu \mathrm{C} / \mathrm{cm}^{2}\right)$ [80-83]. And so it becomes a popular research topic on fundamental theories and practical studies for ferroelectric materials [84-86]. However, the characteristics of high $P_{\mathrm{r}}(\sim 38$ $\left.\mu \mathrm{C} / \mathrm{cm}^{2}\right)$, high $E_{\mathrm{c}}(\sim 73 \mathrm{kV} / \mathrm{cm})$, and poor sintering behavior for pure BNT ceramics hinder its energy storage applications.

$\mathrm{Bi}_{0.5} \mathrm{Na}_{0.5} \mathrm{TiO}_{3}-x \mathrm{BaTiO}_{3}(x=6 \%-7 \%)$ binary solid solution near MPB exhibits excellent electrical properties, and is a most promising candidate for replacing Pb-based ceramics [87-89]. Since then, extensive energy storage studies have been done on this system. It is particularly important that strengthening dynamic of polar nanoregions (PNRs) through disturbing long-range ferroelectric ordering or expanding nonergodic-

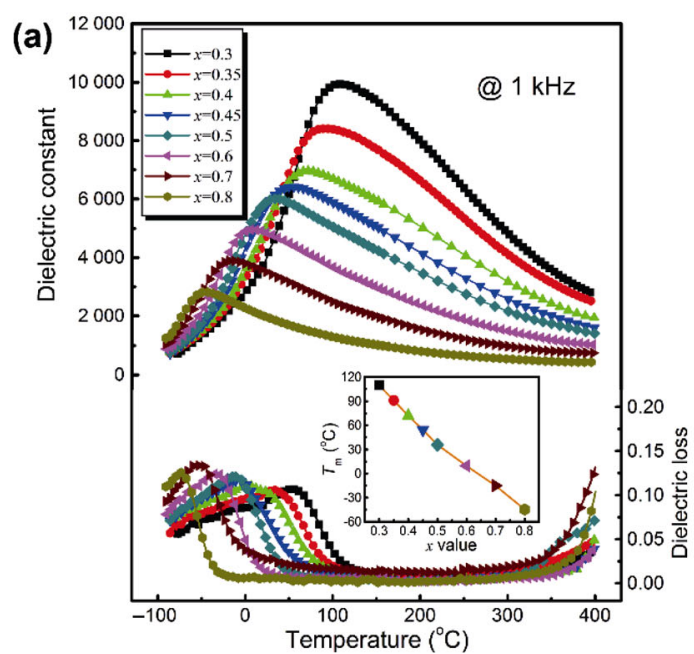

ergodic phase transition range both could optimize polarization behavior to obtain high $W_{\text {rec }}$. In 2011, Gao et al. [90] firstly reported that $0.89 \mathrm{Bi}_{0.5} \mathrm{Na}_{0.5} \mathrm{TiO}_{3}-$ $0.06 \mathrm{BaTiO}_{3}-0.05 \mathrm{~K}_{0.5} \mathrm{Na}_{0.5} \mathrm{NbO}_{3} \quad(0.89 \mathrm{BNT}-0.06 \mathrm{BT}-$ $0.05 \mathrm{KNN}$ ) ceramics possessed a $W_{\text {rec }}$ of $0.46 \mathrm{~J} / \mathrm{cm}^{3}$ at $56 \mathrm{kV} / \mathrm{cm}$. In 2016, Cao et al. [91] used $\mathrm{Mn}^{2+}$ to modify $0.7(0.94 \mathrm{BNT}-0.06 \mathrm{BT})-0.3 \mathrm{ST}$ ceramics to reduce $P_{\mathrm{r}}$ by forming $\mathrm{Mn}_{\mathrm{Ti}}^{\prime \prime}-\mathrm{V}_{\ddot{O}}$ defect complex, which can induce a local electric field influencing domain switch. A $W_{\text {rec }}$ of $1.06 \mathrm{~J} / \mathrm{cm}^{3}$ for $1.1 \mathrm{~mol} \% \mathrm{Mn}$ is obtained at $95 \mathrm{kV} / \mathrm{cm}$ owing to a large $P_{\max }-P_{\mathrm{r}}$ up to $36.8 \mu \mathrm{C} / \mathrm{cm}^{2}$. Actually, similar phenomenon was already reported by Ren et al. [92]. In 2017, Li et al. [93] incorporated $\mathrm{NaNbO}_{3}$ into $0.8 \mathrm{Bi}_{0.5} \mathrm{Na}_{0.5} \mathrm{TiO}_{3}$ $0.2 \mathrm{SrTiO}_{3}$ relaxor ferroelectric ceramics, observed that $P-E$ loop gradually goes slim together with vanished current peaks as NN content increases, which was attributed to the nonergodic-ergodic phase transition. $0.5 \mathrm{~mol} \mathrm{NaNbO}_{3}$ modified ceramics exhibit a high $W_{\text {rec }}$ of $0.74 \mathrm{~J} / \mathrm{cm}^{3}$, accompanied by good high temperature energy storage stability and charging-discharging capability. Indeed, delaying the early saturation of polarization is also an effective method to enhance $W_{\text {rec }}$ [94]. In our previous work [37,95], $\mathrm{Ba}_{0.3} \mathrm{Sr}_{0.7} \mathrm{TiO}_{3}$, which is suitable for pulse power systems, is selected to improve energy storage performances of BNT-based with an optimized ceramic composition. $P-E$ loop of high $\varepsilon_{\mathrm{r}}\left(\mathrm{Ba}_{0.3} \mathrm{Sr}_{0.7}\right)_{0.35}\left(\mathrm{Bi}_{0.5} \mathrm{Na}_{0.5}\right)_{0.65} \mathrm{TiO}_{3}\left(\mathrm{BS}_{0.35} \mathrm{BNT}\right)$ relaxor ferroelectric ceramics originally presents an obvious clamped behavior, but its $P_{\mathrm{r}}$ is still high, as shown in Figs. 9(a) and 9(b). We therefore choose

(b)

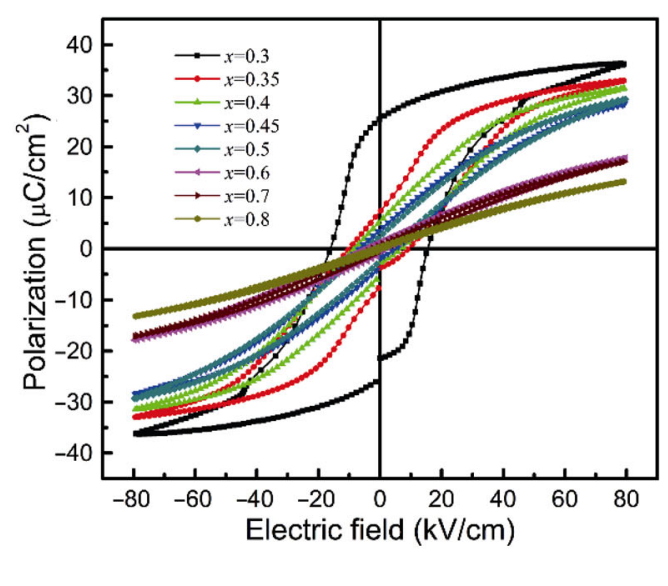

Fig. 9 (a) Temperature dependent dielectric constant and loss of $\mathrm{BS}_{x} \mathrm{BNT}$ ceramics. The inset is $T_{\mathrm{m}}$ as a function of $x$ value. (b) $P-E$ hysteresis loops of the $\mathrm{BS}_{x} \mathrm{BNT}$ ceramics with different $x$ value at room temperature. Reproduced with permission from Ref. [95], (C) The Author(s) 2020. 
$\mathrm{NaNbO}_{3}(\mathrm{NN})$ antiferroelectric to continue to optimize its polarization behavior [96]. 0.94BSBNT-0.06NN relaxor ferroelectric ceramics achieve a high $W_{\text {rec }}$ of $1.25 \mathrm{~J} / \mathrm{cm}^{3}$ at room temperature. Besides, the system exhibits good high temperature stability and fatigue endurance, which may be closely related to the reduction in domain size.

Besides doping modification, multilayer and miniaturization of BNT-based ceramic capacitors are also a significant research direction. In 2018, Li et al. [15] designed a series of $(1-x) \mathrm{Bi}_{0.5} \mathrm{Na}_{0.5} \mathrm{TiO}_{3}-$ $x\left(\mathrm{Sr}_{0.7} \mathrm{Bi}_{0.2}\right) \mathrm{TiO}_{3}(\mathrm{NBT}-x \mathrm{SBT}, x=0.3-0.5)$ ceramics, and corresponding multilayer ceramic capacitors (MLCC) with a single layer thickness of $20 \mu \mathrm{m}$ were fabricated. A high $W_{\text {rec }}$ of $9.5 \mathrm{~J} / \mathrm{cm}^{3}$, together with $\eta$ of $92 \%$, is achieved in NBT-0.45SBT MLCC. Furthermore, energy storage properties of MLCC display good temperature stability, fatigue endurance, and chargingdischarging capability. Recently, Li et al. [97] attempted to enhance $E_{\mathrm{b}}$ through controlling grain orientation, and investigated energy storage performances of NBT0.35SBT MLCC under different stress states. By comparison, Yang et al. [98] reported energy storage properties of gradient structure $\left(\mathrm{SrTiO}_{3}+0.5 \mathrm{wt} \%\right.$ $\left.\mathrm{Li}_{2} \mathrm{CO}_{3}\right) /\left(0.93 \mathrm{Bi}_{0.5} \mathrm{Na}_{0.5} \mathrm{TiO}_{3}-0.07 \mathrm{Ba}_{0.94} \mathrm{La}_{0.04} \mathrm{Zr}_{0.02} \mathrm{Ti}_{0.98} \mathrm{O}_{3}\right)$ (STL/(BNT-BLZT)) ceramics along thickness direction. A high $W_{\text {rec }}$ of $2.72 \mathrm{~J} / \mathrm{cm}^{3}$ for $\mathrm{STL} /(\mathrm{BNT}-\mathrm{BLZT}$ ) ceramics is obtained at $294 \mathrm{kV} / \mathrm{cm}$. Due to the strict requirements of the harsh working environment such as high temperature $\left(>200{ }^{\circ} \mathrm{C}\right.$ or even $\left.300{ }^{\circ} \mathrm{C}\right)$, good insulation and antioxidant, MLCC would encounter many challenges in the future $[99,100]$. Meanwhile, material system selection, electrode design such as equivalent series resistance (ESR) and loss, cost control of fabrication, and so on, need further consideration.

The volatilization of $\mathrm{Bi}$ and $\mathrm{Na}$ and variable valence of $\mathrm{Ti}$ are easy to generate oxygen vacancy for BNT-based thin films resulting in a large leakage current. Single mental oxides $\left(\mathrm{MnO}_{2}\right.$ [101,102], $\mathrm{Fe}_{2} \mathrm{O}_{3}$ [103], etc.) are used to modify BNT films, which would form different defect complexes to compensate charge balance and suppress oxygen vacancy migration. For example, Mn doped BNT thick films display a reduced leakage current due to the formation of $\mathrm{Mn}_{\mathrm{Ti}}^{\prime \prime}-\mathrm{V}_{\ddot{\mathrm{O}}}$. defect complex, which gives rise to a $W_{\text {rec }}$ of $30.2 \mathrm{~J} / \mathrm{cm}^{3}$ for $x=0.01$ composition [102]. In addition, controlling annealing temperature also has a similar effect on reducing leakage current [104]. In addition, Peng et al. [105] deposited La/Zr modified 0.94BNT-0.06BT high epitaxial quality thin films using PLD, and $P_{\max }$ can reach to $10^{2} \mu \mathrm{C} / \mathrm{cm}^{2}$ scale due to the complicated phase composition and great relaxor dispersion. (100) and (111) oriented $\left(\mathrm{Bi}_{1 / 2} \mathrm{Na}_{1 / 2}\right)_{0.9118} \mathrm{La}_{0.02} \mathrm{Ba}_{0.0582}\left(\mathrm{Ti}_{0.97} \mathrm{Zr}_{0.03}\right) \mathrm{O}_{3}$ (BNLBTZ) thin films achieve maximum $W_{\text {rec }}$ of 137 and $154 \mathrm{~J} / \mathrm{cm}^{3}$, respectively, far exceeding other $\mathrm{Pb}$-free even Pb-based systems.

Distinguished from single composition of MLCC, macrostructure modification of BNT-based films mainly focuses on gradient composition. It is widely accepted that BNT-based ceramic film is p-type conductivity due to many vacancies generating acceptor states in the band gap, and thus $\mathrm{p}-\mathrm{n}$ junctions and block layers are applied to inhibit charge transportation. For instance, Guo et al. [108] reported the introduction of $\mathrm{Bi}_{3.25} \mathrm{La}_{0.75} \mathrm{Ti}_{3} \mathrm{O}_{12}$ (BLT) and $\mathrm{Pb}\left(\mathrm{Zr}_{0.4} \mathrm{Ti}_{0.6}\right) \mathrm{O}_{3}(\mathrm{PZT})$ dielectric layer on pyroelectric and ferroelectric properties of $0.94 \mathrm{BNT}-0.06 \mathrm{BT}$ ceramic films, and observed leakage current reduce about 3 orders of magnitude. Besides, Chen et al. [106] studied the effect of interface number on energy storage properties of $0.94\left(\mathrm{Bi}_{0.5} \mathrm{Na}_{0.5}\right) \mathrm{TiO}_{3}-0.06 \mathrm{BaTiO}_{3} / \mathrm{BiFeO}_{3}$ (abbreviated as $\mathrm{BNBT} / n \mathrm{BFO}$ ) multilayer film capacitors under a given total thickness. BNBT/2BF thin films exhibit a $W_{\text {rec }}$ of $31.96 \mathrm{~J} / \mathrm{cm}^{3}$ and a $\eta$ of $61 \%$ at $2400 \mathrm{kV} / \mathrm{cm}$ owing to enhanced insulating characteristic and high polarization. With the rapid development of flexible wearable materials in recent years, related researches on their energy storage performances have gradually increased. Qian et al. [107] prepared a multilayer $\left(\mathrm{Na}_{0.8} \mathrm{~K}_{0.2}\right)_{0.5} \mathrm{Bi}_{0.5} \mathrm{TiO}_{3} / 0.6\left(\mathrm{Na}_{0.8} \mathrm{~K}_{0.2}\right)_{0.5} \mathrm{Bi}_{0.5} \mathrm{TiO}_{3}-$ $0.4 \mathrm{SrTiO}_{3}(\mathrm{NKBT} / \mathrm{NKBT}-\mathrm{ST})_{N}(N=2,3,6,8)$ films on the F-Mica substrate, with measured $W_{\text {rec }}$ of $73.7 \mathrm{~J} / \mathrm{cm}^{3}$ at $3077 \mathrm{kV} / \mathrm{cm}$ for $N=6$. Under different conditions such as $(-50)-200{ }^{\circ} \mathrm{C}, 10^{8}$ cycle numbers, $10^{4}$ bending tests, energy storage performances of (NKBT/NKBT-ST) $)_{6}$ ceramic films both maintain good stability. Energy storage performances of BNT-based relaxor ferroelectric materials are summarized and listed in Table 3.

(2) $\mathrm{BaTiO}_{3}$-based ceramics

$\mathrm{BaTiO}_{3}$ (BT) with simple perovskite structure possesses moderate Curie temperature $\left(T_{\mathrm{C}}\right)$ of $120{ }^{\circ} \mathrm{C}$ and corresponding high $\mathcal{E}_{\mathrm{r}}$ of $10^{4}[109,110]$, and becomes a common dielectric material in passive capacitor. BT-based materials also received more attention in memory and memristor for information 
Table 3 Energy storage characteristics of BNT-based relaxor ferroelectric ceramic bulks and films

\begin{tabular}{|c|c|c|c|c|c|c|c|}
\hline Composition & Category & $t$ & $W_{\text {rec }}\left(\mathrm{J} / \mathrm{cm}^{3}\right)$ & $\eta(\%)$ & $\varepsilon_{\mathrm{r}} @ \mathrm{RT}$ & $E_{\mathrm{b}}(\mathrm{kV} / \mathrm{cm})$ & Ref. \\
\hline $0.89 \mathrm{BNT}-0.06 \mathrm{BT}-0.05 \mathrm{KNN}$ & Bulk & $0.5 \mathrm{~mm}$ & 0.46 & - & $\sim 2000$ & 56 & {$[90]$} \\
\hline $1.1 \mathrm{~mol} \% \mathrm{Mn}$ doped $0.7(0.94 \mathrm{NBT}-0.06 \mathrm{BT})-0.3 \mathrm{ST}$ & Bulk & - & 1.06 & - & - & 95 & [91] \\
\hline $0.95(0.8 \mathrm{BNT}-0.2 \mathrm{ST})-0.05 \mathrm{NN}$ & Bulk & - & 0.74 & 55 & $\sim 2000$ & 70 & {$[93]$} \\
\hline $0.94 \mathrm{BS}_{0.35} \mathrm{BNT}-0.06 \mathrm{NN}$ & Bulk & $0.3-0.35 \mathrm{~mm}$ & 1.25 & 76 & $\sim 3800$ & 116 & {$[96]$} \\
\hline $0.55 \mathrm{BNT}-0.45 \mathrm{SBT}$ & Bulk & $20 \mu \mathrm{m} @ \mathrm{SL}$ & 9.5 & 92 & $\sim 2500$ & 720 & {$[15]$} \\
\hline $\mathrm{STL} /(\mathrm{BNT}-\mathrm{BLZT})$ & Bulk & $0.2 \mathrm{~mm}$ & 2.72 & 74 & $\sim 900$ & 294 & {$[98]$} \\
\hline $0.01 \mathrm{~mol} \mathrm{Mn}$ doped BNT & Thick film & $1200 \mathrm{~nm}$ & 30.2 & 47.7 & $\sim 400$ & 2310 & [102] \\
\hline (111)-oriented BNLBTZ & Thin film & $350 \mathrm{~nm}$ & 154 & 95 & $\sim 2000$ & 3500 & [105] \\
\hline $0.94 \mathrm{BNT}-0.06 \mathrm{BT} / 2 \mathrm{BF}$ & Thin film & $400 \mathrm{~nm}$ & 31.96 & 61 & $\sim 500$ & 2400 & [106] \\
\hline$(\mathrm{NKBT} / \mathrm{NKBT}-\mathrm{ST})_{N=6}$ & Thin film & $260 \mathrm{~nm}$ & 73.7 & 68.1 & $\sim 600$ & 3072 & [107] \\
\hline
\end{tabular}

BNT: $\mathrm{Bi}_{0.5} \mathrm{Na}_{0.5} \mathrm{TiO}_{3} ; \mathrm{BT}: \mathrm{BaTiO}_{3} ; \mathrm{KNN}: \mathrm{K}_{0.5} \mathrm{Na}_{0.5} \mathrm{NbO}_{3} ; \mathrm{ST}: \mathrm{SrTiO}_{3} ; \mathrm{NN}: \mathrm{NaNbO}_{3} ; \mathrm{BS}_{0.35} \mathrm{BNT}_{2}\left(\mathrm{Ba}_{0.3} \mathrm{Sr}_{0.7}\right)_{0.35}\left(\mathrm{Bi}_{0.5} \mathrm{Na}_{0.5}\right)_{0.65} \mathrm{TiO}_{3} ; \mathrm{SBT}_{2} \mathrm{Sr}_{0.7} \mathrm{Bi}_{0.2} \mathrm{TiO}_{3}$; STL/(BNT-BLZT): $\left(\mathrm{SrTiO}_{3}+0.5 \mathrm{wt} \% \mathrm{Li}_{2} \mathrm{CO}_{3}\right) /\left(0.93 \mathrm{Bi}_{0.5} \mathrm{Na}_{0.5} \mathrm{TiO}_{3}-0.07 \mathrm{Ba}_{0.94} \mathrm{La}_{0.04} \mathrm{Zr}_{0.02} \mathrm{Ti}_{0.98} \mathrm{O}_{3}\right) ; \mathrm{BNLBTZ}\left(\mathrm{Bi}_{1 / 2} \mathrm{Na}_{1 / 2}\right)_{0.9118} \mathrm{La}_{0.02} \mathrm{Ba}_{0.0582}\left(\mathrm{Ti}_{0.97} \mathrm{Zr}_{0.03}\right) \mathrm{O}_{3}$; BF: $\mathrm{BiFeO}_{3}$; NKBT: $\left(\mathrm{Na}_{0.8} \mathrm{~K}_{0.2}\right)_{0.5} \mathrm{Bi}_{0.5} \mathrm{TiO}_{3}$. SL means single layer.

storage and transfer. In addition, the structure and physical property research of BT-based materials still attract more attentions [111-113]. However, pure BT ceramic has some problems such as high $P_{\mathrm{r}}$, the reduction from $\mathrm{Ti}^{4+}$ to $\mathrm{Ti}^{3+}$ at high temperature, which restrict it to achieve high $W_{\text {rec }}$ [114].

In 2009, Ogihara et al. [115] synthesized a temperature stable $0.7 \mathrm{BaTiO}_{3}-0.3 \mathrm{BiScO}_{3}(0.7 \mathrm{BT}-0.3 \mathrm{BS})$ relaxor ferroelectric ceramics with a thickness of $0.2 \mathrm{~mm}$, and obtained $W_{\text {rec }}$ of $2.3 \mathrm{~J} / \mathrm{cm}^{3}$ at $225 \mathrm{kV} / \mathrm{cm}$. When thickness reduces to $15 \mu \mathrm{m}, W_{\text {rec }}$ enhances to $6.1 \mathrm{~J} / \mathrm{cm}^{3}$ at $730 \mathrm{kV} / \mathrm{cm}$. By comparison, Wu et al. [116] utilized $\mathrm{BiScO}_{3}$ (BS) as shell material to coat $\mathrm{BT}$, and $W_{\text {rec }}$ only of $0.68 \mathrm{~J} / \mathrm{cm}^{3}$ was measured at $E_{\mathrm{b}}=120 \mathrm{kV} / \mathrm{cm}$ for BT@3 mol\% BS ceramics. Yuan et al. [117] prepared $\mathrm{Bi}\left(\mathrm{Mg}_{1 / 2} \mathrm{Zr}_{1 / 2}\right) \mathrm{O}_{3}$ (BMZ) modified BT-based relaxor ferroelectric, and achieved a high $W_{\text {rec }}=2.9 \mathrm{~J} / \mathrm{cm}^{3}$ for $0.85 \mathrm{BT}-0.15 \mathrm{BMZ}$ ceramics higher than pure BT ceramics $\left(0.4 \mathrm{~J} / \mathrm{cm}^{3}\right)$, and corresponding $P-E$ loop is exhibited in Fig. 10(a). The authors thought the enhancement of $W_{\text {rec }}$ is related to PNRs, as evidenced by piezoelectric force microscope (PFM) and transmission electron microscope (TEM). It should be mentioned that other systems such as $\mathrm{BaTiO}_{3}-$ $\mathrm{Bi}(\mathrm{Mg}, \mathrm{Ti}) \mathrm{O}_{3}$ (BT-BMT) also display good energy storage capabilities due to the low tolerance factor of Bi-based compound [118,119]. In recent years, $\mathrm{Ba}_{0.85} \mathrm{Ca}_{0.15} \mathrm{Zr}_{0.10} \mathrm{Ti}_{0.90} \mathrm{O}_{3} \quad$ (BCZT) based relaxor ferroelectric gains more attention in ferroelectric and pyroelectric properties because of high $\mathcal{E}_{\mathrm{r}}$ at room temperature [120-123]. However, $W_{\text {rec }}$ of BCZT-based ceramic bulks is commonly less than $3 \mathrm{~J} / \mathrm{cm}^{3}$ limited to a low $E_{\mathrm{b}}$. If the trade-off relationship between $\varepsilon_{\mathrm{r}}$ and $E_{\mathrm{b}}$ gets a good balance, BCZT-based ceramics would be a promising energy storage candidate.

"Core-shell" structure is a common way of modifying BT-based ceramics, especially in enhancing temperature stability for ceramic capacitor applications. In 2014, Su et al. [124] coated BT nanocrystals with $65 \mathrm{PbO}-20 \mathrm{~B}_{2} \mathrm{O}_{3}-15 \mathrm{SiO}_{2}$ and $65 \mathrm{Bi}_{2} \mathrm{O}_{3}-20 \mathrm{~B}_{2} \mathrm{O}_{3}-15 \mathrm{SiO}_{2}$ glass phases, reducing sintering temperature to $900{ }^{\circ} \mathrm{C}$. Meanwhile, the authors estimated $W_{\text {rec }}$ approaching to $10 \mathrm{~J} / \mathrm{cm}^{3}$ by equation for Bi-based glass phase. Similarly, high $E_{\mathrm{b}}$ materials such as $\mathrm{SiO}_{2}$ [125] and $\mathrm{SrTiO}_{3}$ (ST) [126] are both used as shell materials to improve breakdown behavior. For example, Wu et al. [126] fabricated BT@ST relaxor ferroelectric ceramics using the sol-precipitation approach, and EDS analysis illustrated BT@ST ceramics in Fig. 10(b). However, with a $W_{\text {rec }}$ only of $0.22 \mathrm{~J} / \mathrm{cm}^{3}$ at $47 \mathrm{kV} / \mathrm{cm}, \eta$ approaches to $90 \%$. It should be pointed that high $E_{\mathrm{b}}$ materials usually possess low $\varepsilon_{\mathrm{r}}$, and so $W_{\text {rec }}$ of coated BT ceramics cannot be effectively enhanced at the sacrifice of $\varepsilon_{\mathrm{r}}$. Bi-based materials such as $\mathrm{BiScO}_{3}$ as shell material also suffer from the same problem of obtaining high $W_{\text {rec }}$. The reason needs to be further explored due to the complex composition gradient.

$\mathrm{Ba}(\mathrm{Zr}, \mathrm{Ti}) \mathrm{O}_{3} \quad$ (BZT) based ceramic films are considered to be a potential energy storage material since $\mathrm{Zr}^{4+}$ has a stable valence and similar ion radius of $\mathrm{Ti}^{4+}$, as well as good relaxor characteristics. As $\mathrm{Zr}^{4+}$ content increases, relaxor degree gradually enhances, and a weak diffuse phase transition accompanying slim $P-E$ loop can be founded when $\mathrm{Zr}^{4+}$ near $15 \mathrm{~mol} \%$, which is attributed to the inhomogeneous distribution of $\mathrm{Zr}$ and mechanical stress $[128,129]$. Therefore, energy 
(a)

(c)

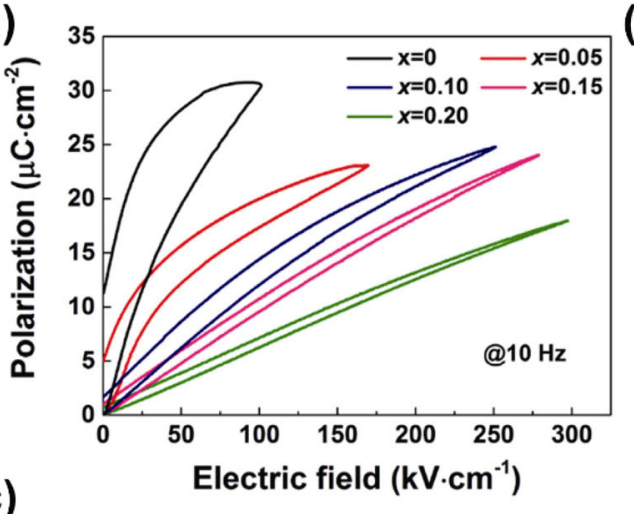

(b)

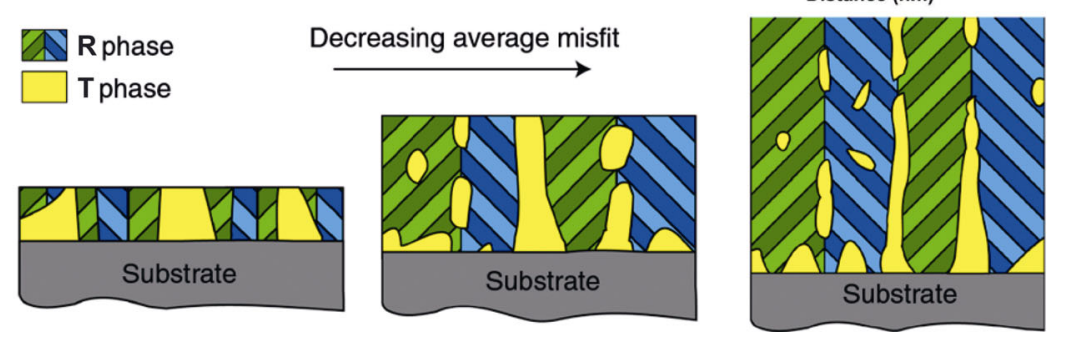

Fig. 10 (a) $P-E$ loop of $\mathrm{BaTiO}_{3}-x \mathrm{Bi}\left(\mathrm{Mg}_{1 / 2} \mathrm{Zr}_{1 / 2}\right) \mathrm{O}_{3}$ at room temperature. Reproduced with permission from Ref. [117], (C) Elsevier Ltd. 2018. (b) EDS line scanning analysis of Sr in the BT@ST ceramic. Reproduced with permission from Ref. [126], (C) The Royal Society of Chemistry 2015. (c) Schematic of the microstructure evolution with film thickness for $\mathrm{Ba}\left(\mathrm{Zr}_{0.2}, \mathrm{Ti}_{0.8}\right) \mathrm{O}_{3}$ thin films. Reproduced with permission from Ref. [127], (c) The Author(s) 2017.

storage performances of BZT-based ceramic systems receive more attention. Instan et al. [130] prepared 400 $\mathrm{nm}<100>$-oriented $\mathrm{Ba}\left(\mathrm{Zr}_{x} \mathrm{Ti}_{1-x}\right) \mathrm{O}_{3}(x=0.3,0.4,0.5)$ relaxor ferroelectric thin films using PLD on $\mathrm{La}_{0.7} \mathrm{Sr}_{0.3} \mathrm{MnO}_{3} / \mathrm{MgO}$ substrates. Importantly, $W_{\text {rec }}$ of all ceramics can reach a scale of $10^{2}$ around $E_{\mathrm{b}} \approx$ $3 \mathrm{MV} / \mathrm{cm}$, and a maximum $W_{\text {rec }}$ of $156 \mathrm{~J} / \mathrm{cm}^{3}$ is obtained at $x=0.3$ composition. In 2017, Cheng et al. [127] reported the influence of thickness and substrate categories on domain/phase of $\mathrm{Ba}\left(\mathrm{Zr}_{0.2} \mathrm{Ti}_{0.8}\right) \mathrm{O}_{3}$ thin films. With increasing thickness, mismatch stress gradually releases and rhombohedral phase content increases, as well as twined domain structure is formed, as shown in Fig. 10(c). A high $W_{\text {rec }}$ of $166 \mathrm{~J} / \mathrm{cm}^{3}$ for $\mathrm{Ba}\left(\mathrm{Zr}_{0.2} \mathrm{Ti}_{0.8}\right) \mathrm{O}_{3}$ thin films is achieved at $E_{\mathrm{b}} \approx$ $5.7 \mathrm{MV} / \mathrm{cm}$. In addition, oxygen pressure is found to generate a positive effect on energy storage properties of BT-based thin films [131].

"Interface engineering", including interface compatibility, periodic number, and space charge, plays a critical role in enhancing $E_{\mathrm{b}}$ and optimizing polarization behavior of BT-based ceramic films. In 2012, Ortega et al. [132] deposited $\mathrm{BaTiO}_{3} / \mathrm{Ba}_{0.3} \mathrm{Sr}_{0.7} \mathrm{TiO}_{3}$ superlattice thin films on $\mathrm{MgO}$ single substrate using PLD, and acquired a $W_{\text {rec }}$ of $12.24 \mathrm{~J} / \mathrm{cm}^{3}$ measured by $P-E$ loop. It should be noted that a theoretical value of
$W_{\mathrm{rec}}=46 \mathrm{~J} / \mathrm{cm}^{3}$ at $E_{\mathrm{b}}$ reach to $5.8-6 \mathrm{MV} / \mathrm{cm}$. Sun et al . [133] studied energy storage properties of laminated $\mathrm{Ba}_{0.7} \mathrm{Ca}_{0.3} \mathrm{TiO}_{3} / \mathrm{BaZr}_{0.2} \mathrm{Ti}_{0.8} \mathrm{O}_{3}$ (BCT/BZT) thin films with two layers as a period and the number is $2,4,8$. With increasing period, $E_{\mathrm{b}}$ enhances from 3 to $4.5 \mathrm{MV} / \mathrm{cm}$, and a maximum $W_{\text {rec }}$ is $52.4 \mathrm{~J} / \mathrm{cm}^{3}$ for $N=8$. Meanwhile, a series of multilayer structures consisting of two materials or a stack of different dielectric layers, have become the most charming model systems since some unique properties can be enhanced. Due to the difference of electric properties in stacked dielectric material, some physical mechanisms such as current leakage mechanism and charge distribution in heterostructure interface, still need to be further investigated $[134,135]$. Energy storage performances of the BT based relaxor ferroelectric materials are summarized and listed in Table 4.

(3) $\mathrm{BiFeO}_{3}$-based ceramics

$\mathrm{BiFeO}_{3}$ (BF) as a multiferroic material with perovskite structure exhibits high $T_{\mathrm{C}}\left(\sim 850{ }^{\circ} \mathrm{C}\right)$, high $P_{\mathrm{s}}\left(\sim 100 \mu \mathrm{C} / \mathrm{cm}^{2}\right)$, and large $S_{\max }(\sim 0.4 \%)$, and gains extensive studies in different cross fields such as piezoelectric, magnetic, and quantum [136-139]. The volatile nature of $\mathrm{Bi}$ and multiple valence variation of Fe during sintering cause large dielectric loss and leakage current [140]. Nevertheless, BF relaxor ferroelectric is 
Table 4 Energy storage properties of BT-based relaxor ferroelectric ceramic bulks and films

\begin{tabular}{cccccccc}
\hline Composition & Category & $t$ & $W_{\text {rec }}\left(\mathrm{J} / \mathrm{cm}^{3}\right)$ & $\eta(\%)$ & $\varepsilon_{\mathrm{r}} @$ RT & $E_{\mathrm{b}}(\mathrm{kV} / \mathrm{cm})$ & Ref. \\
\hline 0.7BT-0.3BS & Bulk & $0.2 \mathrm{~mm}$ & 2.3 & - & $\sim 900$ & 225 & {$[115]$} \\
BT@3BS & Thick film & $15 \mu \mathrm{m}$ & 6.1 & - & $750-800$ & 730 & 120 \\
$0.85 \mathrm{BT}-0.15 \mathrm{BMZ}$ & Bulk & - & 0.68 & 81 & $\sim 1500$ & {$[116]$} \\
BT with BBS glass & Bulk & $0.2 \mathrm{~mm}$ & 2.9 & 86.8 & $\sim 1000$ & 279.8 & {$[117]$} \\
BT@ST & Bulk & - & $\sim 10$ & - & $\sim 550$ & $\sim 1140$ & {$[124]$} \\
$<100>$-oriented Ba $\left(\mathrm{Zr}_{0.3} \mathrm{Ti}_{0.7}\right) \mathrm{O}_{3}$ & Bulk & - & 0.22 & $\sim 90$ & $\sim 2000$ & 47 & {$[126]$} \\
Ba(Zr $\left(\mathrm{Zr}_{0.2} \mathrm{Ti}_{0.8}\right) \mathrm{O}_{3}$ & Thin film & $400 \mathrm{~nm}$ & $156 \pm 1$ & 72.8 & $\sim 3400$ & 3000 & {$[130]$} \\
Superlattice BT/BST & Thin film & $350 \mathrm{~nm}$ & 166 & $\sim 90$ & $\sim 350$ & 5700 & {$[127]$} \\
$(\mathrm{BCT} / \mathrm{BZT})_{N=8}$ & Thin film & $0.6 \mu \mathrm{m}$ & $\sim 12.24$ & - & $\sim 800$ & 1660 & {$[132]$} \\
\hline
\end{tabular}

BT: $\mathrm{BaTiO}_{3}$; BS: $\mathrm{BiScO}_{3} ; \mathrm{BMZ}: \mathrm{Bi}\left(\mathrm{Mg}_{1 / 2} \mathrm{Zr}_{1 / 2}\right) \mathrm{O}_{3} ; \mathrm{BBS}: 65 \mathrm{Bi}_{2} \mathrm{O}_{3}-20 \mathrm{~B}_{2} \mathrm{O}_{3}-15 \mathrm{SiO}_{2} ; \mathrm{ST}: \mathrm{SrTiO}_{3} ; \mathrm{BST}_{2} \mathrm{Ba}_{0.3} \mathrm{Sr}_{0.7} \mathrm{TiO}_{3} ; \mathrm{BCT} \mathrm{Ba}_{0.7} \mathrm{Ca}_{0.3} \mathrm{TiO}_{3} ; \mathrm{BZT}$ $\mathrm{BaZr}_{0.2} \mathrm{Ti}_{0.8} \mathrm{O}_{3}$

still considered as a potential candidate for energy storage capacitors because of high $P_{\mathrm{s}}$.

$\mathrm{BiFeO}_{3}-x \mathrm{BaTiO}_{3}(\mathrm{BF}-x \mathrm{BT}, 0 \leqslant x \leqslant 0.5)$ ceramics maintain high $T_{\mathrm{C}}$, good ferroelectric and piezoelectric properties resulted from complicated phase structure evolution. With increasing $x$ value, $\mathrm{BF}-x \mathrm{BT}$ ceramics possess a high $P_{\max }$ near MPB of BT $\approx 0.33 \mathrm{~mol}$ [141-143]. Energy storage properties of BF-based ceramics, therefore, basically are around $\mathrm{BF}-0.33 \mathrm{BT}$ system to reduce $P_{\mathrm{r}}$. For example, Liu et al. [144] added $\mathrm{Ba}\left(\mathrm{Zn}_{1 / 3} \mathrm{Ta}_{2 / 3}\right) \mathrm{O}_{3}$ (BZT) into $\mathrm{BT}-0.34 \mathrm{BT}$ relaxor ferroelectric ceramics obtaining a $W_{\text {rec }}$ of $2.56 \mathrm{~J} / \mathrm{cm}^{3}$ at $160 \mathrm{kV} / \mathrm{cm}$. To enhance breakdown strength of BF-based ceramics, Qi et al. [145] introduced $\mathrm{NaNbO}_{3}$ (NN) combined with $0.1 \mathrm{wt} \% \mathrm{MnO}_{2}$ and $2 \mathrm{wt} \%$ $\mathrm{BaCu}\left(\mathrm{B}_{2} \mathrm{O}_{5}\right)$ (BCB) as sintering aids to modify $0.67 \mathrm{BF}-0.33 \mathrm{BT}$ relaxor ferroelectric ceramics, and corresponding Weibull distribution of $E_{\mathrm{b}}$ is given in
Fig. 11(a). At $360 \mathrm{kV} / \mathrm{cm}, x=0.1$ sample possesses a maximum $W_{\text {rec }}$ of $8.12 \mathrm{~J} / \mathrm{cm}^{3}$ accompanied to $\eta$ of $90 \%$, which is related to the existence of nanodomain and high density. In addition, Wang et al. [146] reported that $W_{\text {rec }}$ of $0.62 \mathrm{BF}-0.3 \mathrm{BT}-0.08 \mathrm{Nd}\left(\mathrm{Zr}_{0.5} \mathrm{Zn}_{0.5}\right) \mathrm{O}_{3}$ ceramic bulks is $2.45 \mathrm{~J} / \mathrm{cm}^{3}$ at $240 \mathrm{kV} / \mathrm{cm}$. When an MLCC device based on this system is made, $W_{\text {rec }}$ is enhanced to $10.5 \mathrm{~J} / \mathrm{cm}^{3}$.

Similar to BF- $x$ BT systems, ST modified BF-based energy storage ceramics are mainly concentrated on films due to thickness limitation. In 2013, Correia et al. [147] prepared 0.4BF-0.6ST thin films using PLD, obtained a high $W_{\text {rec }}$ of $18.6 \mathrm{~J} / \mathrm{cm}^{3}$ at $972 \mathrm{kV} / \mathrm{cm}$. Recently, Pan et al. [148] reported $(0.55-x) \mathrm{BF}-x \mathrm{BT}-$ $0.45 \mathrm{ST}(x=0-0.4)$ thin films with polymorphic nanodomain structure are grown on Nb-doped $\mathrm{SrTiO}_{3}$ single crystal substrate. Under an electric field of $4.9 \mathrm{MV} / \mathrm{cm}, x=0.3$ composition achieves a maximum (a)

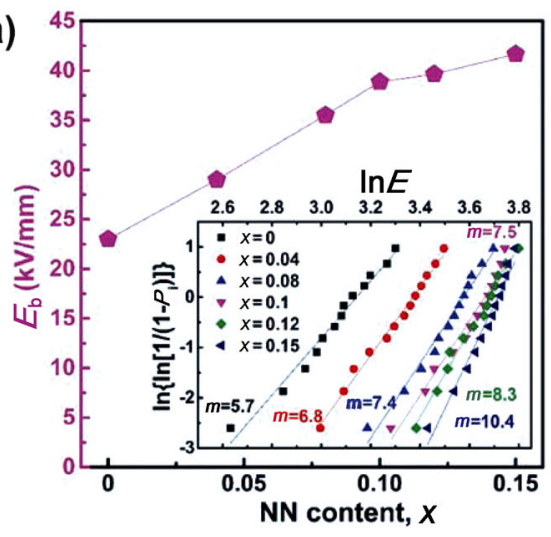

(b)

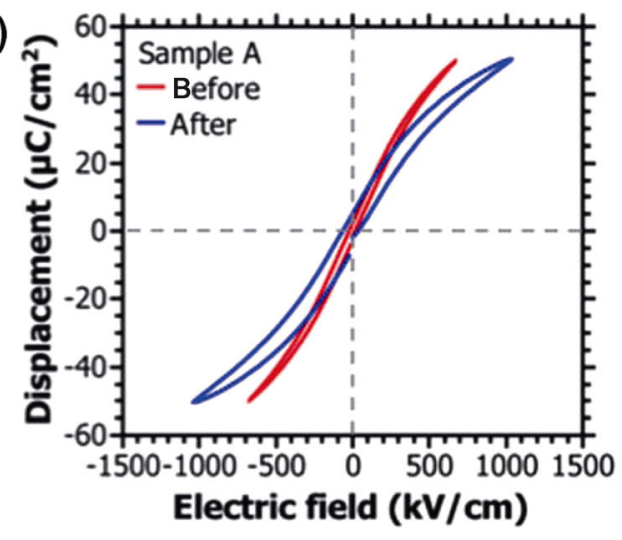

Fig. 11 (a) Weibull distribution and calculated $E_{\mathrm{b}}$ values of $(0.67-x) \mathrm{BF}-0.33 \mathrm{BT}-x \mathrm{NN}$ ceramics. Reproduced with permission from Ref. [145], (C) WILEY-VCH Verlag GmbH \& Co. KGaA, Weinheim 2019. (b) $P-E$ loops from two film capacitor structures before and after the introduction of an alumina layer at the electrode- $0.6 \mathrm{BF}-0.4 \mathrm{ST}$ interface. Reproduced with permission from Ref. [150], (C) AIP Publishing 2012. 
$W_{\text {rec }}=112 \mathrm{~J} / \mathrm{cm}^{3}$ more than $53 \mathrm{~J} / \mathrm{cm}^{3}$ of pure $0.55 \mathrm{BF}-$ $0.45 \mathrm{ST}$ thin films, which is owing to the enhanced relaxor behaviors and breakdown strengthen. Moreover, the energy storage performances of this system maintain good stability in a wide temperature range of $(-100)-150{ }^{\circ} \mathrm{C}$ and $10^{8}$ cycles, respectively. In addition, an important and interesting double $P-E$ loop can be observed in rare earth substituted $\mathrm{BF}$ thin films due to the transition from orthorhombic to rhombohedral phase [149].

In heterostructure design, McMillen et al. [150] firstly proposed to use "artificial dead layer" to enhance $E_{\mathrm{b}}$, deposited $\mathrm{Al}_{2} \mathrm{O}_{3}$ layer with $6 \mathrm{~nm}$ between $0.6 \mathrm{BF}-0.4 \mathrm{ST}$ film and ST substrate, and corresponding $P-E$ loops before and after inserting $\mathrm{Al}_{2} \mathrm{O}_{3}$ layer were illustrated in Fig. 11(b). Interface polarization behavior to some degree increases hysteresis loss while $\mathrm{Al}_{2} \mathrm{O}_{3}$ insulating layer enhances $E_{\mathrm{b}}$, and thus $W_{\text {rec }}$ enhances from 13 to $17 \mathrm{~J} / \mathrm{cm}^{3}$. Since then, a sandwich structure of "soft layer" with high polarization and "hard layer" with high $E_{\mathrm{b}}$ are constructed to prevent "electric tree" growth and achieve high $W_{\text {rec }}$ [151]. It is particularly important that strong interface coupling factors should be considered in designing structure and analyzing properties [152]. Energy storage performances of the BF-based relaxor ferroelectric materials are summarized and listed in Table 5.

(4) $\mathrm{K}_{0.5} \mathrm{Na}_{0.5} \mathrm{NbO}_{3}$-based ceramics

$\mathrm{K}_{0.5} \mathrm{Na}_{0.5} \mathrm{NbO}_{3}(\mathrm{KNN})$ is a binary solid solution of $\mathrm{KNbO}_{3}$ ferroelectric and $\mathrm{NaNbO}_{3}$ antiferroelectric, and possesses a moderate $d_{33}$ around $80 \mathrm{pC} / \mathrm{N}$, high $T_{\mathrm{C}}$ of $420{ }^{\circ} \mathrm{C}$, and complicated phase structure $[153,154]$. Since the 1950s at latest century, the researches of $\mathrm{KNN}$ materials concentrate on piezoelectric properties due to MPB located at $\mathrm{KNbO}_{3}$ content of $47.5 \%$ [154]. The ratio of $\mathrm{K} / \mathrm{Na}$ has a slight variation while mainly concentrated on $0.5 / 0.5$. However, narrow sintering temperature range, easy volatilization characteristic of $\mathrm{K}, \mathrm{Na}$ at high temperature both hinder its applications.
In 2016, Du et al. studied KNN-based energy storage ceramics, and achieved a high $W_{\text {rec }}$ of about 4 $\mathrm{J} / \mathrm{cm}^{3}$ for $\mathrm{SrTiO}_{3}$ (ST) [155] and $\mathrm{Bi}\left(\mathrm{Mg}_{1 / 3} \mathrm{Nb}_{2 / 3}\right) \mathrm{O}_{3}$ $(\mathrm{BMN})$ [156] modified KNN ceramics. And they further used $\mathrm{CuO}$ [157], $\mathrm{ZnO}$ [158], etc., as fruit to improve sintering behavior of KNN-based ceramics. It should be noted that modified KNN-based energy storage ceramics with superfine grain size possess not only high $E_{\mathrm{b}}$ but also good transparency. In addition, utilize "phase boundary engineering" of KNN ceramics to enhance electric properties is a useful method. Recently, Yang et al. [159] proposed "morphotropic relaxor boundary (MRB)" in BT modified KNN ceramics to illustrate an obvious enhancement of electrostrain and dielectric permittivity. At the MRB the electrostrain increases by $\sim 3$ times and the permittivity increases by $\sim 1.5$ times over a wide temperature range of more than $100 \mathrm{~K}$, as compared with off-MRB compositions. In comparison, the studies of KNN-based ceramic films for energy storage are relatively less, which should be related to insolubility of $\mathrm{Nb}$ and volatilization of $\mathrm{K}$ and $\mathrm{Na}$. In 2017, Won et al. [160] reported $6 \mathrm{~mol} \% \mathrm{BiFeO}_{3}$-doped $\left(\mathrm{K}_{0.5}, \mathrm{Na}_{0.5}\right)\left(\mathrm{Mn}_{0.005}, \mathrm{Nb}_{0.995}\right) \mathrm{O}_{3}$ (KNMN) thick film possessed a slim $P-E$ loop, and achieved a $W_{\text {rec }}$ of 28 $\mathrm{J} / \mathrm{cm}^{3}, \eta$ of $90.3 \%$. Recently, Huang et al. [161] also used $\mathrm{MnO}_{2}$ to reduce leakage current of $0.95\left(\mathrm{~K}_{0.49} \mathrm{Na}_{0.49} \mathrm{Li}_{0.02}\right)\left(\mathrm{Nb}_{0.8} \mathrm{Ta}_{0.2}\right) \mathrm{O}_{3}-0.05 \mathrm{CaZrO}_{3}-x \mathrm{~mol} \%$ Mn (KNN-LT-CZ5- $x$ mol\% Mn) thin films prepared by sol-gel methods, and achieved a high $W_{\text {rec }}=$ $64.6 \mathrm{~J} / \mathrm{cm}^{3}$ under an electric field of $3080 \mathrm{kV} / \mathrm{cm}$ at $x=$ 0.5 composition. Energy storage properties of KNN-based relaxor ferroelectric ceramics and films are summarized and listed in Table 6 .

In summary, for relaxor ferroelectric ceramics, the formation of PNRs due to disturbed long-range ferroelectric order or nonergodic-ergodic phase transition can strengthen relaxor characteristics. Reflecting on macroscopic ferroelectric properties, $P-E$ loop goes

Table 5 Energy storage properties of BF-based relaxor ferroelectric ceramic bulks and films

\begin{tabular}{|c|c|c|c|c|c|c|c|}
\hline Composition & Category & $t$ & $W_{\mathrm{rec}}\left(\mathrm{J} / \mathrm{cm}^{3}\right)$ & $\eta(\%)$ & $\varepsilon_{\mathrm{r}} @ \mathrm{RT}$ & $E_{\mathrm{b}}(\mathrm{kV} / \mathrm{cm})$ & Ref. \\
\hline $0.6 \mathrm{BF}-0.34 \mathrm{BT}-0.06 \mathrm{BZT}$ & Bulk & $0.2 \mathrm{~mm}$ & 2.56 & $\sim 70$ & - & 160 & [144] \\
\hline $0.57 \mathrm{BF}-0.33 \mathrm{BT}-0.1 \mathrm{NN}$ & Bulk & $0.15 \mathrm{~mm}$ & 8.12 & 90 & - & 360 & [145] \\
\hline $0.62 \mathrm{BF}-0.3 \mathrm{BT}-0.08 \mathrm{NZZ}$ & Bulk & $16 \mu \mathrm{m} @ \mathrm{SL}$ & 10.5 & 87 & - & 700 & {$[146]$} \\
\hline $0.4 \mathrm{BF}-0.6 \mathrm{ST}$ & Thin film & $400 \mathrm{~nm}$ & 18.6 & $>85$ & $\sim 900$ & 972 & [147] \\
\hline $0.25 \mathrm{BF}-0.3 \mathrm{BT}-0.45 \mathrm{ST}$ & Thin film & $450-500 \mathrm{~nm}$ & 112 & 80 & $\sim 250$ & 4900 & {$[148]$} \\
\hline Dead layer engineered $0.6 \mathrm{BF}-0.4 \mathrm{ST}$ & Thin film & $400 \mathrm{~nm}$ & 17 & - & - & - & {$[150]$} \\
\hline
\end{tabular}

BF: $\mathrm{BiFeO}_{3}$; $\mathrm{BT}: \mathrm{BaTiO}_{3} ; \mathrm{BZT}: \mathrm{Ba}\left(\mathrm{Zn}_{1 / 3} \mathrm{Ta}_{2 / 3}\right) \mathrm{O}_{3} ; \mathrm{NN}: \mathrm{NaNbO}_{3} ; \mathrm{NZZ}: \mathrm{Nd}\left(\mathrm{Zn}_{0.5} \mathrm{Zr}_{0.5}\right) \mathrm{O}_{3} ; \mathrm{ST}: \mathrm{SrTiO}_{3}$. SL means single layer. 
Table 6 Energy storage properties of KNN-based relaxor ferroelectric ceramic bulks and films

\begin{tabular}{cccccccc}
\hline Composition & Category & $t$ & $W_{\text {rec }}\left(\mathrm{J} / \mathrm{cm}^{3}\right)$ & $\eta(\%)$ & $\varepsilon_{\mathrm{r}} @ \mathrm{RT}$ & $E_{\mathrm{b}}(\mathrm{kV} / \mathrm{cm})$ & Ref. \\
\hline $0.85 \mathrm{KNN}-0.15 \mathrm{ST}$ & Bulk & $0.2 \mathrm{~mm}$ & 4.03 & $\sim 52$ & $\sim 1500$ & 400 & {$[155]$} \\
$0.90 \mathrm{KNN}-0.10 \mathrm{BMN}$ & Bulk & $0.2 \mathrm{~mm}$ & 4.08 & 62.7 & $\sim 1000$ & 300 & {$[156]$} \\
BiFeO${ }_{3}$-doped KNMN & Thick film & $1 \mu \mathrm{m}$ & 28 & 90.3 & - & 2000 & {$[160]$} \\
$5 \mathrm{~mol} \% \mathrm{Mn}$-doped KNN-LT-CZ5 & Thin film & $650 \mathrm{~nm}$ & 64.6 & 84.6 & - & 3080 & {$[161]$} \\
\hline
\end{tabular}

ST: $\mathrm{SrTiO}_{3} ; \mathrm{BMN}$ : Bi( $\left(\mathrm{Mg}_{2 / 3} \mathrm{Nb}_{1 / 3}\right) \mathrm{O}_{3} ; \mathrm{KNMN}:\left(\mathrm{K}_{0.5}, \mathrm{Na}_{0.5}\right)\left(\mathrm{Mn}_{0.005}, \mathrm{Nb}_{0.995}\right) \mathrm{O}_{3} ; \mathrm{KNN}-\mathrm{LT}-\mathrm{CZ} 5: 0.95\left(\mathrm{~K}_{0.49} \mathrm{Na}_{0.49} \mathrm{Li}_{0.02}\right)\left(\mathrm{Nb}_{0.8} \mathrm{Ta}_{0.2}\right) \mathrm{O}_{3}-0.05 \mathrm{CaZrO}_{3}$

slim. In addition, delay saturated polarization is also used to optimize polarization behavior. Designing multilayer ceramic capacitor (MLCC), "core-shell" structure with non-ferroelectric phase as shell material is commonly accepted method to improve electric breakdown behavior for ceramic bulks. By comparison, chemical modification of ceramic films functions two roles: For one, suppress the generation and transportation of vacancy defect to reduce leakage current; for the other one, strengthen its relaxor characteristics and optimize polarization behavior. In the heterostructure of ceramic films, match degree of physical paraments such as lattice constant, thermal expansion coefficient, etc., gradient sequence, template or new inert layers are all important factors to influence energy storage performances.

\section{3 Antiferroelectric ceramics}

As a special group of ferroelectric material, antiferroelectric has many similarities with ferroelectric whereas still exists obvious differences. In 1951, Kittel [162] originally proposed the concept of antiferroelectric, predicted the existence, and gave some basic characteristics. Generally speaking, antiferroelectric materials possess $P_{\mathrm{s}}$ in a unit cell, but the direction of $P_{\mathrm{s}}$ is antiparallel to that of neighboring unit cell. Antiferroelectric, therefore, does not exhibit polarization in macroscopic characteristics. It is particularly important that antiferroelectric exists a unique feature: double hysteresis loop under an external field. $P$ is linearly proportional to $E$ at a low electric field. When $E$ exceeds the forward switching (AFE-to-FE) field $E_{\mathrm{A}-\mathrm{F}}$, antiferroelectric displays an obvious ferroelectric behavior, and $P$ fastly increases and gradually reaches $P_{\max }$. Note that antiferroelectric can undergo a ferroelectric-antiferroelectric phase transition field $\left(E_{\mathrm{F}-\mathrm{A}}\right)$ after removing $E$. Consequently, $P$ gradually reduces and returns to the initial state (that is, $E=0$, $\left.P_{\mathrm{r}}=0\right)$. A similar variation in $P$ can be observed as $E$ continuously increases in an opposite direction.

It is hard to see a double hysteresis loop for most pure antiferroelectric materials at a low electric field, which usually requires special conditions of high temperature and strong electric field to stimulate. Thereby, it is a crucial challenge for antiferroelectric to obtain double $P-E$ loop especially for ceramic bulks. In addition, a typical high squareness $P-E$ loop, and corresponding internal strain induced by antiferroelectricferroelectric phase transition both result in low $W_{\text {rec }}$ and reduced device life [12]. In this regard, how to stabilize and relax the antiferroelectric phase (corresponding to enhancing $E_{\mathrm{A}-\mathrm{F}}$, reducing the difference of $\left.E_{\mathrm{A}-\mathrm{F}}-E_{\mathrm{F}-\mathrm{A}}\right)$ and enhance $E_{\mathrm{b}}$ has become a particularly important issue to acquire good energy storage performances.

\subsubsection{Pb-based antiferroelectric ceramics}

(1) $\mathrm{PbZrO}_{3}$

$\mathrm{PbZrO}_{3}(\mathrm{PZ})$ is the prototype antiferroelectric, and serves as a model system to be thoroughly studied so far. The origin of the phase transition mechanism, however, is not well understood [163]. Despite this, a characteristic double $P-E$ loop with high $P_{\max }$ and low $P_{\mathrm{r}}$ makes it suitable for energy storage capacitors. PZ-based energy storage ceramics gain increasing attention since Chen et al. [164] reported $W_{\text {rec }}$ of $7.1 \mathrm{~J} / \mathrm{cm}^{3}$ for PZ thin films during phase transition, but basically around ceramic films.

It is widely accepted that tolerance factor $t$ of perovskite structure is closely related to phase stability, and the equation is represented as

$$
t=\frac{r_{\mathrm{A}}+r_{\mathrm{O}}}{\sqrt{2}\left(r_{\mathrm{B}}+r_{\mathrm{O}}\right)}
$$

where $r_{\mathrm{A}}, r_{\mathrm{B}}, r_{\mathrm{O}}$ denote ion radius of $\mathrm{A}, \mathrm{B}$, and $\mathrm{O}$, respectively. In general, AFE phase can be stabilized for $t<1$, and reducing $t$ can enhance in some degree the stability of AFE phase. For example, Hao et al. [165] substituted $\mathrm{Pb}^{2+}(1.20 \AA)$ with smaller $\mathrm{Sr}^{2+}$ $(1.12 \AA)$ to reduce $t$, and $P-E$ loop goes slim together with increased $E_{\mathrm{A}-\mathrm{F}}$ and decreased $\Delta E$. As a consequence, $\left(\mathrm{Pb}_{0.95} \mathrm{Sr}_{0.05}\right) \mathrm{ZrO}_{3}(\mathrm{PSZ} 5)$ thin films obtain a $W_{\text {rec }}$ of 
$14.5 \mathrm{~J} / \mathrm{cm}^{3}$. Choosing smaller ion radius while aliovalent of $\mathrm{La}^{3+}$ as donor dopant has a similar effect [166]. In addition, controlling the orientation of PZ thin film also achieves the purpose of stabilizing the antiferroelectric phase. PZ thin film with (100) orientation needs a higher electric field than with (111) one to finish antiferroelectric-ferroelectric phase transition [167].

Tailoring local electric field and stress to enhance $W_{\text {rec }}$ is hard but interesting work. As is well known, introducing a new nanoparticle in materials often brings novel properties and improved properties. For example, Sa et al. [169] used $\alpha-\mathrm{Fe}_{2} \mathrm{O}_{3}$ nanoparticles to modify PZ thin films, obtained a $W_{\text {rec }}$ of $17.4 \mathrm{~J} / \mathrm{cm}^{3}$ and $P_{\max }$ as high as $78 \mu \mathrm{C} / \mathrm{cm}^{2}$ attributing to the local field effect. By comparison, Chen et al. [170] fabricated a self-assembled PZ:NiO nano-columnar composite using PLD, and proposed that tensile stress mainly comes from the interface of two phases. At $E_{\mathrm{b}}=$ $1000 \mathrm{kV} / \mathrm{cm}, 5 \mathrm{vol} \% \mathrm{NiO}$ thin films possess a high $P_{\max }$ of $\sim 91 \mu \mathrm{C} / \mathrm{cm}^{2}$, and $W_{\text {rec }}$ of $24.6 \mathrm{~J} / \mathrm{cm}^{3}$. Meanwhile, Ge et al. [171,172] also did a series of works on optimizing polarization behavior mainly such as enhancing $P_{\max }$, reducing $E_{\mathrm{A}-\mathrm{F}}-E_{\mathrm{F}-\mathrm{A}}$ using the stress engineering method. To our best knowledge, it is difficult to directly measure and characterize local electric field and stress, and thus corresponding methods need to be developed. Furthermore, the gradient sequence of thin film is significant for enhancing $W_{\text {rec }}$ Ye et al. [168] reported a $W_{\text {rec }}$ of $16.3 \mathrm{~J} / \mathrm{cm}^{3}$ for down-graded higher than that of $9.7 \mathrm{~J} / \mathrm{cm}^{3}$ for up-graded PZ-based thin films, and corresponding $P-E$ loops are shown in Fig. 12.

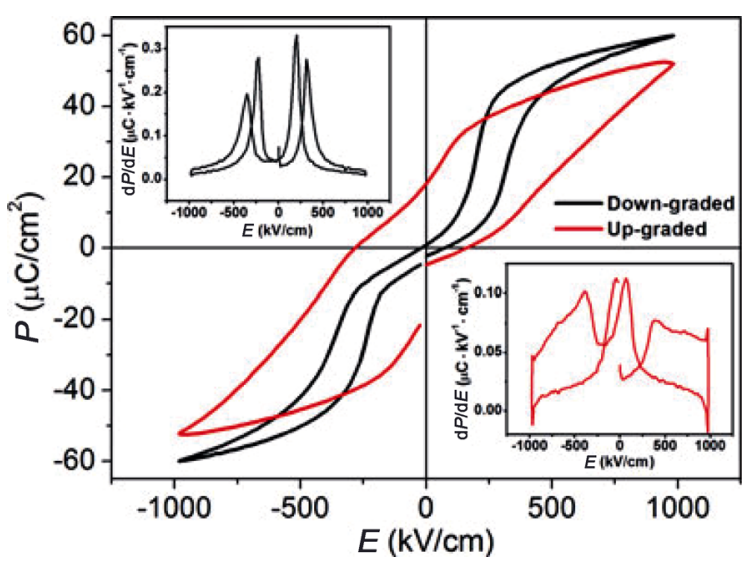

Fig. $12 P-E$ loops of up- and down-graded Eu-doped $\mathrm{PZ}$ thin films. Inset: the differentiated $P-E$ hysteresis loops of down- and up-graded thin films, respectively. Reproduced with permission from Ref. [168], (C) The American Ceramic Society 2012.
It should be mentioned that $\mathrm{PbHfO}_{3}$ (PHO) antiferroelectric ceramics have some similarity with $\mathrm{PZO}$, and thus the related studies still concentrate on phase structure [173-175]. Nevertheless, the energy storage properties of $\mathrm{PHO}-$ based ceramics have rarely been reported. In 2020, Chao et al. [176] prepared $\mathrm{Pb}_{0.98} \mathrm{La}_{0.02}\left(\mathrm{Hf}_{x} \mathrm{Sn}_{1-x}\right)_{0.995} \mathrm{O}_{3}$ antiferroelectric ceramics, and achieved a good energy storage performance: $W_{\text {rec }}$ and $\eta$ are of $7.63 \mathrm{~J} / \mathrm{cm}^{3}$ and $94 \%$ for $x=0.45$ composition, respectively. Recently, Huang et al. [177] reported pure PHO ceramic films by sol-gel method at $650{ }^{\circ} \mathrm{C}$ annealing temperature, and achieved a $W_{\text {rec }}$ of $24.9 \mathrm{~J} / \mathrm{cm}^{3}$.

(2) $(\mathrm{Pb}, \mathrm{La})(\mathrm{Zr}, \mathrm{Sn}, \mathrm{Ti}) \mathrm{O}_{3}$

As discussed in Section 3.2.1, $\mathrm{Pb}\left(\mathrm{Zr}_{1-x} \mathrm{Ti}_{x}\right) \mathrm{O}_{3}(\mathrm{PZT}$, $x \approx 0.05)$ solid solutions located at rich $\mathrm{Zr}$ regions of ferroelectric-antiferroelectric (FE-AFE) phase boundary, exhibit rich phase structures and well electrical properties $[61,62]$. It is worth noting that PZT systems at $\mathrm{FE}-\mathrm{AFE}$ phase boundary differ from $\mathrm{MPB}$ in electric properties. For instance, FE and AFE cannot be transformed into each other under force or electric field, while temperature, stress, or other factors induced by FE-AFE phase transition can occur. Meanwhile, the region of the antiferroelectric phase for PZT 95/5 is relatively narrow, and a slight composition fluctuation would easily cause deviation from FE-AFE phase boundary.

$\mathrm{La}^{3+}$ and $\mathrm{Sn}^{4+}$ are very popular A/B site dopants in PZT 95/5 ceramics where their functions are similar [178-182]. $\mathrm{La}^{3+}$, as a donor dopant, substitutes $\mathrm{Pb}^{2+}$ to disturb long-range ordering of domain by vacancy defect, which would strengthen the relaxor characteristic and expand the stabilized region of the antiferroelectric phase. $\mathrm{Sn}^{4+}$ as an equal valence dopant of $\mathrm{Ti}^{4+}$ functions not only expands the stabilized region of antiferroelectric, but also adjusts $\mathrm{Zr} / \mathrm{Ti}$ ratio to enable Ti up to $10 \mathrm{~mol} \%$. Currently, the related works of stabilizing the $\mathrm{Pb}$-based antiferroelectric phase mainly focus on adjusting suitable $\mathrm{Zr} / \mathrm{Sn} / \mathrm{Ti}$ ratio [183-185]. Liu et al. [186] found that $E_{\mathrm{A}-\mathrm{F}}$ linearly increased and the squareness of $P-E$ loop slightly improved when Ti content reduces from 0.11 to $0.07 \mathrm{~mol}$ at a fixed $\mathrm{Zr}$ of 0.58 mol. $W_{\text {rec }}$ enhances, thereby, from 0.28 to $2.35 \mathrm{~J} / \mathrm{cm}^{3}$ for $\mathrm{Pb}_{0.97} \mathrm{La}_{0.02}\left(\mathrm{Zr}_{0.58} \mathrm{Sn}_{0.35} \mathrm{Ti}_{0.07}\right) \mathrm{O}_{3}$ antiferroelectric ceramic bulks. In addition, it should be particularly noted that a high $W_{\text {rec }}$ is difficult to obtain when $E_{\mathrm{A}-\mathrm{F}}$ exceeds $E_{\mathrm{b}}$.

In improving the breakdown behavior of $\mathrm{Pb}$-based antiferroelectric ceramic bulks, Zhang et al. [187-189] 
did a series of works using some special sintering technology. For instance, Zhang et al. [188] reported that $\left(\mathrm{Pb}_{0.87} \mathrm{Ba}_{0.1} \mathrm{La}_{0.02}\right)\left(\mathrm{Zr}_{0.68} \mathrm{Sn}_{0.24} \mathrm{Ti}_{0.08}\right) \mathrm{O}_{3}$ (PBLZST) ceramics using hot-press (HP) possessed a high $W_{\text {rec }}$ of $3.2 \mathrm{~J} / \mathrm{cm}^{3}$ at $E_{\mathrm{b}}=180 \mathrm{kV} / \mathrm{cm}$ due to smaller grain size and well insulation. Considering that special sintering technology requires expensive equipment, this method is not suitable for large-scale production. Some low-cost and convenient solutions are proposed, such as Bian et al. [190] used amorphous $\mathrm{SiO}_{2}$ to coat $\mathrm{Pb}_{0.97} \mathrm{La}_{0.02}\left(\mathrm{Zr}_{0.33} \mathrm{Sn}_{0.55} \mathrm{Ti}_{0.12}\right) \mathrm{O}_{3}$ (PLZST 2/33/55/12), and measured a high $W_{\text {rec }}$ of $2.68 \mathrm{~J} / \mathrm{cm}^{3}$ due to $E_{\mathrm{b}}$ enhancing from 12.2 to $23.8 \mathrm{kV} / \mathrm{mm}$. It should be noticed that the introduction of non-antiferroelectric phase will reduce the content of the original antiferroelectric phase, even that $E_{\mathrm{A}-\mathrm{F}}$ would disappear. In a physical method, Wang et al. [191] used a rolling process to enhance the mechanical strength of $\left(\mathrm{Pb}_{0.98} \mathrm{La}_{0.02}\right)\left(\mathrm{Zr}_{0.55} \mathrm{Sn}_{0.45}\right)_{0.995} \mathrm{O}_{3}$ (PLZS) antiferroelectric ceramics. At $400 \mathrm{kV} / \mathrm{cm}$, PLZS ceramics obtain a high $W_{\text {rec }}$ of $10.4 \mathrm{~J} / \mathrm{cm}^{3}$ and a $\eta$ of $87 \%$. Similarly, Zhang et al. [192] and Liu et al. [193] both utilized tape-casting method to fabricate antiferroelectric thick film. For example, Liu et al. [193] utilized tape-casting method to fabricate $\left(\mathrm{Pb}_{0.98-x} \mathrm{La}_{0.02} \mathrm{Sr}_{x}\right)\left(\mathrm{Zr}_{0.9} \mathrm{Sn}_{0.1}\right)_{0.995} \mathrm{O}_{3}$ (PLSZS) antiferroelectric thick films, and achieved $W_{\text {rec }}$ and $\eta$ of $11.18 \mathrm{~J} / \mathrm{cm}^{3}$ and $82.2 \%$ for $x=0.04$, respectively.

Due to the phase structure complexity of PZT-based ceramics near FE-AFE boundary, it usually displays different polarization behavior especially for ceramic films. Gao et al. [194] reported different oriented $\left(\mathrm{Pb}_{0.98} \mathrm{La}_{0.02}\right)\left(\mathrm{Zr}_{0.95} \mathrm{Ti}_{0.05}\right) \mathrm{O}_{3}$ (PLZT) thin films using PLD, obtained a $W_{\text {rec }}$ of $\sim 40 \mathrm{~J} / \mathrm{cm}^{3}$ while $\eta$ only of $\sim 50 \%$ for (111) PLZT, which may be related to ferroelectric-like behavior (i.e., high $P_{\mathrm{r}}$ ) under high electric field. Despite this condition, the combination of relaxor ferroelectric and antiferroelectric still receives more attention to enhance $W_{\text {rec }}$. In addition, note that antiferroelectric behavior can be observed at different formulas such as PLZT at $\mathrm{Zr} / \mathrm{Ti} \approx 52: 48$ [196] or PLZST at $\mathrm{Zr} /(\mathrm{Sn}+\mathrm{Ti}) \approx 65: 55$ [197]. With the development of micro-electric devices, flexible substrate such as $\mathrm{Ti}, \mathrm{Si}$, Ni foils, etc., is required to meet future application scenes. Ma et al. [195,198] did a series of meaningful works in the low-cost integration development of PLZT-based thin films. For instance, $\mathrm{Pb}_{0.92} \mathrm{La}_{0.08} \mathrm{Zr}_{0.95} \mathrm{Ti}_{0.05} \mathrm{O}_{3}$ (PLZT 8/95/5) antiferroelectric ceramic films possess a high $W_{\text {rec }}$ of $53 \mathrm{~J} / \mathrm{cm}^{3}$ at mental foil by CSD, and effective work time would maintain $5000 \mathrm{~h}$ at room temperature [195]. Energy storage properties of $\mathrm{Pb}$-based antiferroelectric ceramics and films are summarized and listed in Table 7.

\subsubsection{Lead-free antiferroelectric ceramics}

(1) $\mathrm{NaNbO}_{3}$

$\mathrm{NaNbO}_{3}(\mathrm{NN})$ is a well-documented nonpolar antiferroelectric phase and possesses a complicated crystal structure due to the rotation of oxygen octahedron

Table 7 Energy storage properties of $\mathrm{Pb}$-based antiferroelectric ceramic bulks and films

\begin{tabular}{|c|c|c|c|c|c|c|c|}
\hline Composition & Category & $t$ & $W_{\text {rec }}\left(\mathrm{J} / \mathrm{cm}^{3}\right)$ & $\eta(\%)$ & $\varepsilon_{\mathrm{r}} @ \mathrm{RT}$ & $E_{\mathrm{b}}(\mathrm{kV} / \mathrm{cm})$ & Ref. \\
\hline $\mathrm{PZ}$ & Thin film & $300-600 \mathrm{~nm}$ & 7.1 & - & $120-200$ & - & [164] \\
\hline PSZ5 & Thin film & $500 \mathrm{~nm}$ & 14.5 & 78 & $\sim 150$ & 900 & {$[165]$} \\
\hline$\alpha-\mathrm{Fe}_{2} \mathrm{O}_{3}$ modified PZ & Thin film & $660 \mathrm{~nm}$ & 17.4 & $\sim 58$ & - & 600 & [169] \\
\hline $\mathrm{PZ}: \mathrm{NiO}$ & Thin film & $140-170 \mathrm{~nm}$ & 24.6 & $\sim 70$ & $\sim 600$ & 1000 & {$[170]$} \\
\hline Up-graded Eu-doped PZ & Thin film & $400 \mathrm{~nm}$ & 16.3 & 67.4 & $\sim 300$ & 1000 & {$[168]$} \\
\hline PLHS & Bulk & $0.11 \mathrm{~mm}$ & 7.63 & 94 & $\sim 280$ & 380 & {$[176]$} \\
\hline $\mathrm{PHO}$ & Thin film & $330 \mathrm{~nm}$ & 24.9 & 73 & - & 2957 & {$[177]$} \\
\hline PLZST 2/58/35/7 & Bulk & $0.5 \mathrm{~mm}$ & 2.35 & 86.1 & $\sim 450$ & 120 & {$[186]$} \\
\hline PBLZST & Bulk & $0.6 \mathrm{~mm}$ & 3.2 & - & - & 180 & {$[188]$} \\
\hline PLZST 2/33/55/12@5 mol\% $\mathrm{SiO}_{2}$ & Bulk & $0.2 \mathrm{~mm}$ & 2.68 & - & $\sim 800$ & 238 & {$[190]$} \\
\hline PLZS & Bulk & $0.11 \mathrm{~mm}$ & 10.4 & 87 & $\sim 180$ & 400 & {$[191]$} \\
\hline PLSZS & Thick film & $0.1 \mathrm{~mm}$ & 11.18 & 82.2 & $\sim 200$ & $\sim 400$ & {$[193]$} \\
\hline PLZT 2/95/5 & Thin film & $300 \mathrm{~nm}$ & 40 & 53 & - & 1000 & [194] \\
\hline PLZT 8/95/5 & Thick film & $1 \mu \mathrm{m}$ & 53 & - & $\sim 560$ & 3500 & [195] \\
\hline
\end{tabular}

PZ: PbZrO $;$ PSZ5: $\left(\mathrm{Pb}_{0.95} \mathrm{Sr}_{0.05}\right) \mathrm{ZrO}_{3}$; PLHS: Pb ${ }_{0.98} \mathrm{La}_{0.02}\left(\mathrm{Hf}_{0.45} \mathrm{Sn}_{55}\right)_{0.995} \mathrm{O}_{3} ;$ PHO: PbHfO $;$ PLZST 2/58/35/7: Pb ${ }_{0.97} \mathrm{La}_{0.02}\left(\mathrm{Zr}_{0.58} \mathrm{Sn}_{0.42-\gamma} \mathrm{Ti}_{y}\right) \mathrm{O}_{3} ; \mathrm{PBLZST}$ $\left(\mathrm{Pb}_{0.87} \mathrm{Ba}_{0.1} \mathrm{La}_{0.02}\right)\left(\mathrm{Zr}_{0.68} \mathrm{Sn}_{0.24} \mathrm{Ti}_{0.08}\right) \mathrm{O}_{3} ; \quad$ PLZST 2/33/55/12: $\quad \mathrm{Pb}_{0.97} \mathrm{La}_{0.02}\left(\mathrm{Zr}_{0.33} \mathrm{Sn}_{0.55} \mathrm{Ti}_{0.12}\right) \mathrm{O}_{3} ; \quad$ PLZS: $\quad\left(\mathrm{Pb}_{0.98} \mathrm{La}_{0.02}\right)\left(\mathrm{Zr}_{0.55} \mathrm{Sn}_{0.45}\right){ }_{0.995} \mathrm{O}_{3} ; \quad \mathrm{PLSZS}$ $\left(\mathrm{Pb}_{0.94} \mathrm{La}_{0.02} \mathrm{Sr}_{0.04}\right)\left(\mathrm{Zr}_{0.9} \mathrm{Sn}_{0.1}\right)_{0.995} \mathrm{O}_{3}$; PLZT 2/95/5: $\mathrm{Pb}_{0.98} \mathrm{La}_{0.02} \mathrm{Zr}_{0.95} \mathrm{Ti}_{0.05} \mathrm{O}_{3} ;$ PLZT 8/95/5: $\left(\mathrm{Pb}_{0.92} \mathrm{La}_{0.08}\right)\left(\mathrm{Zr}_{0.95} \mathrm{Ti}_{0.05}\right) \mathrm{O}_{3}$. 
and off-centered displacement of $\mathrm{Nb}^{5+}[199,200]$. In addition to temperature-induced transition, antiferroelectricferroelectric phase transition can also be induced by mechanical stress [201], grain size [202], and electric field [203]. Note that an electric field-induced antiferroelectric-ferroelectric phase transition is usually irreversible at room temperature because of the small free energy difference between antiferroelectric and ferroelectric.

Generally, reducing tolerance factor $t$ is still a widely accepted method to stabilize antiferroelectric phase of NN ceramics. For instance, Shimizu et al. [204] used $\mathrm{CaZrO}_{3}(\mathrm{CZ})$, with similar electronegativity but smaller tolerance factor $t$, to modify $\mathrm{NN}$ ceramics. As the content of $\mathrm{CZ}$ increases, an obvious double $P-E$ loop accompanying to $E_{\mathrm{A}-\mathrm{F}}$ gradually increases while $P_{\max }$ decreases, as shown in Fig. 13. Since then, other compounds such as $\mathrm{SrZrO}_{3}$ (SZ) [205], $\mathrm{CaHfO}_{3}(\mathrm{CH})$ [206], $\mathrm{BiScO}_{3}$ (BS) [207], are both utilized to stabilize antiferroelectric phase, but few reports their energy storage performances. It should be pointed that double $P-E$ loop of NN-based ceramics still has more hysteresis loop at room temperature resulting in low $W_{\text {rec. }}$. Moreover, Zhou et al. [208] firstly reported $\mathrm{Bi}_{2} \mathrm{O}_{3}$ modified $\mathrm{NN}$ energy storage ceramic bulks, obtained a high $W_{\text {rec }}$ of $4.03 \mathrm{~J} / \mathrm{cm}^{3}$ for $\mathrm{Na}_{0.7} \mathrm{Bi}_{0.1} \mathrm{NbO}_{3}$ ceramics at $E_{\mathrm{b}}=250 \mathrm{kV} / \mathrm{cm}$ attributed to the disrupted random electric field and reduced domain size. Energy storage properties of $\mathrm{Na}_{0.7} \mathrm{Bi}_{0.1} \mathrm{NbO}_{3}$ system show good temperature stability $\left(20-100{ }^{\circ} \mathrm{C}\right)$, fatigue endurance ( $10^{5}$ cycles), and charge-discharge properties. After that, more Bi-based compounds including $\mathrm{Bi}\left(\mathrm{Mg}_{1 / 3} \mathrm{Nb}_{2 / 3}\right) \mathrm{O}_{3}$ (BMN) [209], $\mathrm{Bi}\left(\mathrm{Ni}_{1 / 2} \mathrm{Sn}_{1 / 2}\right) \mathrm{O}_{3}$ (BNS) [210], and so on, are used to improve the relaxor characteristics and acquire high $W_{\text {rec. }}$ It is particularly important that $P-E$ loop of $\mathrm{BiMeO}_{3}$ modified system becomes slimmer than pure NN ceramic, but characteristic double hysteresis loop fails to be observed.

A double $P-E$ hysteresis loop can be observed in high quality $\mathrm{NN}$ single crystal and ceramic film compared with ceramic bulk. However, a few studies reported energy storage properties of NN-based ceramic films, and concentrated on piezoelectric, dielectric tunability. In 2018, Fujii et al. [211] deposited $0.92 \mathrm{NaNbO}_{3}-0.08 \mathrm{SrZrO}_{3}(0.92 \mathrm{NN}-0.08 \mathrm{SZ})$ antiferroelectric thin films on $\mathrm{SrRuO}_{3}$ buffered ST substrates with different orientations by using PLD. $0.92 \mathrm{NN}-0.08 \mathrm{SZ}$ thin films with (110) oriented ST substrate exhibit antiferroelectric behavior, while that with (001) oriented substrate is still ferroelectric. Recently, Beppu et al. [212] obtained $W_{\text {rec }}$ only of $2.9 \mathrm{~J} / \mathrm{cm}^{3}$ for $0.92 \mathrm{NN}-0.08 \mathrm{SZ}$ thin films at $E_{\mathrm{b}} \approx$ $400 \mathrm{kV} / \mathrm{cm}$. In addition, Luo et al. [213] fabricated Mn-doped $0.96 \mathrm{NaNbO}_{3}-0.04 \mathrm{CaZrO}_{3}(0.96 \mathrm{NN}-0.04 \mathrm{CZ})$ thin films using sol-gel method, and leakage current of $1 \mathrm{~mol} \% \mathrm{Mn}$ reduces the magnitude of $10^{3}-10^{4}$ compared to pure compositions. $W_{\text {rec }}$ and $\eta$ of $1 \mathrm{~mol} \%$ Mn thin films are $19.64 \mathrm{~J} / \mathrm{cm}^{3}$ and $64.5 \%$, respectively. Nevertheless, simple composition and no toxic metal elements make it have broad prospects for energy storage research in the future.

(2) $\mathrm{AgNbO}_{3}$

$\mathrm{AgNbO}_{3}$ (AN) has a complicated phase structure and relatively low bandgap $(\sim 2.8 \mathrm{eV})$, and still has difficulty in observing double hysteresis loop at room temperature. Early studies of AN ceramics therefore concentrated on microwave communication and photocatalysis [214,215]. In addition, $\mathrm{Ag}_{2} \mathrm{O}$ decomposition
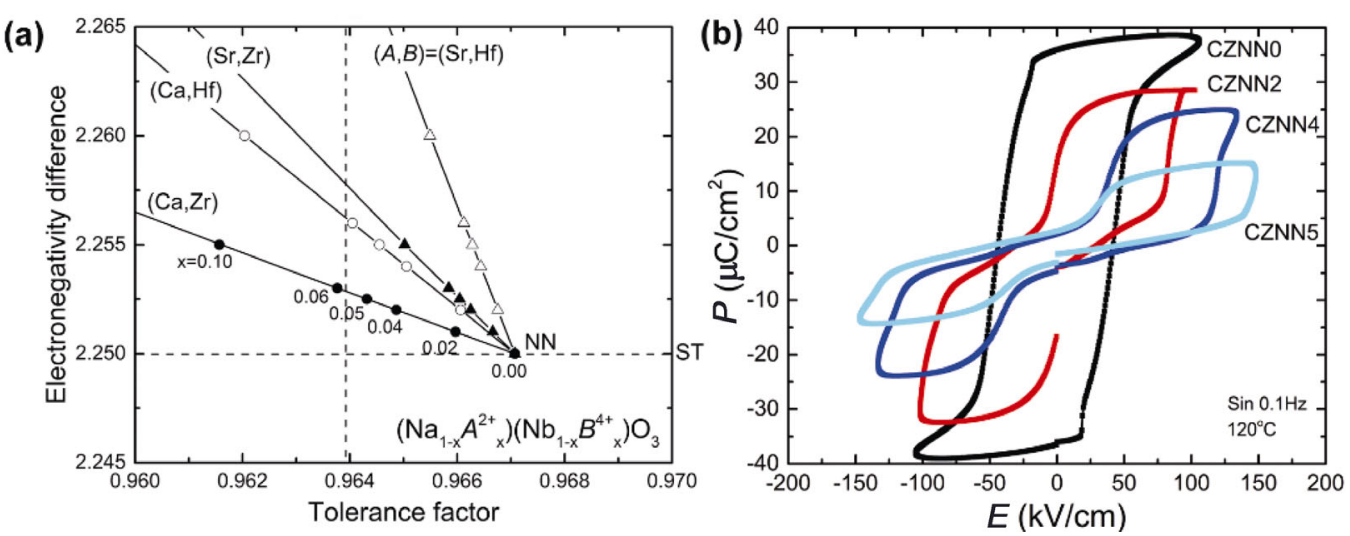

Fig. 13 (a) Tolerance factor versus averaged electronegativity difference for $\left(\mathrm{Na}_{1-x} \mathrm{~A}_{2+x}\right)\left(\mathrm{Nb}_{1-x} \mathrm{~B}_{4+x}\right) \mathrm{O}_{3}$ composition, where $(\mathrm{A}, \mathrm{B})=(\mathrm{Ca}, \mathrm{Zr}),(\mathrm{Ca}, \mathrm{Hf}),(\mathrm{Sr}, \mathrm{Zr})$, and $(\mathrm{Sr}, \mathrm{Hf}) ;(\mathrm{b}) P-E$ loops in the $\mathrm{CZNN}$ ceramics at $120{ }^{\circ} \mathrm{C}$. Reproduced with permission from Ref. [204], (C) Royal Society of Chemistry 2015. 
at a high temperature requires the fabrication of AN-based ceramics at the oxygen-rich environment. Similar to NN, AN-based ceramic bulk is a main research direction for energy storage capacitors.

In 2007, Fu et al. [216] successfully fabricated AN ceramics with a double hysteresis loop, and $P_{\max }$ can up to $52 \mu \mathrm{C} / \mathrm{cm}^{2}$ at $220 \mathrm{kV} / \mathrm{cm}$ exceeding other dielectric materials at the same electric field. The phenomenon strongly stimulates the studies of AN ceramics on energy storage applications. Tian et al. [217] synthesized pure AN antiferroelectric ceramic bulks, found two polarization structures by TEM and variable temperature $P-I-E$ loops, and attained a high $W_{\text {rec }}$ of $2.1 \mathrm{~J} / \mathrm{cm}^{3}$. In general, AN ceramics experience a series phase transition [218]:

$$
\begin{aligned}
\mathrm{M} 1 \stackrel{67{ }^{\circ} \mathrm{C}}{\longrightarrow} \mathrm{M} 2 \stackrel{267^{\circ} \mathrm{C}}{\longrightarrow} \mathrm{M} 3 \stackrel{353^{\circ} \mathrm{C}}{\longrightarrow} \\
\mathrm{O} 1 \stackrel{361^{\circ} \mathrm{C}}{\longrightarrow} \mathrm{O} 2 \stackrel{387^{\circ} \mathrm{C}}{\longrightarrow} \mathrm{T} \stackrel{579^{\circ} \mathrm{C}}{\longrightarrow} \mathrm{C}
\end{aligned}
$$

where M1, M2, and M3 denote orthorhombic phases in rhombic orientation, $\mathrm{O} 1$ and $\mathrm{O} 2$ are the orthorhombic phases in a parallel orientation, while $\mathrm{T}$ and $\mathrm{C}$ denote the tetragonal and cubic phases, respectively. It is known that the stability of antiferroelectric phase of AN ceramic is closely related to phase transition among M1, M2, and M3. Therefore, reducing phase transition temperature among M1, M2, and M3 to low temperature would enhance $W_{\text {rec }}$ of AN-based ceramics [218-221].

Chemical doping is a simple and effective method to enhance $W_{\text {rec }}$ of AN-based ceramic bulks. For example, $\mathrm{Ta}^{5+}[218,222]$ and $\mathrm{W}^{3+}[223]$ substitute $\mathrm{Nb}^{5+}$ of B site, and $\mathrm{Bi}^{3+}$ [224], $\mathrm{Ca}^{2+}$ [225], and $\mathrm{La}^{3+}$ [226] replace $\mathrm{Ag}^{+}$ of A site. In 2017, Zhao et al. [218] fabricated $\operatorname{Ag}\left(\mathrm{Nb}_{1-x} \mathrm{Ta}_{x}\right) \mathrm{O}_{3}$ antiferroelectric ceramics, and $P_{\mathrm{r}}$ decreases from 3.6 to $1.2 \mu \mathrm{C} / \mathrm{cm}^{2}$ whereas $E_{\mathrm{b}}$ enhances from 175 to $242 \mathrm{kV} / \mathrm{cm}$ with increasing Ta content. $\mathrm{Ag}\left(\mathrm{Nb}_{0.85} \mathrm{Ta}_{0.15}\right) \mathrm{O}_{3}$ exhibits a high $W_{\text {rec }}$ of $4.2 \mathrm{~J} / \mathrm{cm}^{3}$, together with $\eta$ of $69 \%$, as shown in Figs. 14(a) and 14(b). The authors attribute the enhancement of $W_{\text {rec }}$ to the low polarizability of $\mathrm{Ta}^{5+}$ because of a closed $t$ value. Since then, Zhao et al. [223] have done some works to verify the possibility. Besides, electronegativity difference is also playing a crucial role in influencing the function behavior of antiferroelectric materials [227].

Note that fine-grain ceramics is a good choice to enhance $E_{\mathrm{b}}$ due to an inverse relationship between $E_{\mathrm{b}}$ and grain size. Recently, Wang et al. [228] synthesized AN ceramics using hydrothermal process, and obtained a maximum $E_{\mathrm{b}}=250 \mathrm{kV} / \mathrm{cm}$ among pure AN ceramics so far. However, $P_{\max }$ has an obvious decrease compared with other AN ceramics using solid-state method, and thus $W_{\text {rec }}$ and $\eta$ are only of $1.8 \mathrm{~J} / \mathrm{cm}^{3}$ and $40 \%$, respectively. It is noteworthy that little attention has been shared on enhancing $E_{\mathrm{b}}$ of AN ceramics by other different methods apart from ion-doping. Energy storage behaviors of $\mathrm{NN}$ and $\mathrm{AN}$ antiferroelectric ceramic bulks and films are summarized and listed in Table 8 .

In summary, for antiferroelectric ceramics, tolerance factor $t$, electronegative difference, and polarizability are all influencing the stability of antiferroelectric phase. Note that the characteristic double $P-E$ loop of pure antiferroelectric phase is difficult to be observed, which needs to further explore the related reasons. Physical (special sintering technology, rolling process, etc.) and chemical (coating, hydrothermal process, etc.) methods can enhance $E_{\mathrm{b}}$ by improving sintering behavior or mechanical strength.
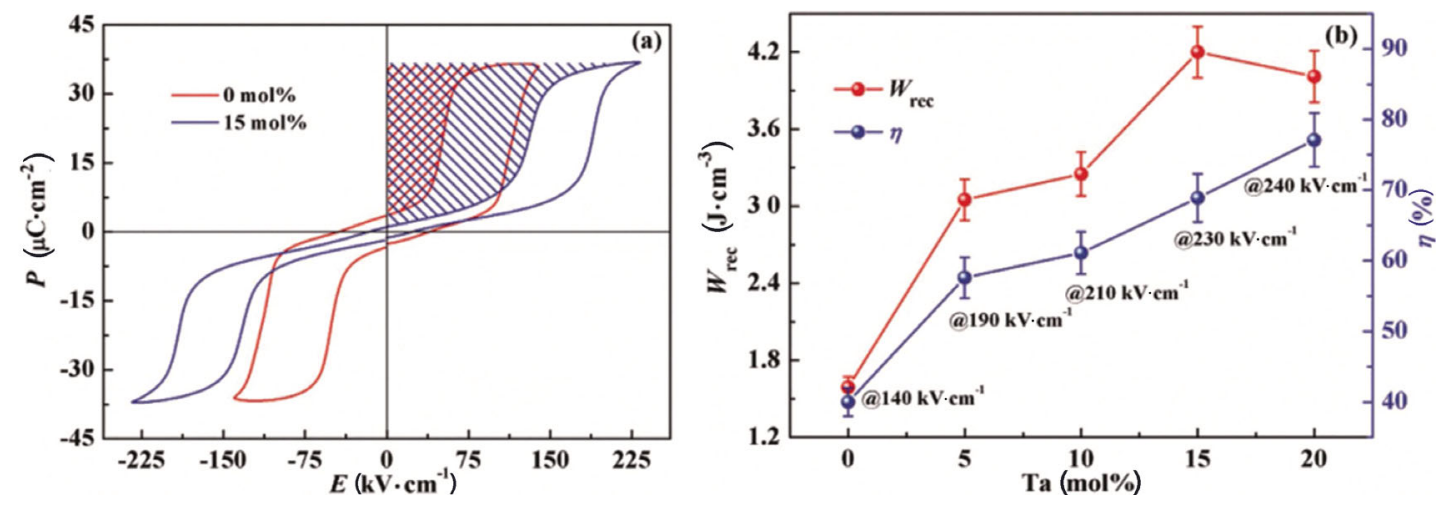

Fig. 14 (a) $P-E$ loops of $\mathrm{AgNbO}_{3}$ and $\mathrm{Ag}\left(\mathrm{Nb}_{0.85} \mathrm{Ta}_{0.15}\right) \mathrm{O}_{3}$ ceramic; (b) energy storage performances of $\mathrm{Ag}\left(\mathrm{Nb}_{1-x} \mathrm{Ta}_{x}\right) \mathrm{O}_{3}$ ceramics prior to their breakdown. Reproduced with permission from Ref. [218], (C) WILEY-VCH Verlag GmbH \& Co. KGaA, Weinheim 2017. 
Table 8 Energy storage properties of $\mathrm{NN}$ and AN-based antiferroelectric ceramic bulks and films

\begin{tabular}{cccccccc}
\hline Composition & Category & $t$ & $W_{\text {rec }}\left(\mathrm{J} / \mathrm{cm}^{3}\right)$ & $\eta(\%)$ & $\varepsilon_{\mathrm{r}} @$ RT & $E_{\mathrm{b}}(\mathrm{kV} / \mathrm{cm})$ & Ref. \\
\hline $\mathrm{Na}_{0.7} \mathrm{Bi}_{0.1} \mathrm{NbO}_{3}$ & Bulk & $0.2 \mathrm{~mm}$ & 3.44 & 85.4 & $\sim 1700$ & 351 & {$[208]$} \\
$0.92 \mathrm{NN}-0.08 \mathrm{SZ}$ & Thick film & $1 \mu \mathrm{m}$ & 2.9 & 67 & 211 & 400 & {$[212]$} \\
$1 \mathrm{~mol} \%$ Mn-doped 0.96NN-0.04CZ & Thin film & $300 \mathrm{~nm}$ & 19.64 & 64.5 & $\sim 2200$ & 833.3 & {$[213]$} \\
AN & Bulk & $0.5 \mathrm{~mm}$ & 2.1 & - & $\sim 300$ & 175 & {$[217]$} \\
ANT15 & Bulk & $200 \mu \mathrm{m}$ & 4.2 & 69 & $\sim 200$ & 233 & {$[218]$} \\
AN & Bulk & $150 \mu \mathrm{m}$ & $\sim 1.8$ & $\sim 40$ & $\sim 80$ & 250 & {$[228]$} \\
\hline
\end{tabular}

$\mathrm{NN}: \mathrm{NaNbO}_{3} ; \mathrm{SZ}: \mathrm{SrZrO}_{3} ; \mathrm{CZ}: \mathrm{CaZrO}_{3} ; \mathrm{AN}: \mathrm{AgNbO}_{3} ; \mathrm{ANT} 15: \mathrm{Ag}\left(\mathrm{Nb}_{0.85} \mathrm{Ta}_{0.15}\right) \mathrm{O}_{3}$.

\section{Conclusions and perspectives}

From the perspectives of composition modification, structural design, and electrical performance optimization, this paper briefly compares the research progress of energy storage ceramic bulks and films. Currently, $W_{\text {rec }}$ of ceramic bulks is generally less than $10 \mathrm{~J} / \mathrm{cm}^{3}$, while that of films can reach $10^{2} \mathrm{~J} / \mathrm{cm}^{3}$. Except for ceramic composition, $W_{\text {rec }}$ is also closely related to other factors such as sample thickness, preparation, and testing methods. Although giant $\varepsilon_{\mathrm{r}}$ linear dielectric attracts more attention, it may be not suitable for energy storage capacitors. In contrast, relaxor ferroelectric and antiferroelectric with high $P_{\max }$ and low $P_{\mathrm{r}}$ are easier to obtain high $W_{\text {rec }}$ than linear dielectric, so they are relatively ideal energy storage dielectric materials. Whether for bulks or films, $E_{\mathrm{b}}$ is a decisive factor for affecting the upper limit of $W_{\text {rec. }}$. In addition, the development from material to device still has a large gap, and thus needs to make more efforts to solve this problem. Judging from the existing researches, the authors believe that the following aspects need further exploration and improvement:

1) It is still a long process to select the ideal energy storage ceramics through a single experiment. If relevant predictions and screenings can be combined with theoretical calculations or machine learning methods, work efficiency will be greatly improved.

2) In order to better understand the variation in domain and phase structures as functions of the electric field, thermal, force, magnetic, etc., external fields, in-situ observation technique would be an important direction, which would help us to comprehensively understand the microscopic evolution mechanism of polarization.

3) For materials with crystalline/amorphous phase and multilayer structure, the issues of generation reason and corresponding mechanisms of interface behaviors (such as interface polarization, fatigue, etc.) and stress still need to be deeply investigated.

4) Considering many factors to influence $W_{\text {rec }}$ and $\eta$, it is important to standardize the test parameters such as sample thickness, area of electrode, testing frequency, and $\mathrm{AC} / \mathrm{DC}$ conditions, and establish the relevant test standard for performance evaluation of energy storage materials.

\section{Acknowledgements}

This work was financially supported by the National Natural Science Foundation of China (51767010).

\section{References}

[1] Yang LT, Kong X, Li F, et al. Perovskite lead-free dielectrics for energy storage applications. Prog Mater Sci 2019, 102: 72-108.

[2] Yao ZH, Song Z, Hao $\mathrm{H}$, et al. Homogeneous/ inhomogeneous-structured dielectrics and their energystorage performances. Adv Mater 2017, 29: 1601727.

[3] Li Q, Han K, Gadinski MR, et al. High energy and power density capacitors from solution-processed ternary ferroelectric polymer nanocomposites. Adv Mater 2014, 26 : 6244-6249.

[4] Wang Y, Song Y, Xia Y. Electrochemical capacitors: Mechanism, materials, systems, characterization and applications. Chem Soc Rev 2016, 45: 5925-5950.

[5] Bruce PG, Freunberger SA, Hardwick LJ, et al. $\mathrm{Li}-\mathrm{O}_{2}$ and Li-S batteries with high energy storage. Nat Mater 2012, 11: 19-29.

[6] Shao Z, Haile SM. A high-performance cathode for the next generation of solid-oxide fuel cells. Nature 2004, 431 : 170-173.

[7] Palneedi H, Peddigari M, Hwang GT, et al. Highperformance dielectric ceramic films for energy storage capacitors: progress and outlook. Adv Funct Mater 2018, 28: 1803665 .

[8] Hao X. A review on the dielectric materials for high energy-storage application. $J$ Adv Dielect 2013, 3: 1330001. 
[9] Yao FZ, Yuan Q, Wang Q, et al. Multiscale structural engineering of dielectric ceramics for energy storage applications: From bulk to thin films. Nanoscale 2020, 12: 17165-17184.

[10] Tong S. Size and temperature effects on dielectric breakdown of ferroelectric films. $J$ Adv Ceram 2021, 10: 181-186.

[11] Zhao P, Wang $\mathrm{H}, \mathrm{Wu} \mathrm{L}$, et al. High-performance relaxor ferroelectric materials for energy storage applications. $A d v$ Energy Mater 2019, 9: 1803048.

[12] Chen X, Zhang H, Cao F, et al. Charge-discharge properties of lead zirconate stannate titanate ceramics. $J$ Appl Phys 2009, 106: 034105.

[13] Yang SM, Jo JY, Kim TH, et al. AC dynamics of ferroelectric domains from an investigation of the frequency dependence of hysteresis loops. Phys Rev B 2010, 82: 174125.

[14] Huang Y, Li F, Hao H, et al. $\left(\mathrm{Bi}_{0.51} \mathrm{Na}_{0.47}\right) \mathrm{TiO}_{3}$ based lead free ceramics with high energy density and efficiency. $J$ Materiomics 2019, 5: 385-393.

[15] Li J, Li F, Xu Z, et al. Multilayer lead-free ceramic capacitors with ultrahigh energy density and efficiency. Adv Mater 2018, 30: 1802155.

[16] Lou XJ. Polarization fatigue in ferroelectric thin films and related materials. J Appl Phys 2009, 105: 024101.

[17] Ye Y, Zhang SC, Dogan F, et al. Influence of nanocrystalline grain size on the breakdown strength of ceramic dielectrics. In: Proceedings of the 14th IEEE International Pulsed Power Conference, 2003: 719-722.

[18] Dervos CT, Thirios, Novacovich J, et al. Permittivity properties of thermally treated $\mathrm{TiO}_{2}$. Mater Lett 2004, 58: 1502-1507.

[19] Reddy CV, Reddy KR, Shetti NP, et al. Heteronanostructured metal oxide-based hybrid photocatalysts for enhanced photoelectrochemical water splitting-A review. Int J Hydrog Energy 2020, 45: 18331-18347.

[20] Mehta A, Mishra A, Basu S, et al. Band gap tuning and surface modification of carbon dots for sustainable environmental remediation and photocatalytic hydrogen production-A review. J Environ Manag 2019, 250: 109486.

[21] Parker R, Wasilik J. Dielectric constant and dielectric loss of $\mathrm{TiO}_{2}$ (rutile) at low frequencies. Phys Rev 1960, 120: 1631-1637.

[22] Guo D, Ito A, Goto T, et al. Preparation of rutile $\mathrm{TiO}_{2}$ thin films by laser chemical vapor deposition method. $J A d v$ Ceram 2013, 2: 162-166.

[23] $\mathrm{Hu} \mathrm{W}$, Liu Y, Withers RL, et al. Electron-pinned defect-dipoles for high-performance colossal permittivity materials. Nat Mater 2013, 12: 821-826.

[24] Li J, Li F, Li C, et al. Evidences of grain boundary capacitance effect on the colossal dielectric permittivity in $(\mathrm{Nb}+\mathrm{In})$ co-doped $\mathrm{TiO}_{2}$ ceramics. Sci Rep 2015, 5: 8295.

[25] Li J, Li F, Zhuang Y, et al. Microstructure and dielectric properties of $(\mathrm{Nb}+\mathrm{In})$ co-doped rutile $\mathrm{TiO}_{2}$ ceramics. $J$
Appl Phys 2014, 116: 074105.

[26] Dong $\mathrm{W}, \mathrm{Hu} \mathrm{W}$, Berlie A, et al. Colossal dielectric behavior of $\mathrm{Ga}+\mathrm{Nb}$ co-doped rutile $\mathrm{TiO}_{2}$. ACS Appl Mater Interfaces 2015, 7: 25321-25325.

[27] Nachaithong T, Kidkhunthod P, Thongbai P, et al. Surface barrier layer effect in $(\mathrm{In}+\mathrm{Nb})$ co-doped $\mathrm{TiO}_{2}$ ceramics: An alternative route to design low dielectric loss. $\mathrm{J} \mathrm{Am}$ Ceram Soc 2017, 100: 1452-1459.

[28] Petzelt J, Nuzhnyy D, Bovtun V, et al. Origin of the colossal permittivity of $(\mathrm{Nb}+\mathrm{In})$ co-doped rutile ceramics by wide-range dielectric spectroscopy. Phase Transitions 2018, 91: 932-941.

[29] Chao S, Petrovsky V, Dogan F. Effects of sintering temperature on the microstructure and dielectric properties of titanium dioxide ceramics. J Mater Sci 2010, 45: 6685-6693.

[30] Liu J, Zhang J, Wei M, et al. Dielectric properties of manganese-doped $\mathrm{TiO}_{2}$ with different alkali-free glass contents for energy storage application. J Mater Sci: Mater Electron 2016, 27: 7680-7684.

[31] Chao S, Dogan F. Processing and dielectric properties of $\mathrm{TiO}_{2}$ thick films for high-energy density capacitor applications. Int J Appl Ceram Technol 2011, 8: 13631373.

[32] Pai YY, Tylan-Tyler A, Irvin P, et al. Physics of $\mathrm{SrTiO}_{3}$-based heterostructures and nanostructures: A review. Rep Prog Phys 2018, 81: 036503.

[33] Kumar Yadav A, Gautam CR. A review on crystallisation behaviour of perovskite glass ceramics. Adv Appl Ceram 2014, 113: 193-207.

[34] Hu QG, Shen ZY, Li YM, et al. Enhanced energy storage properties of dysprosium doped strontium titanate ceramics. Ceram Int 2014, 40: 2529-2534.

[35] Kong X, Yang L, Cheng Z, et al. Bi-modified $\mathrm{SrTiO}_{3}$ based ceramics for high-temperature energy storage applications. J Am Ceram Soc 2020, 103: 1722-1731.

[36] Fergus JW. Oxide materials for high temperature thermoelectric energy conversion. J Eur Ceram Soc 2012, 32: 525-540.

[37] Wang Y, Shen ZY, Li YM, et al. Optimization of energy storage density and efficiency in $\mathrm{Ba}_{x} \mathrm{Sr}_{1-x} \mathrm{TiO}_{3}(x \leq 0.4)$ paraelectric ceramics. Ceram Int 2015, 41: 8252-8256.

[38] Nishigaki S, Murano K, Ohkoshi A. Dielectric properties of ceramics in the system $\left(\mathrm{Sr}_{0.50} \mathrm{~Pb}_{0.25} \mathrm{Ca}_{0.25}\right) \mathrm{TiO}_{3}-$ $\mathrm{Bi}_{2} \mathrm{O}_{3} \cdot 3 \mathrm{TiO}_{2}$ and their applications in a high-voltage capacitor. J Am Ceram Soc 1982, 65: 554-560.

[39] Kong X, Yang L, Cheng Z, et al. $(\mathrm{Ba}, \mathrm{Sr}) \mathrm{TiO}_{3}-$ $\mathrm{Bi}(\mathrm{Mg}, \mathrm{Hf}) \mathrm{O}_{3}$ lead-free ceramic capacitors with high energy density and energy efficiency. ACS Appl Energy Mater 2020, 3: 12254-12262.

[40] Fletcher NH, Hilton AD, Ricketts BW. Optimization of energy storage density in ceramic capacitors. $J$ Phys $D$ : Appl Phys 1996, 29: 253-258.

[41] Ang C, Yu Z, Cross LE. Oxygen-vacancy-related low-frequency dielectric relaxation and electrical 
conduction in Bi: $\mathrm{SrTiO}_{3}$. Phys Rev B 2000, 62: 228-236.

[42] Yu Z, Ang C. Dielectric relaxor and ferroelectric relaxor: Bi-doped paraelectric $\mathrm{SrTiO}_{3}$. J Appl Phys 2002, 91: 1487-1494.

[43] Yu Z, Ang C. High capacitance-temperature sensitivity and "giant" dielectric constant in $\mathrm{SrTiO}_{3}$. Appl Phys Lett 2007, 90: 202903.

[44] Shen ZY, Hu QG, Li YM, et al. Structure and dielectric properties of $\mathrm{Re}_{0.02} \mathrm{Sr}_{0.97} \mathrm{TiO}_{3}(\mathrm{Re}=\mathrm{La}, \mathrm{Sm}, \mathrm{Gd}, \mathrm{Er})$ ceramics for high-voltage capacitor applications. $J \mathrm{Am}$ Ceram Soc 2013, 96: 2551-2555.

[45] Shen ZY, Li YM, Luo WQ, et al. Structure and dielectric properties of $\mathrm{Nd}_{x} \mathrm{Sr}_{1-x} \mathrm{TiO}_{3}$ ceramics for energy storage application. J Mater Sci: Mater Electron 2013, 24: 704-710.

[46] Shen ZY, Luo WQ, Li YM, et al. Electrical heterostructure of $\mathrm{Nd}_{0.1} \mathrm{Sr}_{0.9} \mathrm{TiO}_{3}$ ceramic for energy storage applications. J Mater Sci: Mater Electron 2013, 24: 607-612.

[47] Song Z, Liu H, Zhang S, et al. Effect of grain size on the energy storage properties of $\left(\mathrm{Ba}_{0.4} \mathrm{Sr}_{0.6}\right) \mathrm{TiO}_{3}$ paraelectric ceramics. J Eur Ceram Soc 2014, 34: 1209-1217.

[48] Wu YJ, Huang YH, Wang N, et al. Effects of phase constitution and microstructure on energy storage properties of barium strontium titanate ceramics. $J$ Eur Ceram Soc 2017, 37: 2099-2104.

[49] Zhang Q, Wang L, Luo J, et al. Improved energy storage density in barium strontium titanate by addition of $\mathrm{BaO}-\mathrm{SiO}_{2}-\mathrm{B}_{2} \mathrm{O}_{3}$ glass. $J$ Am Ceram Soc 2009, 92: 1871-1873.

[50] Kim SH, Koh JH. ZnBO-doped $(\mathrm{Ba}, \mathrm{Sr}) \mathrm{TiO}_{3}$ ceramics for the low-temperature sintering process. J Eur Ceram Soc 2008, 28: 2969-2973.

[51] Shen ZY, Wang Y, Tang YX, et al. Glass modified Barium strontium titanate ceramics for energy storage capacitor at elevated temperatures. J Materiomics 2019, 5: 641-648.

[52] Yang X, Li W, Qiao Y, et al. High energy-storage density of lead-free $\left(\mathrm{Sr}_{1-1.5 \mathrm{x}} \mathrm{Bi}_{\mathrm{x}}\right) \mathrm{Ti}_{0} \cdot 99 \mathrm{Mn}_{0.01} \mathrm{O}_{3}$ thin films induced by $\mathrm{Bi}^{3+}$-VSr dipolar defects. Phys Chem Chem Phys 2019, 21: 16359-16366.

[53] Zhang Y, Li W, Wang Z, et al. Ultrahigh energy storage and electrocaloric performance achieved in $\mathrm{SrTiO}_{3}$ amorphous thin films via polar cluster engineering. $J$ Mater Chem A 2019, 7: 17797-17805.

[54] Pan $\mathrm{H}$, Zeng $\mathrm{Y}$, Shen $\mathrm{Y}$, et al. $\mathrm{BiFeO}_{3}-\mathrm{SrTiO}_{3}$ thin film as a new lead-free relaxor-ferroelectric capacitor with ultrahigh energy storage performance. J Mater Chem A 2017, 5: 5920-5926.

[55] Hou C, Huang W, Zhao W, et al. Ultrahigh energy density in $\mathrm{SrTiO}_{3}$ film capacitors. ACS Appl Mater Interfaces 2017, 9: 20484-20490.

[56] Gao W, Yao M, Yao X. Improvement of energy density in $\mathrm{SrTiO}_{3}$ film capacitor via self-repairing behavior. Ceram Int 2017, 43: 13069-13074.

[57] Gao W, Yao M, Yao X. Achieving ultrahigh breakdown strength and energy storage performance through periodic interface modification in $\mathrm{SrTiO}_{3}$ thin film. ACS Appl Mater Interfaces 2018, 10: 28745-28753.

[58] Chen X, Peng B, Ding M, et al. Giant energy storage density in lead-free dielectric thin films deposited on $\mathrm{Si}$ wafers with an artificial dead-layer. Nano Energy 2020, 78: 105390.

[59] Cross LE. Relaxor ferroelectrics. Ferroelectrics 1987, 76: 241-267.

[60] Pan Z, Wang P, Hou X, et al. Fatigue-free aurivillius phase ferroelectric thin films with ultrahigh energy storage performance. Adv Energy Mater 2020, 10: 2001536.

[61] Shrout TR, Zhang SJ. Lead-free piezoelectric ceramics: Alternatives for PZT? J Electroceramics 2007, 19: 113-126.

[62] Jaffe B, Cook WR, Jaffe H. Piezoelectric Ceramics Academic. Amsterdam: Elsevier, 1971.

[63] Chen Y, Wang S, Zhou H, et al. A systematic analysis of the radial resonance frequency spectra of the PZT-based $(\mathrm{Zr} / \mathrm{Ti}=52 / 48)$ piezoceramic thin disks. J Adv Ceram 2020, 9: 380-392.

[64] Gao J, Liu Y, Wang Y, et al. High temperature-stability of $\left(\mathrm{Pb}_{0.9} \mathrm{La}_{0.1}\right)\left(\mathrm{Zr}_{0.65} \mathrm{Ti}_{0.35}\right) \mathrm{O}_{3}$ ceramic for energy-storage applications at finite electric field strength. Scripta Mater 2017, 137: 114-118.

[65] Zhang TF, Tang XG, Liu QX, et al. Energy-storage properties and high-temperature dielectric relaxation behaviors of relaxor ferroelectric $\mathrm{Pb}\left(\mathrm{Mg}_{1 / 3} \mathrm{Nb}_{2 / 3}\right) \mathrm{O}_{3}$ $\mathrm{PbTiO}_{3}$ ceramics. J Phys D: Appl Phys 2016, 49: 095302.

[66] Kumar A, Kim SH, Peddigari M, et al. High energy storage properties and electrical field stability of energy efficiency of $\left(\mathrm{Pb}_{0.89} \mathrm{La}_{0.11}\right)\left(\mathrm{Zr}_{0.70} \mathrm{Ti}_{0.30}\right)_{0.9725} \mathrm{O}_{3}$ relaxor ferroelectric ceramics. Electron Mater Lett 2019, 15: 323-330.

[67] Zhang T, Li W, Hou Y, et al. High-energy storage density and excellent temperature stability in antiferroelectric/ ferroelectric bilayer thin films. J Am Ceram Soc 2017, 100: 3080-3087.

[68] Zhang T, Li W, Zhao Y, et al. High energy storage performance of opposite double-heterojunction ferroelectricity-insulators. Adv Funct Mater 2018, 28: 1706211.

[69] Ma B, Hu Z, Koritala RE, et al. PLZT film capacitors for power electronics and energy storage applications. J Mater Sci: Mater Electron 2015, 26: 9279-9287.

[70] Peng B, Tang S, Lu L, et al. Low-temperature-poling awakened high dielectric breakdown strength and outstanding improvement of discharge energy density of $(\mathrm{Pb}, \mathrm{La})(\mathrm{Zr}, \mathrm{Sn}, \mathrm{Ti}) \mathrm{O}_{3}$ relaxor thin film. Nano Energy 2020, 77: 105132.

[71] Dai X, Viehland D. Effects of lanthanum modification on the antiferroelectric-ferroelectric stability of high zirconium-content lead zirconate titanate. J Appl Phys 1994, 76: 3701-3709.

[72] Gupta SM, Li JF, Viehland D. Coexistence of relaxor and normal ferroelectric phases in morphotropic phase 
boundary compositions of lanthanum-modified lead zirconate titanate. J Am Ceram Soc 1998, 81: 557-564.

[73] $\mathrm{Hu} \mathrm{Z,} \mathrm{Ma} \mathrm{B,} \mathrm{Liu} \mathrm{S,} \mathrm{et} \mathrm{al.} \mathrm{Relaxor} \mathrm{behavior} \mathrm{and} \mathrm{energy}$ storage performance of ferroelectric PLZT thin films with different $\mathrm{Zr} / \mathrm{Ti}$ ratios. Ceram Int 2014, 40: 557-562.

[74] Liu Y, Hao X, An S. Significant enhancement of energy-storage performance of $\left(\mathrm{Pb}_{0.91} \mathrm{La}_{0.09}\right)\left(\mathrm{Zr}_{0.65} \mathrm{Ti}_{0.35}\right) \mathrm{O}_{3}$ relaxor ferroelectric thin films by Mn doping. J Appl Phys 2013, 114: 174102.

[75] Peng B, Xie Z, Yue Z, et al. Improvement of the recoverable energy storage density and efficiency by utilizing the linear dielectric response in ferroelectric capacitors. Appl Phys Lett 2014, 105: 052904.

[76] Zhang L, Hao X, Yang J, et al. Large enhancement of energy-storage properties of compositional graded $\left(\mathrm{Pb}_{1-x} \mathrm{La}_{x}\right)\left(\mathrm{Zr}_{0.65} \mathrm{Ti}_{0.35}\right) \mathrm{O}_{3}$ relaxor ferroelectric thick films. Appl Phys Lett 2013, 103: 113902.

[77] Nguyen MD, Houwman EP, Rijnders G. Energy storage performance and electric breakdown field of thin relaxor ferroelectric PLZT films using microstructure and growth orientation control. J Phys Chem C 2018, 122: 15171-15179.

[78] Nguyen MD, Nguyen CTQ, Vu HN, et al. Controlling microstructure and film growth of relaxor-ferroelectric thin films for high break-down strength and energy-storage performance. J Eur Ceram Soc 2018, 38: 95-103.

[79] Smolenskii GA, Isupov VA, Agranovskaya AI, et al. New ferroelectrics of complex composition IV. J Sov Phy Solid State 1961, 2: 2651-2654.

[80] Rao BN, Datta R, Chandrashekaran SS, et al. Local structural disorder and its influence on the average global structure and polar properties in $\mathrm{Na}_{0.5} \mathrm{Bi}_{0.5} \mathrm{TiO}_{3}$. Phys Rev $B$ 2013, 88: 224103.

[81] Reichmann K, Feteira A, Li M. Bismuth sodium titanate based materials for piezoelectric actuators. Materials 2015, 8: 8467-8495.

[82] Suchanicz J, Kluczewska-Chmielarz K, Sitko D, et al. Electrical transport in lead-free $\mathrm{Na}_{0.5} \mathrm{Bi}_{0.5} \mathrm{TiO}_{3}$ ceramics. $J$ Adv Ceram 2021, 10: 152-165.

[83] Qiao X, Zhang F, Wu D, et al. Superior comprehensive energy storage properties in $\mathrm{Bi}_{0.5} \mathrm{Na}_{0.5} \mathrm{TiO}_{3}$-based relaxor ferroelectric ceramics. Chem Eng J 2020, 388: 124158.

[84] Yang F, Pan Z, Ling Z, et al. Realizing high comprehensive energy storage performances of BNT-based ceramics for application in pulse power capacitors. $J$ Eur Ceram Soc 2021, 41: 2548-2558.

[85] Zhang X, Hu D, Pan Z, et al. Enhancement of recoverable energy density and efficiency of lead-free relaxorferroelectric BNT-based ceramics. Chem Eng J 2021, 406: 126818

[86] Zhu C, Cai Z, Luo B, et al. High temperature lead-free BNT-based ceramics with stable energy storage and dielectric properties. J Mater Chem A 2020, 8: 683-692.

[87] Ma C, Tan X. In situ transmission electron microscopy study on the phase transitionsin lead-free
$(1-x)\left(\mathrm{Bi}_{1 / 2} \mathrm{Na}_{1 / 2}\right) \mathrm{TiO}_{3}-x \mathrm{BaTiO}_{3}$ ceramics. J Am Ceram Soc 2011, 94: 4040-4044.

[88] Jo W, Schaab S, Sapper E, et al. On the phase identity and its thermal evolution of lead free $\left(\mathrm{Bi}_{1 / 2} \mathrm{Na}_{1 / 2}\right) \mathrm{TiO}_{3}-6 \mathrm{~mol} \%$ $\mathrm{BaTiO}_{3}$. J Appl Phys 2011, 110: 074106.

[89] Ye H, Yang F, Pan Z, et al. Significantly improvement of comprehensive energy storage performances with leadfree relaxor ferroelectric ceramics for high-temperature capacitors applications. Acta Mater 2021, 203: 116484.

[90] Gao F, Dong X, Mao C, et al. Energy-storage properties of $0.89 \mathrm{Bi}_{0.5} \mathrm{Na}_{0.5} \mathrm{TiO}_{3}-0.06 \mathrm{BaTiO}_{3}-0.05 \mathrm{~K}_{0.5} \mathrm{Na}_{0.5} \mathrm{NbO}_{3}$

lead-free anti-ferroelectric ceramics. J Am Ceram Soc 2011, 94: 4382-4386.

[91] Cao W, Li W, Feng Y, et al. Defect dipole induced large recoverable strain and high energy-storage density in lead-free $\mathrm{Na}_{0.5} \mathrm{Bi}_{0.5} \mathrm{TiO}_{3}{ }^{-}$based systems. Appl Phys Lett 2016, 108: 202902.

[92] Ren X. Large electric-field-induced strain in ferroelectric crystals by point-defect-mediated reversible domain switching. Nat Mater 2004, 3: 91-94.

[93] Li F, Zhai J, Shen B, et al. Influence of structural evolution on energy storage properties in $\mathrm{Bi}_{0.5} \mathrm{Na}_{0.5} \mathrm{TiO}_{3}-\mathrm{SrTiO}_{3}-$ $\mathrm{NaNbO}_{3}$ lead-free ferroelectric ceramics. J Appl Phys 2017, 121: 054103.

[94] Yang L, Kong X, Cheng Z, et al. Ultra-high energy storage performance with mitigated polarization saturation in lead-free relaxors. J Mater Chem A 2019, 7: 8573-8580.

[95] Li D, Shen ZY, Li ZP, et al. $P-E$ hysteresis loop going slim in $\mathrm{Ba}_{0.3} \mathrm{Sr}_{0.7} \mathrm{TiO}_{3}$-modified $\mathrm{Bi}_{0.5} \mathrm{Na}_{0.5} \mathrm{TiO}_{3}$ ceramics for energy storage applications. $J$ Adv Ceram 2020, 9: 183-192.

[96] Li D, Shen Z-Y, Li Z, et al. Optimization of polarization behavior in $(1-x) \mathrm{BSBNT}-x \mathrm{NN}$ ceramics for pulsed power capacitors. J Mater Chem C 2020, 8: 7650-7657.

[97] Li J, Shen Z, Chen X, et al. Grain-orientation-engineered multilayer ceramic capacitors for energy storage applications. Nat Mater 2020, 19: 999-1005.

[98] Yang H, Liu P, Yan F, et al. A novel lead-free ceramic with layered structure for high energy storage applications. $J$ Alloys Compd 2019, 773: 244-249.

[99] Jia W, Hou Y, Zheng M, et al. Superior temperature-stable dielectrics for MLCCs based on $\mathrm{Bi}_{0.5} \mathrm{Na}_{0.5} \mathrm{TiO}_{3}-\mathrm{NaNbO}_{3}$ system modified by $\mathrm{CaZrO}_{3}$. J Am Ceram Soc 2018, 101: 3468-3479.

[100] Wang H, Zhao P, Chen L, et al. Energy storage properties of $0.87 \mathrm{BaTiO}_{3}-0.13 \mathrm{Bi}\left(\mathrm{Zn}_{2 / 3}\left(\mathrm{Nb}_{0.85} \mathrm{Ta}_{0.15}\right)_{1 / 3}\right) \mathrm{O}_{3}$ multilayer ceramic capacitors with thin dielectric layers. $J$ Adv Ceram 2020, 9: 292-302.

[101] Feng C, Yang CH, Li SX, et al. Reduced leakage current and large polarization of $\mathrm{Na}_{0.5} \mathrm{Bi}_{0.5} \mathrm{Ti}_{0.98} \mathrm{Mn}_{0.02} \mathrm{O}_{3}$ thin film annealed at low temperature. Ceram Int 2015, 41: 14179-14183.

[102] Wang J, Sun N, Li Y, et al. Effects of Mn doping on dielectric properties and energy-storage performance of $\mathrm{Na}_{0.5} \mathrm{Bi}_{0.5} \mathrm{TiO}_{3}$ thick films. Ceram Int 2017, 43: 
7804-7809.

[103] Feng C, Yang CH, Sui HT, et al. Effect of Fe doping on the crystallization and electrical properties of $\mathrm{Na}_{0.5} \mathrm{Bi}_{0.5} \mathrm{TiO}_{3}$ thin film. Ceram Int 2015, 41: 4214-4217.

[104] Zhang YL, Li WL, Cao WP, et al. Enhanced energy-storage performance of $0.94 \mathrm{NBT}-0.06 \mathrm{BT}$ thin films induced by a $\mathrm{Pb}_{0.8} \mathrm{La}_{0.1} \mathrm{Ca}_{0.1} \mathrm{Ti}_{0.975} \mathrm{O}_{3}$ seed layer. Ceram Int 2016, 42: 14788-14792.

[105] Peng B, Zhang Q, Li X, et al. Giant electric energy density in epitaxial lead-free thin films with coexistence of ferroelectrics and antiferroelectrics. Adv Electron Mater 2015, 1: 1500052.

[106] Chen P, Wu S, Li P, et al. Great enhancement of energy storage density and power density in $\mathrm{BNBT} / x \mathrm{BFO}$ multilayer thin film hetero-structures. Inorg Chem Front 2018, 5: 2300-2305.

[107] Qian J, Han Y, Yang C, et al. Energy storage performance of flexible NKBT/NKBT-ST multilayer film capacitor by interface engineering. Nano Energy 2020, 74: 104862.

[108] Guo Y, Li M, Zhao W, et al. Ferroelectric and pyroelectric properties of $\left(\mathrm{Na}_{0.5} \mathrm{Bi}_{0.5}\right) \mathrm{TiO}_{3}-\mathrm{BaTiO}_{3}$ based trilayered thin films. Thin Solid Films 2009, 517: 2974-2978.

[109] Pan MJ, Randall CA. A brief introduction to ceramic capacitors. IEEE Electr Insul Mag 2010, 26: 44-50.

[110] Zheng L, Yuan L, Liang G, et al. An in situ $\left(\mathrm{K}_{0.5} \mathrm{Na}_{0.5}\right) \mathrm{NbO}_{3}$-doped Barium titanate foam framework and its cyanate ester resin composites with temperature-stable dielectric properties and low dielectric loss. Mater Chem Front 2019, 3: 726-736.

[111] Acosta M, Novak N, Rojas V, et al. $\mathrm{BaTiO}_{3}$-based piezoelectrics: Fundamentals, current status, and perspectives. Appl Phys Rev 2017, 4: 041305.

[112] Gao WX, Zhu Y, Wang YJ, et al. A review of flexible perovskite oxide ferroelectric films and their application. $J$ Materiomics 2020, 6: 1-16.

[113] Zheng $\mathrm{H}$, Wang J, Lofland SE, et al. Multiferroic $\mathrm{BaTiO}_{3}-\mathrm{CoFe}_{2} \mathrm{O}_{4}$ nanostructures. Science 2004, 303: 661-663.

[114] Hu D, Pan Z, Tan X, et al. Optimization the energy density and efficiency of $\mathrm{BaTiO}_{3}$-based ceramics for capacitor applications. Chem Eng J 2021, 409: 127375.

[115] Ogihara H, Randall CA, Trolier-Mckinstry S. High-energy density capacitors utilizing $0.7 \mathrm{BaTiO}_{3}-0.3 \mathrm{BiScO}_{3}$ ceramics. J Am Ceram Soc 2009, 92: 1719-1724.

[116] Wu L, Wang X, Li L. Core-shell BaTiO $@ \mathrm{BiScO}_{3}$ particles for local graded dielectric ceramics with enhanced temperature stability and energy storage capability. J Alloys Compd 2016, 688: 113-121.

[117] Yuan Q, Li G, Yao F, et al. Simultaneously achieved temperature-insensitive high energy density and efficiency in domain engineered $\mathrm{BaTiO}_{3}-\mathrm{Bi}\left(\mathrm{Mg}_{0.5} \mathrm{Zr}_{0.5}\right) \mathrm{O}_{3}$ lead-free relaxor ferroelectrics. Nano Energy 2018, 52: 203-210.

[118] Choi DH, Baker A, Lanagan $\mathrm{M}$, et al. Structural and dielectric properties in $(1-x) \mathrm{BaTiO}_{3}-x \mathrm{Bi}\left(\mathrm{Mg}_{1 / 2} \mathrm{Ti}_{1 / 2}\right) \mathrm{O}_{3}$ ceramics $(0.1 \leqslant x \leqslant 0.5)$ and potential for high-voltage multilayer capacitors. J Am Ceram Soc 2013, 96 2197-2202.

[119] Li MD, Tang XG, Zeng SM, et al. Oxygen-vacancy-related dielectric relaxation behaviours and impedance spectroscopy of $\mathrm{Bi}\left(\mathrm{Mg}_{1 / 2} \mathrm{Ti}_{1 / 2}\right) \mathrm{O}_{3}$ modified $\mathrm{BaTiO}_{3}$ ferroelectric ceramics. J Materiomics 2018, 4: 194-201.

[120] Hanani Z, Mezzane D, Amjoud M, et al. Phase transitions, energy storage performances and electrocaloric effect of the lead-free $\mathrm{Ba}_{0.85} \mathrm{Ca}_{0.15} \mathrm{Zr}_{0.10} \mathrm{Ti}_{0.90} \mathrm{O}_{3}$ ceramic relaxor. $J$ Mater Sci: Mater Electron 2019, 30: 6430-6438.

[121] Wang XW, Zhang BH, Shi YC, et al. Enhanced energy storage properties in $\mathrm{Ba}_{0.85} \mathrm{Ca}_{0.15} \mathrm{Zr}_{0.1} \mathrm{Ti}_{0.9} \mathrm{O}_{3}$ ceramics with glass additives. $J$ Appl Phys 2020, 127: 074103.

[122] Hanani Z, Merselmiz S, Danine A, et al. Enhanced dielectric and electrocaloric properties in lead-free rod-like BCZT ceramics. J Adv Ceram 2020, 9: 210-219.

[123] Patel S, Sharma D, Singh A, et al. Enhanced thermal energy conversion and dynamic hysteresis behavior of Sr-added $\mathrm{Ba}_{0.85} \mathrm{Ca}_{0.15} \mathrm{Ti}_{0.9} \mathrm{Zr}_{0.1} \mathrm{O}_{3}$ ferroelectric ceramics. $J$ Materiomics 2016, 2: 75-86.

[124] Su X, Riggs BC, Tomozawa M, et al. Preparation of $\mathrm{BaTiO}_{3} /$ low melting glass core-shell nanoparticles for energy storage capacitor applications. $J$ Mater Chem A 2014, 2: 18087-18096.

[125] Zhang Y, Cao M, Yao Z, et al. Effects of silica coating on the microstructures and energy storage properties of $\mathrm{BaTiO}_{3}$ ceramics. Mater Res Bull 2015, 67: 70-76.

[126] Wu L, Wang $\mathrm{X}$, Gong $\mathrm{H}$, et al. Core-satellite $\mathrm{BaTiO}_{3} @ \mathrm{SrTiO}_{3}$ assemblies for a local compositionally graded relaxor ferroelectric capacitor with enhanced energy storage density and high energy efficiency. J Mater Chem C 2015, 3: 750-758.

[127] Cheng H, Ouyang J, Zhang YX, et al. Demonstration of ultra-high recyclable energy densities in domainengineered ferroelectric films. Nat Commun 2017, 8: 1999.

[128] Yu Z, Ang C, Guo RY, et al. Ferroelectric-relaxor behavior of $\mathrm{Ba}\left(\mathrm{Ti}_{0.7} \mathrm{Zr}_{0.3}\right) \mathrm{O}_{3}$ ceramics. J Appl Phys 2002, 92: 2655-2657.

[129] Hennings D, Schnell A, Simon G. Diffuse ferroelectric phase transitions in $\mathrm{Ba}\left(\mathrm{Ti}_{1-y} \mathrm{Zry}_{\mathrm{O}} \mathrm{O}_{3}\right.$ ceramics. $J$ Am Ceram Soc 1982, 65: 539-544.

[130] Instan AA, Pavunny SP, Bhattarai MK, et al. Ultrahigh capacitive energy storage in highly oriented $\mathrm{Ba}\left(\mathrm{Zr}_{x} \mathrm{Ti}_{1-x}\right) \mathrm{O}_{3}$ thin films prepared by pulsed laser deposition. Appl Phys Lett 2017, 111: 142903.

[131] Reddy SR, Prasad VVB, Bysakh S, et al. Superior energy storage performance and fatigue resistance in ferroelectric BCZT thin films grown in an oxygen-rich atmosphere. $J$ Mater Chem C 2019, 7: 7073-7082.

[132] Ortega N, Kumar A, Scott JF, et al. Relaxor-ferroelectric superlattices: High energy density capacitors. J Phys: Condens Matter 2012, 24: 445901.

[133] Sun Z, Ma C, Liu M, et al. Ultrahigh energy storage performance of lead-free oxide multilayer film capacitors via interface engineering. Adv Mater 2017, 29: 1604427. 
[134] Zhang W, Gao Y, Kang L, et al. Space-charge dominated epitaxial $\mathrm{BaTiO}_{3}$ heterostructures. Acta Mater 2015, 85: 207-215.

[135] Ru J, Min D, Lanagan M, et al. Enhanced energy storage properties of thermostable sandwich-structured $\mathrm{BaTiO}_{3} /$ polyimide nanocomposites with better controlled interfaces. Mater Des 2021, 197: 109270.

[136] Rojac T, Bencan A, Malic B, et al. $\mathrm{BiFeO}_{3}$ ceramics: Processing, electrical, and electromechanical properties. $J$ Am Ceram Soc 2014, 97: 1993-2011.

[137] Yang CH, Qian J, Lv P, et al. Flexible lead-free BFO-based dielectric capacitor with large energy density, superior thermal stability, and reliable bending endurance. $J$ Materiomics 2020, 6: 200-208.

[138] Gao X, Li Y, Chen J, et al. High energy storage performances of $\mathrm{Bi}_{1-x} \mathrm{Sm}_{x} \mathrm{Fe}_{0.95} \mathrm{Sc}_{0.05} \mathrm{O}_{3}$ lead-free ceramics synthesized by rapid hot press sintering. J Eur Ceram Soc 2019, 39: 2331-2338.

[139] Yin L, Mi W. Progress in $\mathrm{BiFeO}_{3}$-based heterostructures: Materials, properties and applications. Nanoscale 2020, 12: 477-523.

[140] Li Q, Ji S, Wang D, et al. Simultaneously enhanced energy storage density and efficiency in novel $\mathrm{BiFeO}_{3}$-based lead-free ceramic capacitors. J Eur Ceram Soc 2021, 41: 387-393.

[141] Lee MH, Kim DJ, Park JS, et al. High-performance lead-free piezoceramics with high curie temperatures. $A d v$ Mater 2015, 27: 6976-6982.

[142] Wu J, Fan Z, Xiao D, et al. Multiferroic bismuth ferrite-based materials for multifunctional applications: Ceramic bulks, thin films and nanostructures. Prog Mater Sci 2016, 84: 335-402.

[143] Hang Q, Zhou W, Zhu X, et al. Structural, spectroscopic, and dielectric characterizations of Mn-doped $0.67 \mathrm{BiFeO}_{3}-0.33 \mathrm{BaTiO}_{3}$ multiferroic ceramics. $J \mathrm{Adv}$ Ceram 2013, 2: 252-259.

[144] Liu N, Liang R, Zhou Z, et al. Designing lead-free bismuth ferrite-based ceramics learning from relaxor ferroelectric behavior for simultaneous high energy density and efficiency under low electric field. J Mater Chem C 2018, 6: 10211-10217.

[145] Qi H, Xie A, Tian A, et al. Superior energy-storage capacitors with simultaneously giant energy density and efficiency using nanodomain engineered $\mathrm{BiFeO}_{3}-\mathrm{BaTiO}_{3}-$ $\mathrm{NaNbO}_{3}$ lead-free bulk ferroelectrics. Adv Energy Mater 2020, 10: 1903338.

[146] Wang G, Li J, Zhang X, et al. Ultrahigh energy storage density lead-free multilayers by controlled electrical homogeneity. Energy Environ Sci 2019, 12: 582-588.

[147] Correia TM, McMillen M, Rokosz MK, et al. A lead-free and high-energy density ceramic for energy storage applications. J Am Ceram Soc 2013, 96: 2699-2702.

[148] Pan H, Li F, Liu Y, et al. Ultrahigh-energy density lead-free dielectric films via polymorphic nanodomain design. Science 2019, 365: 578-582.
[149] Kan D, Pálová L, Anbusathaiah V, et al. Universal behavior and electric-field-induced structural transition in rare-earth-substituted $\mathrm{BiFeO}_{3}$. Adv Funct Mater 2010, 20: $1108-1115$.

[150] McMillen M, Douglas AM, Correia TM, et al. Increasing recoverable energy storage in electroceramic capacitors using "dead-layer" engineering. Appl Phys Lett 2012, 101: 242909.

[151] Hou Y, Han R, Li W, et al. Significantly enhanced energy storage performance in $\mathrm{BiFeO}_{3} / \mathrm{BaTiO}_{3} / \mathrm{BiFeO}_{3}$ sandwichstructured films through crystallinity regulation. Phys Chem Chem Phys 2018, 20: 21917-21924.

[152] Zhu H, Liu M, Zhang Y, et al. Increasing energy storage capabilities of space-charge dominated ferroelectric thin films using interlayer coupling. Acta Mater 2017, 122: 252-258.

[153] Li JF, Wang K, Zhu FY, et al. (K,Na) $\mathrm{NbO}_{3}$-based lead-free piezoceramics: Fundamental aspects, processing technologies, and remaining challenges. J Am Ceram Soc 2013, 96: 3677-3696.

[154] Egerton L, Dillon DM. Piezoelectric and dielectric properties of ceramics in the system potassium-sodium niobate. J Am Ceram Soc 1959, 42: 438-442

[155] Yang Z, Du H, Qu S, et al. Significantly enhanced recoverable energy storage density in potassium-sodium niobate-based lead free ceramics. J Mater Chem A 2016, 4: 13778-13785.

[156] Shao T, Du H, Ma H, et al. Potassium-sodium niobate based lead-free ceramics: novel electrical energy storage materials. J Mater Chem A 2017, 5: 554-563.

[157] Qu B, Du H, Yang Z, et al. Large recoverable energy storage density and low sintering temperature in potassium-sodium niobate-based ceramics for multilayer pulsed power capacitors. J Am Ceram Soc 2017, 100: $1517-1526$.

[158] Qu B, Du H, Yang Z, et al. Enhanced dielectric breakdown strength and energy storage density in lead-free relaxor ferroelectric ceramics prepared using transition liquid phase sintering. RSC Adv 2016, 6: 34381-34389.

[159] Yang Y, Ji Y, Fang M, et al. Morphotropic relaxor boundary in a relaxor system showing enhancement of electrostrain and dielectric permittivity. Phys Rev Lett 2019, 123: 137601.

[160] Won SS, Kawahara M, Kuhn L, et al. $\mathrm{BiFeO}_{3}$-doped $\left(\mathrm{K}_{0.5}, \mathrm{Na}_{0.5}\right)\left(\mathrm{Mn}_{0.005}, \mathrm{Nb}_{0.995}\right) \mathrm{O}_{3}$ ferroelectric thin film capacitors for high energy density storage applications. Appl Phys Lett 2017, 110: 152901.

[161] Huang Y, Shu L, Zhang SW, et al. Simultaneously achieved high-energy storage density and efficiency in $(\mathrm{K}, \mathrm{Na}) \mathrm{NbO}_{3}$-based lead-free ferroelectric films. $J \mathrm{Am}$ Ceram Soc 2021, 104: 4119-4130.

[162] Kittel C. Theory of antiferroelectric crystals. Phys Rev 1951, 82: 729-732.

[163] Tagantsev A, Vaideeswaran K, Vakhrushev S, et al. The origin of antiferroelectricity in $\mathrm{PbZrO}_{3}$. Nat Commun 2013, 


\section{4: 2229}

[164] Chen N, Bai G, Auciello O, et al. Properties and orientation of antiferroelectric lead zirconate thin films grown by MOCVD. MRS Online Proc Libr 1998, 541: 345-350.

[165] Hao X, Zhai J, Yao X. Improved energy storage performance and fatigue endurance of Sr-doped $\mathrm{PbZrO}_{3}$ antiferroelectric thin films. J Am Ceram Soc 2009, 92: 1133-1135.

[166] Parui J, Krupanidhi SB. Enhancement of charge and energy storage in sol-gel derived pure and La-modified $\mathrm{PbZrO}_{3}$ thin films. Appl Phys Lett 2008, 92: 192901.

[167] Tani T, Li JF, Viehland D, et al. Antiferroelectricferroelectric switching and induced strains for sol-gel derived lead zirconate thin layers. J Appl Phys 1994, 75: 3017-3023.

[168] Ye M, Sun Q, Chen X, et al. Electrical and energy storage performance of Eu-doped $\mathrm{PbZrO}_{3}$ thin films with different gradient sequences. $J$ Am Ceram Soc 2012, 95: 1486-1488.

[169] Sa T, Cao Z, Wang Y, et al. Enhancement of charge and energy storage in $\mathrm{PbZrO}_{3}$ thin films by local field engineering. Appl Phys Lett 2014, 105: 043902.

[170] Chen MJ, Ning XK, Wang SF, et al. Significant enhancement of energy storage density and polarization in self-assembled $\mathrm{PbZrO}_{3}: \mathrm{NiO}$ nano-columnar composite films. Nanoscale 2019, 11: 1914-1920.

[171] Ge J, Remiens D, Costecalde J, et al. Effect of residual stress on energy storage property in $\mathrm{PbZrO}_{3}$ antiferroelectric thin films with different orientations. Appl Phys Lett 2013, 103: 162903.

[172] Ge J, Remiens D, Dong X, et al. Enhancement of energy storage in epitaxial $\mathrm{PbZrO}_{3}$ antiferroelectric films using strain engineering. Appl Phys Lett 2014, 105: 112908.

[173] Corker DL, Glazer AM, Kaminsky W, et al. Investigation into the crystal structure of the perovskite lead hafnate, $\mathrm{PbHfO}_{3}$. Acta Crystallogr Sect B 1998, 54: 18-28.

[174] Madigout V, Baudour JL, Bouree F, et al. Crystallographic structure of lead hafnate $\left(\mathrm{PbHfO}_{3}\right)$ from neutron powder diffraction and electron microscopy. Philos Mag A 1999, 79: $847-858$.

[175] Burkovsky RG, Bronwald I, Andronikova D, et al. Triggered incommensurate transition in $\mathrm{PbHfO}_{3}$. Phys Rev $B$ 2019, 100: 014107.

[176] Chao W, Yang T, Li Y. Achieving high energy efficiency and energy density in $\mathrm{PbHfO}_{3}$ based antiferroelectric ceramics. J Mater Chem C 2020, 8: 17016-17024.

[177] Huang XX, Zhang TF, Wang W, et al. Tailoring energy-storage performance in antiferroelectric $\mathrm{PbHfO}_{3}$ thin films. Mater Des 2021, 204: 109666.

[178] Xu B, Moses P, Pai NG, et al. Charge release of lanthanum-doped lead zirconate titanate stannate antiferroelectric thin films. Appl Phys Lett 1998, 72: 593-595.

[179] Sharifzadeh Mirshekarloo M, Yao K, Sritharan T. Large strain and high energy storage density in orthorhombic perovskite $\left(\mathrm{Pb}_{0.97} \mathrm{La}_{0.02}\right)\left(\mathrm{Zr}_{1-x-y} \mathrm{Sn}_{x} \mathrm{Ti}_{y}\right) \mathrm{O}_{3}$ antiferroelectric thin films. Appl Phys Lett 2010, 97: 142902.

[180] Zhang AH, Wang W, Li QJ, et al. Internal-strain release and remarkably enhanced energy storage performance in PLZT-SrTiO 3 multilayered films. Appl Phys Lett 2020, 117: 252901

[181] Dan Y, Xu H, Zou K, et al. Energy storage characteristics of $(\mathrm{Pb}, \mathrm{La})(\mathrm{Zr}, \mathrm{Sn}, \mathrm{Ti}) \mathrm{O}_{3}$ antiferroelectric ceramics with high Sn content. Appl Phys Lett 2018, 113: 063902.

[182] Liu P, Fan B, Yang G, et al. High energy density at high temperature in PLZST antiferroelectric ceramics. J Mater Chem C 2019, 7: 4587-4594.

[183] Xu B, Ye Y, Cross L. Dielectric properties and field-induced phase switching of lead zirconate titanate stannate antiferroelectric thick films on silicon substrates. J Appl Phys 2000, 87: 2507-2515.

[184] Markowski K, Park SE, Yoshikawa S, et al. Effect of compositional variations in the lead lanthanum zirconate stannate titanate system on electrical properties. $J \mathrm{Am}$ Ceram Soc 1996, 79: 3297-3304.

[185] Zheng Q, Yang T, Wei K, et al. Effect of Sn:Ti variations on electric filed induced AFE-FE phase transition in PLZST antiferroelectric ceramics. Ceram Int 2012, 38: S9-S12.

[186] Liu Z, Bai Y, Chen X, et al. Linear composition-dependent phase transition behavior and energy storage performance of tetragonal PLZST antiferroelectric ceramics. $J$ Alloys Compd 2017, 691: 721-725.

[187] Zhang L, Jiang S, Fan B, et al. Enhanced energy storage performance in $\left(\mathrm{Pb}_{0.858} \mathrm{Ba}_{0.1} \mathrm{La}_{0.02} \mathrm{Y}_{0.008}\right)\left(\mathrm{Zr}_{0.65} \mathrm{Sn}_{0.3} \mathrm{Ti}_{0.05}\right) \mathrm{O}_{3}$ $\left(\mathrm{Pb}_{0.97} \mathrm{La}_{0.02}\right)\left(\mathrm{Zr}_{0.9} \mathrm{Sn}_{0.05} \mathrm{Ti}_{0.05}\right) \mathrm{O}_{3}$ anti-ferroelectric composite ceramics by Spark Plasma Sintering. J Alloys Compd 2015, 622: $162-165$.

[188] Zhang G, Zhu D, Zhang X, et al. High-energy storage performance of $\left(\mathrm{Pb}_{0.87} \mathrm{Ba}_{0.1} \mathrm{La}_{0.02}\right)\left(\mathrm{Zr}_{0.68} \mathrm{Sn}_{0.24} \mathrm{Ti}_{0.08}\right) \mathrm{O}_{3}$ antiferroelectric ceramics fabricated by the hot-press sintering method. J Am Ceram Soc 2015, 98: 1175-1181.

[189] Zhang G, Liu S, Yu Y, et al. Microstructure and electrical properties of $\left(\mathrm{Pb}_{0.87} \mathrm{Ba}_{0.1} \mathrm{La}_{0.02}\right)\left(\mathrm{Zr}_{0.68} \mathrm{Sn}_{0.24} \mathrm{Ti}_{0.08}\right) \mathrm{O}_{3}$ anti-ferroelectric ceramics fabricated by the hot-press sintering method. J Eur Ceram Soc 2013, 33: 113-121.

[190] Bian F, Yan S, Xu C, et al. Enhanced breakdown strength and energy density of antiferroelectric $\mathrm{Pb}, \mathrm{La}(\mathrm{Zr}, \mathrm{Sn}, \mathrm{Ti}) \mathrm{O}_{3}$ ceramic by forming core-shell structure. J Eur Ceram Soc 2018, 38: 3170-3176.

[191] Wang H, Liu Y, Yang T, et al. Ultrahigh energy-storage density in antiferroelectric ceramics with field-induced multiphase transitions. Adv Funct Mater 2019, 29: 1807321.

[192] Zhang Y, Liu P, Kandula KR, et al. Achieving excellent energy storage density of $\mathrm{Pb}_{0.97} \mathrm{La}_{0.02}\left(\mathrm{Zr}_{x} \mathrm{Sn}_{0.05} \mathrm{Ti}_{0.95-x}\right) \mathrm{O}_{3}$ ceramics by the B-site modification. $J$ Eur Ceram Soc 2021, 41: 360-367.

[193] Liu X, Li Y, Hao X. Ultra-high energy-storage density and fast discharge speed of $\left(\mathrm{Pb}_{0.98-x} \mathrm{La}_{0.02} \mathrm{Sr}_{x}\right)\left(\mathrm{Zr}_{0.9} \mathrm{Sn}_{0.1}\right)_{0.995} \mathrm{O}_{3}$ antiferroelectric ceramics prepared via the tape-casting 
method. J Mater Chem A 2019, 7: 11858-11866.

[194] Gao M, Tang X, Leung CM, et al. Phase transition and energy storage behavior of antiferroelectric PLZT thin films epitaxially deposited on SRO buffered STO single crystal substrates. J Am Ceram Soc 2019, 102: 5180-5191.

[195] Ma B, Kwon DK, Narayanan M, et al. Dielectric properties and energy storage capability of antiferroelectric $\mathrm{Pb}_{0.92} \mathrm{La}_{0.08} \mathrm{Zr}_{0.95} \mathrm{Ti}_{0.05} \mathrm{O}_{3}$ film-on-foil capacitors. J Mater Res 2009, 24: 2993-2996.

[196] Tong S, Ma B, Narayanan M, et al. Lead lanthanum zirconate titanate ceramic thin films for energy storage. ACS Appl Mater Interfaces 2013, 5: 1474-1480.

[197] Lin Z, Chen Y, Liu Z, et al. Large energy storage density, low energy loss and highly stable $\left(\mathrm{Pb}_{0.97} \mathrm{La}_{0.02}\right)\left(\mathrm{Zr}_{0.66} \mathrm{Sn}_{0.23} \mathrm{Ti}_{0.11}\right) \mathrm{O}_{3}$ antiferroelectric thin-film capacitors. J Eur Ceram Soc 2018, 38: 3177-3181.

[198] Ma B, Kwon DK, Narayanan M, et al. Fabrication of antiferroelectric PLZT films on metal foils. Mater Res Bull 2009, 44: 11-14.

[199] Zhang MH, Fulanović L, Egert S, et al. Electricfield-induced antiferroelectric to ferroelectric phase transition in polycrystalline $\mathrm{NaNbO}_{3}$. Acta Mater 2020, 200: $127-135$.

[200] Chen J, Feng D. TEM study of phases and domains in $\mathrm{NaNbO}_{3}$ at room temperature. Phys Status Solidi a 1988, 109: 171-185.

[201] Saito T, Adachi H, Wada T, et al. Pulsed-laser deposition of ferroelectric $\mathrm{NaNbO}_{3}$ Thin films. Jpn J Appl Phys 2005, 44: 6969-6972.

[202] Koruza J, Groszewicz P, Breitzke H, et al. Grain-sizeinduced ferroelectricity in $\mathrm{NaNbO}_{3}$. Acta Mater 2017, 126: $77-85$.

[203] Shuvaeva VA, Antipin MY, Lindeman RSV, et al. Crystal structure of the electric-fieldinduced ferroelectric phase of $\mathrm{NaNbO}_{3}$. Ferroelectrics 1993, 141: 307-311.

[204] Shimizu H, Guo H, Reyes-Lillo SE, et al. Lead-free antiferroelectric: $x \mathrm{CaZrO}_{3}-(1-x) \mathrm{NaNbO}_{3}$ system $(0 \leq x \leq$ 0.10). Dalton Trans 2015, 44: 10763-10772.

[205] Guo H, Shimizu H, Mizuno Y, et al. Strategy for stabilization of the antiferroelectric phase (Pbma) over the metastable ferroelectric phase (P21ma) to establish double loop hysteresis in lead-free $(1-x) \mathrm{NaNbO}_{3}-x \mathrm{SrZrO}_{3}$ solid solution. J Appl Phys 2015, 117: 214103.

[206] Gao L, Guo H, Zhang S, et al. A perovskite lead-free antiferroelectric $x \mathrm{CaHfO}_{3}-(1-x) \mathrm{NaNbO}_{3}$ with induced double hysteresis loops at room temperature. J Appl Phys 2016, 120: 204102.

[207] Gao L, Guo H, Zhang S, et al. Stabilized antiferroelectricity in $x \mathrm{BiScO}_{3}-(1-x) \mathrm{NaNbO}_{3}$ lead-free ceramics with established double hysteresis loops. Appl Phys Lett 2018, 112: 092905.

[208] Zhou M, Liang R, Zhou Z, et al. Superior energy storage properties and excellent stability of novel $\mathrm{NaNbO}_{3}$-based lead-free ceramics with A-site vacancy obtained via a $\mathrm{Bi}_{2} \mathrm{O}_{3}$ substitution strategy. $J$ Mater Chem A 2018, 6:
17896-17904.

[209] Ye J, Wang G, Zhou M, et al. Excellent comprehensive energy storage properties of novel lead-free $\mathrm{NaNbO}_{3}$-based ceramics for dielectric capacitor applications. J Mater Chem C 2019, 7: 5639-5645.

[210] Dong X, Li X, Chen X, et al. High energy storage density and power density achieved simultaneously in $\mathrm{NaNbO}_{3}$-based lead-free ceramics via antiferroelectricity enhancement. J Materiomics 2021, 7: 629-639.

[211] Fujii I, Shimasaki T, Nobe T, et al. Effects of $\mathrm{SrTiO}_{3}$ substrate orientations on crystal and domain structures and electric properties of $\mathrm{NaNbO}_{3}-\mathrm{SrZrO}_{3}$ films. Jpn J Appl Phys 2018, 57: 11UF13.

[212] Beppu K, Shimasaki T, Fujii I, et al. Energy storage properties of antiferroelectric $0.92 \mathrm{NaNbO}_{3}-0.08 \mathrm{SrZrO}_{3}$ film on (001) $\mathrm{SrTiO}_{3}$ substrate. Phys Lett $A$ 2020, 384: 126690.

[213] Luo B, Dong H, Wang D, et al. Large recoverable energy density with excellent thermal stability in Mn-modified $\mathrm{NaNbO}_{3}-\mathrm{CaZrO}_{3}$ lead-free thin films. $J$ Am Ceram Soc 2018, 101: 3460-3467.

[214] Kania A, Kwapulinski J. $\mathrm{Ag}_{1-x} \mathrm{Na}_{x} \mathrm{NbO}_{3}$ (ANN) solid solutions: From disordered antiferroelectric $\mathrm{AgNbO}_{3}$ to normal antiferroelectric $\mathrm{NaNbO}_{3}$.J Phys: Condens Matter 1999, 11: 8933-8946.

[215] Wang D, Kako T, Ye J. New series of solid-solution semiconductors $\left(\mathrm{AgNbO}_{3}\right)_{1-x}\left(\mathrm{SrTiO}_{3}\right)_{x}$ with modulated band structure and enhanced visible-light photocatalytic activity. J Phys Chem C 2009, 113: 3785-3792.

[216] Fu D, Endo M, Taniguchi H, et al. $\mathrm{AgNbO}_{3}$ : A lead-free material with large polarization and electromechanical response. Appl Phys Lett 2007, 90: 252907.

[217] Tian Y, Jin L, Zhang H, et al. High energy density in silver niobate ceramics. J Mater Chem A 2016, 4: 17279-17287.

[218] Zhao L, Liu Q, Gao J, et al. Lead-free antiferroelectric silver niobate tantalate with high energy storage performance. Adv Mater 2017, 29: 1701824.

[219] Luo N, Han K, Cabral MJ, et al. Constructing phase boundary in $\mathrm{AgNbO}_{3}$ antiferroelectrics: Pathway simultaneously achieving high energy density and efficiency. Nat Commun 2020, 11: 4824.

[220] Yan Z, Zhang D, Zhou X, et al. Silver niobate based lead-free ceramics with high energy storage density. $J$ Mater Chem A 2019, 7: 10702-10711.

[221] Luo N, Han K, Zhuo F, et al. Aliovalent A-site engineered $\mathrm{AgNbO}_{3}$ lead-free antiferroelectric ceramics toward superior energy storage density. J Mater Chem A 2019, 7: 14118-14128.

[222] Lu Z, Bao W, Wang G, et al. Mechanism of enhanced energy storage density in $\mathrm{AgNbO}_{3}$-based lead-free antiferroelectrics. Nano Energy 2021, 79: 105423.

[223] Zhao L, Gao J, Liu Q, et al. Silver niobate lead-free antiferroelectric ceramics: Enhancing energy storage density by B-site doping. ACS Appl Mater Interfaces 2018, 10: $819-826$. 
[224] Tian Y, Jin L, Zhang H, et al. Phase transitions in bismuth-modified silver niobate ceramics for high power energy storage. J Mater Chem A 2017, 5: 17525-17531.

[225] Luo N, Han K, Zhuo F, et al. Design for high energy storage density and temperature-insensitive lead-free antiferroelectric ceramics. J Mater Chem C 2019, 7: 4999-5008.

[226] Gao J, Zhang Y, Zhao L, et al. Enhanced antiferroelectric phase stability in La-doped $\mathrm{AgNbO}_{3}$ : Perspectives from the microstructure to energy storage properties. $J$ Mater Chem A 2019, 7: 2225-2232.

[227] Han K, Luo N, Mao S, et al. Realizing high low-electric-field energy storage performance in $\mathrm{AgNbO}_{3}$ ceramics by introducing relaxor behaviour. J Materiomics 2019, 5: 597-605.

[228] Wang J, Wan X, Rao Y, et al. Hydrothermal synthesized $\mathrm{AgNbO}_{3}$ powders: Leading to greatly improved electric breakdown strength in ceramics. $J$ Eur Ceram Soc 2020, 40: 5589-5596.

Open Access This article is licensed under a Creative Commons Attribution 4.0 International License, which permits use, sharing, adaptation, distribution and reproduction in any medium or format, as long as you give appropriate credit to the original author(s) and the source, provide a link to the Creative Commons licence, and indicate if changes were made.

The images or other third party material in this article are included in the article's Creative Commons licence, unless indicated otherwise in a credit line to the material. If material is not included in the article's Creative Commons licence and your intended use is not permitted by statutory regulation or exceeds the permitted use, you will need to obtain permission directly from the copyright holder.

To view a copy of this licence, visit http://creativecommons. org/licenses/by/4.0/. 